\title{
00993
}

Universidad Nacional de LA PLATA

Facultad de Ciencias Exactas

Departamento de Ciencias Biológicas

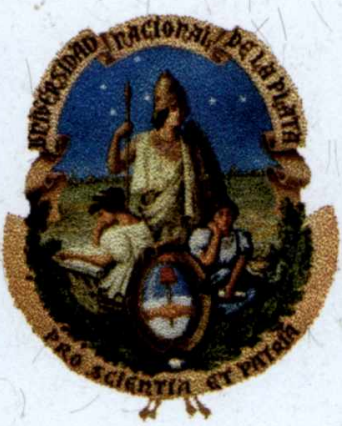

17. Biblioteca Central

Fac. Cs. Exactas

U.N.L.P

\section{Rol de la insulina en la regulación \\ del calcio citosólico \\ del músculo liso vascular

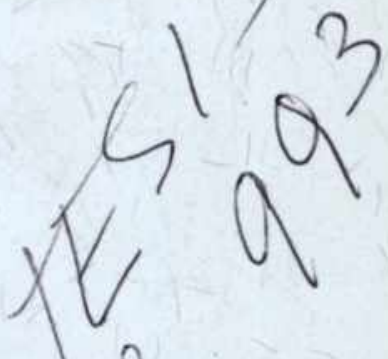

\section{TESIS DOCTORAL}

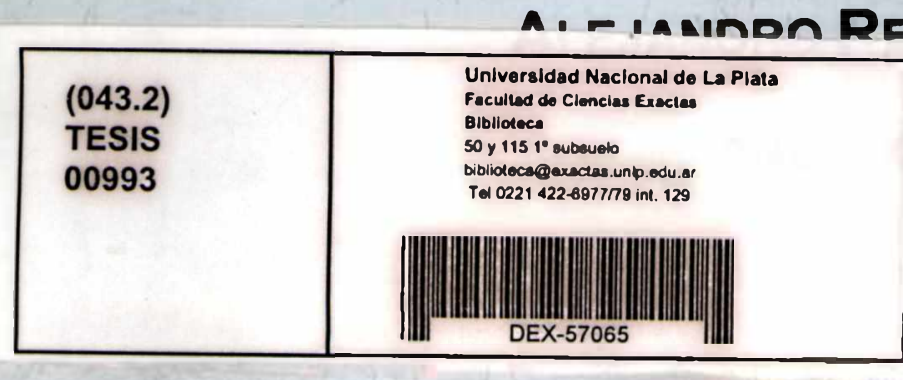

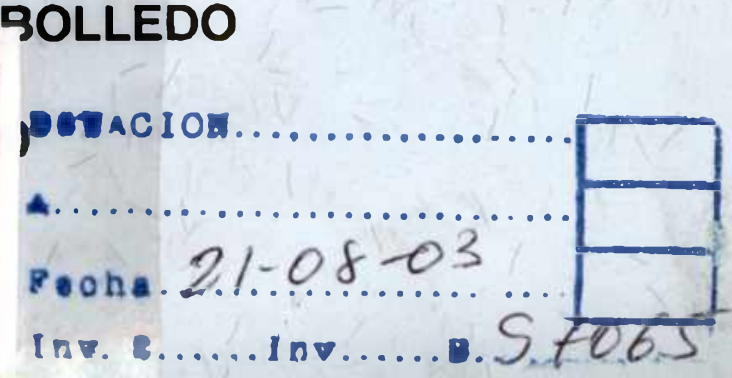


El presente trabajo de tesis para optar al grado de Doctor de la Facultad de Ciencias Exactas de la Universidad Nacional de La Plata ha sido realizado en el Área de Anatomía, Fisiología e Histología de la Facultad de Ciencias Exactas de la Universidad Nacional de La Plata bajo la dirección de la Dra. Ángela O. Grassi de Gende, y la codirección del Dr. Gustavo J. Rinaldi.

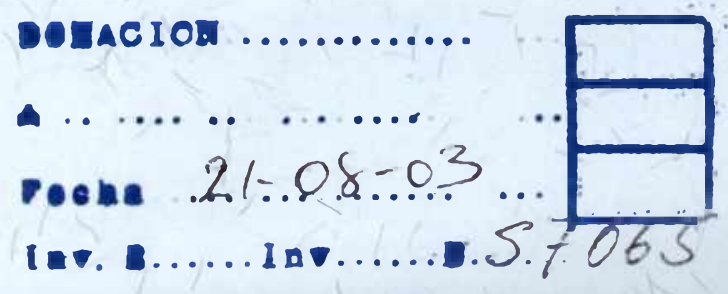


E.T. y N.T.

in memoriam

"When shall we three meet again?

In thunder, lightning or in rain?" 
Agradecimientos:

- A mi directora, la Dra. Angela Grassi de Gende, por haber sido el incansable motor de esta empresa y haber recorrido conmigo todo el camino.

- A mi codirector, el Dr. Gustavo Rinaldi, por sus valiosos consejos.

- A mis compañeros de trabajo, por su amistad, apoyo y colaboración.

- A mis amigos, que siempre me alentaron.

- Al CONICET y a la Facultad de Ciencias Exactas, por haberme brindado el lugar y los medios necesarios para realizar este trabajo.

- A mis padres, que confiaron en mi. 


\section{INDICE}

\section{INTRODUCCIÓN AL TEMA INSULINA E HIPERTENSION ARTERIAL}

1.1 Mecanismos por los cuales la insulina puede causar hipertensión arterial.

1.2 Mecanismos por los cuales la insulina puede causar hipotensión arterial

1.3 Antecedentes que relacionan la hipertensión arterial con la insulina

1.3.1 Estudios epidemiológicos

1.3.2 Estudios de efectos vasculares 'in vivo'

1.3.3 Estudios de efectos vasculares 'in vitro'

\section{ESTUDIOS MECÁNICOS Y RADIOISOTÓPICOS EN ANILLOS VASCULARES}

\subsection{MÉTODOS}

\subsubsection{Materiales y equipos}

3.1.2 -Protocolos experimentales de preincubación con insulina, a dosis fisiológicas, interpuesta entre dos estimulaciones sucesivas con un agonista (angiotensina II [Ang.II] y arginina vasopresina [AVP]). Determinaciones mecánicas.

-Captación de ${ }^{45} \mathrm{Ca}$ en retículo sarcoplásmico de segmentos de aorta preincubados con dosis fisiológicas de insulina.

3.1.3 Protocolos experimentales de preincubación con insulina y estimulación única con un agonista. Dosis fisiológicas de insulina (Angll, AVP y endotelina-1 $\left[E T_{1}\right]$ ) y dosis hiperinsulinémicas (AVP y ET 1 ). Determinaciones mecánicas.

3.1.4 Preincubación con insulina y liberación de NO por ACh

3.1.5 Estudios de los posibles mecanismos afectados por la preincubación con insulina (dosis hiperinsulinémica) para modificar las contracciones inducidas por $E T_{1}$. Determinaciones mecánicas y radioisotópicas de captación de ${ }^{45} \mathrm{Ca}$ en segmentos vasculares intactos y en retículo sarcoplásmico. 


\subsection{RESULTADOS}

3.2.1 Preincubación con insulina, a dosis fisiológicas, interpuesta entre dos estimulaciones sucesivas con un agonista.

-en aorta de rata, Angll yAVP; en vena safena humana, Ang II. Determinaciones mecánicas.

-Captación de ${ }^{45} \mathrm{Ca}$ en retículo sarcoplásmico de segmentos de aorta preincubados con dosis fisiológicas de insulina e hiperpermeabilizados por tratamiento químico.

3.2.2 Preincubación con insulina y estimulación única con un agonista. Dosis fisiológicas de insulina en aorta de rata (Angll, AVP y endotelina-1 $\left[E T_{1}\right]$ ). Determinaciones mecánicas. Dosis hiperinsulinémicas en aorta de rata y en arteria de la cola de rata (AVP y ET 1 ). Determinaciones mecánicas.

3.2.3 Preincubación con insulina y liberación de NO inducida por ACh. 49

3.2.4 Estudio de los posibles mecanismos afectados por la preincubación con insulina (dosis hiperinsulinémica) para modificar las contracciones inducidas por $\mathrm{ET}_{1}$.

-participación del retículo sarcoplásmico: determinaciones mecánicas y radioisotópicas de captación de ${ }^{45} \mathrm{Ca}$ en retículo sarcoplásmico.

-participación de fosforilaciones por proteina quinasa C [PKC]; determinaciones mecánicas.

-participación del $\mathrm{Ca}^{2+}$ extracelular. Determinaciones radioisotópicas

-participación de derivados de metabolitos del ácido araquidónico;determinaciones mecánicas.

-efectos agudos de la insulina; determinaciones mecánicas.

\section{ESTUDIOS ELECTROFISIOLÓGICOS EN CÉLULAS DE MÚSCULO LISO CULTIVADAS}


4.3 RESULTADOS

$80-84$

4.4 ANÁLISIS Y DISCUSIÓN DE LOS RESULTADOS

85-89

5. CONCLUSIONES

$90-94$

6. BIBLIOGRAFIA

$95-107$ 


\section{INTRODUCCIÓN}




\section{INTRODUCCIÓN AL TEMA DE INSULINA E HIPERTENSIÓN}

\section{ARTERIAL}

En los últimos años se ha generado mucho interés en la hipótesis de que la resistencia insulínica y la hiperinsulinemia podrian contribuir a la patogénesis de la hipertensión arterial (1-7). En un estudio epidemiológico de 1985, Modan y col. (1) informaron que pacientes con hipertensión presentaban niveles postprandiales de insulina más elevados que los de pacientes normotensos, independientemente de la obesidad o la intolerancia a la glucosa. De alli en más, se han realizado numerosos estudios sobre la asociación insulina-hipertensión arterial (se encuentran listados en los trabajos de revisión de T.Baba y col.(2), W.P.Meehan y col. (3) y M.Epstein y col.(4)). De ellos surge que la insulina es capaz de modificar mecanismos fisiológicos que podrían conducir tanto a un aumento como a una disminución de la presión arterial. Describiremos en primer término estos efectos de la insulina y luego resumiremos el estado actual de tres enfoques con los cuales se puede analizar la relación entre insulina e hipertensión arterial: (1) estudios epidemiológicos, (2) estudios in vivo de efectos de la insulina sobre la presión arterial y el tono vascular y (3) estudios in vitro de efectos de la insulina sobre el músculo liso vascular.

\subsection{MECANISMOS POR LOS CUALES LA INSULINA PUEDE CAUSAR HIPERTENSIÓN ARTERIAL}

(a) Estimulación del sistema nervioso simpático:

La insulina aumenta la actividad del sistema nervioso simpático (SNS) en 
forma indirecta a través de la hipoglucemia, pero también a través de mecanismos independientes de la glucemia, como ha sido demostrado en experimentos con infusión simultánea de insulina y glucosa (clamp euglucémico) $(2,3,5)$. Rowe y col. (8) propusieron que esto es asi porque la infusión de la hormona en humanos aumenta los niveles plasmáticos de noradrenalina a concentraciones plasmáticas de glucosa constantes. En este estudio también se registraron aumentos de la frecuencia cardiaca y de la presión arterial. Sin embargo la teoria de que la hiperinsulinemia produce hipertensión a través de la activación del SNS ha sido objetada por los niveles extremos de insulinemia $(600 \mathrm{mU} / \mathrm{ml})$ a los cuales se demostró hipertensión (8). Resultados recientes confirmaron que la activación simpática se da aún con dosis fisiológicas de insulina (70-150 $\mu \mathrm{U} / \mathrm{ml})$, pero sin aumentos simultáneos en la presión arterial $(2,3,9,10)$, e incluso se demostró una pequeña disminución en la presión diastólica en individuos normotensos (10). Esto cuestiona la hipótesis de producción de hipertensión por la insulina debida a hiperactividad simpática, aunque se debe hacer notar que una hiperinsulinemia crónica, no aguda como la de los estudios descriptos, podría activar el SNS y causar hipertensión $(2,3,9,10)$. Sin embargo, se ha visto que la hiperinsulinemia crónica en perros conscientes no produce hipertensión arterial (11).

(b) Retención renal de sodio:

Estudios en humanos (12), perros (13) y ratas (14) han demostrado una acción antinatriurética de la insulina. Se cree que esta hormona tiene un efecto directo sobre los túbulos renales, aunque aún es discutido el sitio exacto de acción en el nefrón $(12,14)$. El aumento en el $\mathrm{Na}^{+}$corporal total, debido a la retención renal de $\mathrm{Na}^{+}$generada por la hiperinsulinemia, conduciria a hipertensión arterial por expansión del volumen intravascular. Esta teoria supone que los efectos re- 
nales de insulina no se ven afectados por la insulinorresistencia.

Hay resultados en contra de esta propuesta que muestran que niveles basales de insulina ya tienen efectos antinatriuréticos máximos (15). También se ha descripto que la hiperinsulinemia crónica en perros produce retención de $\mathrm{Na}^{+}$pero no aumento de la presión arterial (16); esto último podría explicarse porque la retención de $\mathrm{Na}^{+}$estimula la liberación de factor natriurético auricular, y se ha propuesto que en humanos esto no permitiria la manifestación de los efectos renales de la insulina (17).

(c) Hipertrofia del músculo liso vascular:

La insulina es un potente mitógeno y factor de crecimiento (18), actuando tanto a través de sus propios receptores, como a través de receptores de otros factores de crecimiento (por ejemplo el factor de crecimiento insulinosímil, $\left(G F_{1}\right.$ ), lo que le permitiria actuar aún en estados de resistencia insulínica (3). El aumento del espesor de la capa intima y media de los vasos, secundario a una hiperinsulinemia prolongada, disminuiria la luz del vaso produciendo hipertensión por aumento de la resistencia vascular $(3,19)$. Se postula que este mecanismo, junto con la aceleración de la aterogénesis y de la glicosilación de proteinas de la pared vascular, son factores importantes en la generación de hipertensión en los pacientes con diabetes de tipo II (4).

(d) Efectos sobre el intercambio $\mathrm{Na}^{+} / \mathrm{H}^{+}$:

La insulina estimula la actividad del intercambiador $\mathrm{Na}^{+} / \mathrm{H}^{+}(3,4,20)$. Como resultado de este efecto se produce alcalinización y aumento del $\mathrm{Na}^{+}$intracelular. La alcalinización promueve el crecimiento celular y puede conducir a un aumento de la capa de músculo liso de los vasos (3). El aumento del $\mathrm{Na}^{+}$intracelular dis- 
minuye la extrusión de $\mathrm{Ca}^{2+}$ por vía del intercambiador $\mathrm{Na}^{+} / \mathrm{Ca}^{2+}$ y aumenta el $\mathrm{Ca}^{2+}$ citosólico en las células de músculo liso vascular (21). Ambos efectos, engrosamiento de la pared vascular y elevación del $\mathrm{Ca}^{2+}$ en los miocitos de la misma, aumentarian la resistencia vascular. Por otra parte el aumento del $\mathrm{Na}^{+}$en el citosol de las células del músculo liso vascular lo sensibiliza a agentes presores como noradrenalina y angiotensina II (22).

A nivel de los túbulos renales el aumento de la actividad del intercambiador $\mathrm{Na}^{+} / \mathrm{H}^{+}$generaria una mayor retención de $\mathrm{Na}^{+}$, otro factor más para aumentar la presión arterial (3).

Como marcador de la actividad del intercambiador $\mathrm{Na}^{+} / \mathrm{H}^{+}$se utiliza la medida del intercambio $\mathrm{Na}^{+} / \mathrm{Li}^{+}$en eritrocitos (23). En pacientes con hipertensión esencial se ha detectado mayor actividad de este intercambio (23), pero no se halló un aumento en pacientes con diabetes asociada a hiperinsulinemia (24).

(e) Efectos sobre productos endoteliales:

La insulina aumenta la liberación de endotelina por células endoteliales (25), y la hiperinsulinemia es un estímulo in vivo para generar aumentos en la endotelina circulante (26). Además, en células musculares lisas en cultivo, se observó que la insulina es capaz de incrementar la respuesta mitogénica debida a la endotelina (27). Se ha demostrado también que la preincubación de células en cultivo derivadas de aorta de rata con dosis altas de insulina genera un aumento en la expresión de RNAm de receptores $E T_{A}$ para endotelina, y esto se acompaña de un aumento en la respuesta transitoria de $\mathrm{Ca}^{2+}$ inducida por este agonista (28). Todos estos efectos convergerian a aumentar el tono vascular. Se debe hacer notar, sin embargo, que también hay estudios en los que se demostró que el tratamiento agudo con insulina produce una atenuación del aumento del $\mathrm{Ca}^{2+}$ citosó- 
lico inducido por $\mathrm{ET}_{1}$ (29).

\subsection{MECANISMOS POR LOS CUALES LA INSULINA PUEDE CAUSAR HIPOTENSIÓN ARTERIAL}

(a) Efectos sobre el endotelio:

La insulina puede causar vasodilatación a través de liberación de factores endoteliales $(6,30,31)$. Hay abundante evidencia de que uno de ellos es óxido nítrico (NO) $(6,30-32)$, pero también se sabe que la insulina es capaz de liberar otros factores relajantes, como las prostaglandinas (33). No se puede descartar la posibilidad de que inhiba la liberación de factores vasoconstrictores endoteliales como los tromboxanos. Se ha visto que los efectos de la insulina sobre el endotelio son distintos según el tipo de vaso considerado (30).

La insulina también afectaría la función de los receptores adrenérgicos. La infusión de insulina en perros produce vasodilatación en el músculo esquelético que es inhibida con el bloqueante $\beta$-adrenérgico propranolol (34). Hallazgos similares se han descripto en humanos (35). Este efecto vasodilatador dependiente de los receptores $\beta$ sería mediado por endotelio ya que en anillos de aorta de rata contraídos con fenilefrina (36) la insulina aumenta la relajación $\beta$-adrenérgica sólo si el endotelio se halla intacto. Como la insulina no afectó la respuesta $\beta$ adrenérgica en aortas de ratas hipertensas espontáneas (SHR) se asume que esta cepa posee una disfunción endotelial con deterioro de su capacidad relajante (36).

(b) Estimulación de la $\mathrm{Na}^{+} / \mathrm{K}^{+}-\mathrm{ATPasa}$ :

Se sabe que la insulina estimula la actividad de la bomba de $\mathrm{Na}^{+}$y $\mathrm{K}^{+}$en 
varios tejidos (37). El aumento de actividad de esta bomba produce relajación del músculo liso, ya que por un lado lo hiperpolariza y, por otro lado, al disminuir el $\mathrm{Na}^{+}$intracelular estimula la extrusión del $\mathrm{Ca}^{2+}$ citosólico por vía del intercambiador $\mathrm{Na}^{+} / \mathrm{Ca}^{2+}$. Ambos efectos favorecen la relajación vascular.

Blaustein $(21,38)$ ha propuesto una disminución en la actividad de la $\mathrm{Na}^{+} / \mathrm{K}^{+}$-ATPasa como mecanismo generador de hipertensión. La falta de insulina o la resistencia insulínica podrian conducir a la supresión de su efecto estimulante sobre la $\mathrm{Na}^{+} / \mathrm{K}^{+}$ATPasa. En este sentido se demostró en ratas diabéticas una disminución tanto en la expresión de la bomba (medida como cantidad de su ARNm) asi como en su actividad (39).

(c) Activación de $\mathrm{Ca}^{2+}$-ATPasas:

La actividad de las bombas $\mathrm{Ca}^{2+}$-ATPasas disminuye la concentración de $\mathrm{Ca}^{2+}$ en el citosol, la de membrana extruyendo el $\mathrm{Ca}^{2+}$ fuera de la célula y la de retículo sarcoplásmico acumulándolo en su interior. La insulina aumenta la expresión de las dos $\mathrm{Ca}^{2+}$-ATPasas $(40,41)$; por otra parte, en estados de insulinopenia o de resistencia insulinica hay una disminución de la actividad de la $\mathrm{Ca}^{2+}$-ATPasa de membrana (42). Si bien este efecto de insulina favorece la relajación del músculo liso vascular, se ha propuesto que el mayor funcionamiento de la $\mathrm{Ca}^{2+}$ ATPasa del retículo sarcoplásmico podría aumentar el contenido de $\mathrm{Ca}^{2+}$ en los depósitos intracelulares e incrementar la respuesta contráctil a agonistas presores que liberan $\mathrm{Ca}^{2+}$ de estos depósitos (43).

(d) Influencia sobre los canales iónicos:

No son muchos los datos que se encuentran en la bibliografía acerca de los posibles efectos de la insulina sobre los canales iónicos en el músculo liso vas- 
cular. Hay trabajos en donde se estudian estos efectos en forma indirecta, por ejemplo, evaluando los cambios que produce la insulina sobre los aumentos transitorios de $\mathrm{Ca}^{2+}$ citosólico inducidos por agonistas (43-45) o sobre la vasodilatación inducida por insulina $(46,47)$, y viendo cómo son afectados estos mecanismos por distintos bloqueantes de canales iónicos.

La insulina podría inhibir los canales de $\mathrm{Ca}^{2+}$ operados por voltaje (VOC) de forma indirecta a través de la hiperpolarización resultante del aumento de actividad que ella induce sobre la $\mathrm{Na}^{+} / \mathrm{K}^{+}$-ATPasa o a través de la activación de canales de $\mathrm{K}^{+}(48)$. Esto atenuaria los aumentos transitorios de $\mathrm{Ca}^{2+}$ evocados por diversos agonistas al inhibir la actividad de los VOC de $\mathrm{Ca}^{2+}(44,45)$. Sin embargo, la insulina seria también capaz de producir un pequeño incremento transitorio en el $\mathrm{Ca}^{2+}$ intracelular que no genera contracción en la célula muscular lisa y es bloqueado por diltiazem (45).

Con respecto a los canales de $\mathrm{K}^{+}$, se ha medido eflujo de $\mathrm{Rb}^{+}$, el cual no es modificado por exposición a la insulina (49). Una posible interacción de la insulina con los canales de $\mathrm{K}^{+}$dependientes de ATP $\left(\mathrm{K}_{\mathrm{ATP}}\right)$ ha sido sugerida en base a que la inhibición de dichos canales impide la vasodilatación inducida por insulina en arteriolas de hámster (48), y porque las arterias de ratas diabéticas se dilatan menos por exposición a agentes que abren los canales de $\mathrm{K}_{\mathrm{ATP}}$ que las arterias de ratas no diabéticas (50).

(e) Vasodilatación metabólica:

El aumento del consumo de $\mathrm{O}_{2}$ causado por la insulina, o la aparición de algún producto del metabolismo podrian generar una respuesta vasodilatadora $(5,6)$. 
La figura 1 resume los posibles sitios de acción de la insulina sobre las células de músculo liso vascular que pueden modificar su repuesta contráctil.
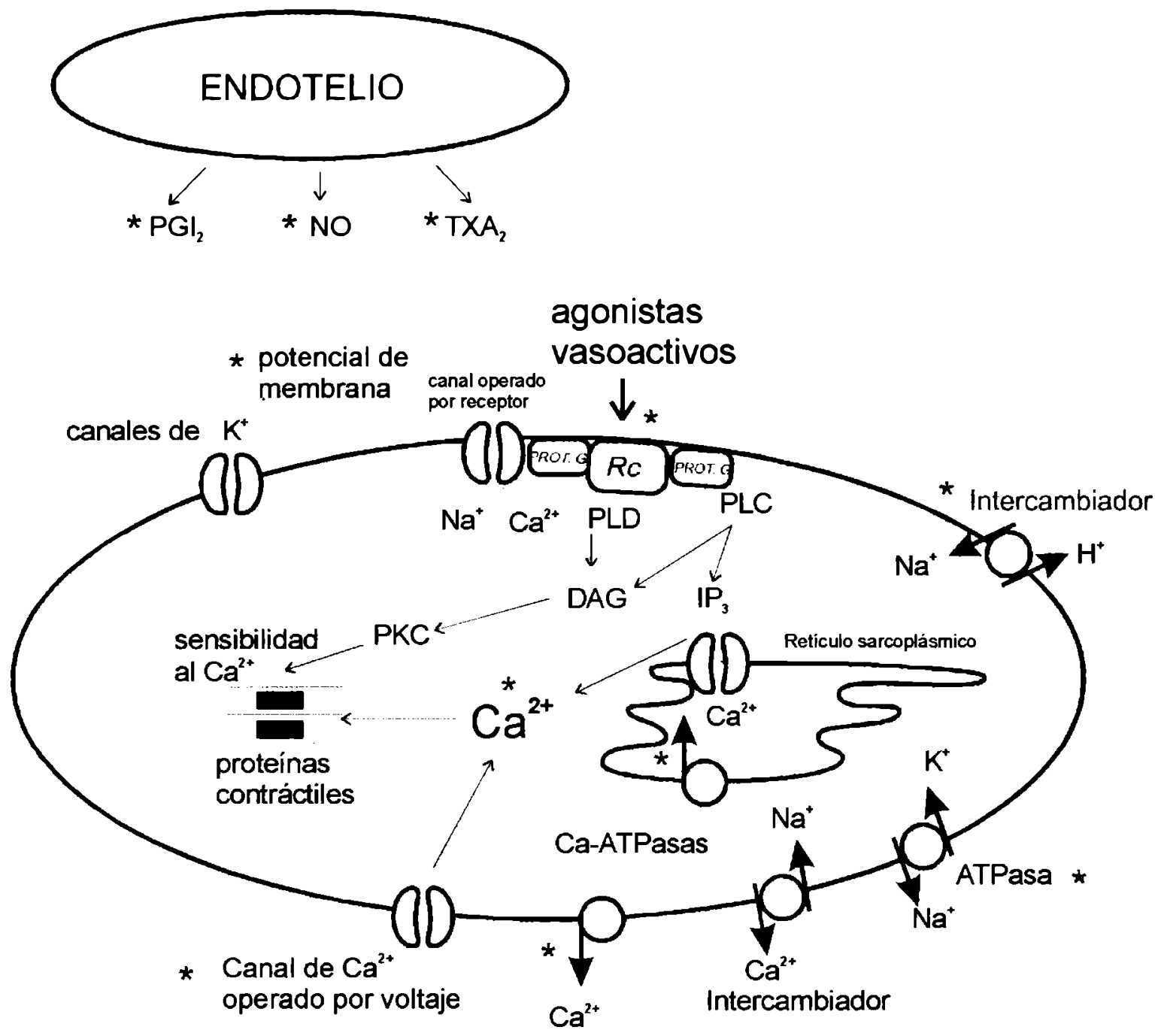

Fig 1 : El esquema resume: (1) las vias de señalización intracelular a partir de la activación de receptores $(R C)$ acoplados a proteínas $G$ (prot. $G$ ) que estimulan fosfolipasas $C(P L C)$ y fosfolipasas $D(P L D)$. El aumento de inositol trifosfato $\left(\mathrm{IP}_{3}\right)$ y diacilglicerol (DAG) por estas vías produce liberación de $\mathrm{Ca}^{2+}$ del retículo sarcoplásmico y activación de la proteína quinasa $C(P K C)$, respectivamente. (2) los mecanismos que regulan la contracción del músculo liso vascular determinando: a) la concentracion de $\mathrm{Ca}^{2+}$ intracelular en forma directa $\left(\mathrm{Ca}^{2+}\right.$-ATPasas, canales de $\mathrm{Ca}^{2+}$, intercambiador $\mathrm{Na}^{+} / \mathrm{Ca}^{2+}$ ) o en forma indirecta (intercambiador $\mathrm{Na}^{+} / \mathrm{H}^{+}, \mathrm{Na}^{+} / \mathrm{K}^{+}$-ATPasa, canales de $\mathrm{Na}^{+}$, canales de $\mathrm{K}^{+}$), o b) la sensibilidad al $\mathrm{Ca}^{2+}$ de las proteinas contráctiles (PKC). (3) los factores producidos por el endotelio con propiedades vasoactivas. El simbolo * indica los mecanismos que pueden ser afectados por la insulina para producir modificaciones en la contracción vascular. 


\subsection{ANTECEDENTES QUE RELACIONAN LA HIPERTENSIÓN ARTERIAL CON}

\section{LA INSULINA}

\subsubsection{ESTUDIOS EPIDEMIOLÓGICOS}

Una lista detallada de los estudios epidemiológicos se halla en las revisiones de Baba y col. (2), Meehan y col. (3) y Epstein y col. (4). La primera de estas revisiones divide a los estudios epidemiológicos en dos grupos de acuerdo a las variables medidas:

Grupo a): se midieron niveles de insulina basales y post administración de glucosa en función de presión arterial.

Grupo b): se midieron presión arterial versus sensibilidad a la insulina.

\section{- Grupo (a):}

Son estudios que compararon los niveles de insulina de pacientes hipertensos no diabéticos, hipertensos diabéticos o hipertensos con intolerancia a la glucosa con los de sus controles normotensos. Muchos investigadores encontraron niveles de insulina más altos en los hipertensos $(2,3,5)$, mientras que en varios estudios no encontraron diferencias con los normotensos $(2,3)$. Con respecto a los hipertensos esenciales se ha descripto hiperinsulinemia tanto en obesos como en delgados $(1,51,52)$ o exclusivamente en uno de los dos grupos (53). La hipertensión arterial secundaria a otras patologias (estenosis de la arteria renal, hiperaldosteronismo) no está asociada a hiperinsulinemia (2). En un estudio con más de 11.000 participantes no se encontró una correlación entre niveles de insulina plasmática y presión arterial, pero cuando se consideraron sólo los pacientes 
con historia familiar de diabetes o hipertensión sí hubo una fuerte correlación positiva (54).

También pertenecen a este grupo estudios en los que se midió la presión a pacientes hiperinsulinémicos. Algunos encontraron que los pacientes con niveles de insulina más altos que lo normal tenían presión elevada $(2,3)$, mientras que otros estudios no encuentran diferencias con los controles $(2,3,55)$. En grupos étnicos caracterizados por ser hiperinsulinémicos, como los indios Pima, no se ha podido demostrar un promedio de presión arterial más alto que lo normal (56), como tampoco se ha visto en pacientes con hiperinsulinemia causada por un insulinoma $(57,58)$; en este último caso, la corrección de la hiperinsulinemia por extirpación del tumor no produjo una disminución de la presión arterial (58).

Se puede concluir, entonces, que la asociación de hiperinsulinemia con hipertensión arterial no es una constante.

$$
\text { ○. }
$$

\section{- Grupo (b):}

La resistencia a la insulina se puede definir como un estado en el cual la acción de la insulina produce una respuesta menor a lo normal. En la mayoría de los casos el término "insulinorresistencia" se refiere a una disminución de su acción hipoglucemiante (2).

Se ha reportado resistencia insulínica en pacientes con hipertensión esencial $(59,60)$ y en hijos sanos de hipertensos esenciales (61). También se observa hipertensión en dos tipos de patologias con resistencia insulínica: en el síndrome X (10) (asociación de hiperinsulinemia, intolerancia a la glucosa, obesidad e hipertensión ) y en la diabetes tipo II (4).

Varios investigadores no han hallado un vínculo entre la resistencia insulínica y la hipertensión, o al menos no lo han visto en todos los grupos de hiperten- 
sos estudiados (3). Hay algunos estudios que encontraron resistencia insulínica solamente en hipertensos obesos (62), y otros sólo en los hipertensos que también presentaban un aumento en la actividad del contratransportador $\mathrm{Na}^{+} / \mathrm{Li}^{+}$de los eritrocitos (63). Los indios Pima, además de ser hiperinsulinémicos, tienen una sensibilidad a la insulina disminuída, pero como ya se ha mencionado no presentan en su población un porcentaje de hipertensos mayor que lo normal (56). Las mujeres con sindrome de ovario poliquístico también suelen presentar resistencia insulínica e hiperinsulinemia, y tampoco en este caso se han encontrado promedios de presión elevados (64).

Parece ser, entonces, que la resistencia insulínica no está siempre asociada con la hipertensión.

\footnotetext{
8

Parte de la discrepancia en los resultados descriptos podria deberse a falta de ajuste con respecto a edad, sexo, obesidad o distribución de la grasa corporal en los grupos estudiados. También es necesario considerar las diferencias interétnicas, ya que casi todos los estudios que mostraron correlaciones entre hiperinsulinemia y/o resistencia insulínica e hipertensión arterial se realizaron en individuos de raza blanca $(2,3)$. En otros grupos étnicos como los indios Pima $(56,65)$, pacientes de raza negra (65), grupos de nativos polinesios (66) o japoneses (67) no se ha demostrado esa asociación.
}

\subsubsection{ESTUDIOS DE EFECTOS VASCULARES IN VIVO}

La infusión de insulina en dosis fisiológicas en humanos no produce aumentos de la presión arterial $(9,10)$, e incluso se ha descripto una caída del 3 al $5 \%$ en la presión media (6) (en estos estudios no se produce hipoglucemia porque 
se administra simultáneamente glucosa). Resultados similares se obtuvieron con perros (11) en los que se mantuvieron durante 7 o 28 dias niveles de insulina en un rango del orden del hallado en los de pacientes obesos hipertensos. La reducción de la masa renal en un $70 \%$ no favoreció la aparición de hipertensión (68). En perros obesos insulino resistentes tampoco hubo un aumento de la presión arterial por una hiperinsulinemia de 7 dias, aunque en este caso los efectos vasodilatadores periféricos de la insulina fueron mucho menores (69). En ratas, sin embargo, se han observado aumentos de la presión arterial con la administración de dosis fisiológicas de insulina (70), postulándose para explicar las discrepancias con perros y humanos que en las ratas las acciones vasoconstrictoras de la insulina podrían ser más importantes que las vasodilatadoras. Sin embargo, en ratas con diabetes inducida por estreptozotocina la administración de insulina previno la aparición de hipertensión, aunque una vez establecida ésta, la insulina no produjo una ătenuación de la presión (71).

Las ratas Zucker obesas (ZOR) son un modelo experimental de resistencia insulínica junto con hiperinsulinemia e hipertensión arterial (72) y las ratas hipertensas espontáneas (SHR) son un modelo de hipertensión que también presentan resistencia insulínica e hiperinsulinemia (73) (aunque hay investigadores que reportan que las SHR tienen una sensibilidad normal a la insulina (74)). La administración de drogas que aumentan la sensibilidad periférica a la insulina produjo una disminución de la presión en las ZOR pero no en las $\operatorname{SHR}(73,75)$, aunque en otros estudios se ha visto una disminución de la presión también en las SHR (76). Se ha demostrado que en las SHR el tratamiento con compuestos del vanadio redujo la hiperinsulinemia y la presión arterial (74). La restitución de los niveles preexistentes de insulina retornó la presión a niveles elevados, indicando que en esta cepa la hiperinsulinemia podria tener una relación con el desarrollo de hi- 
pertensión arterial (74).

Varios estudios han descripto que la infusión de insulina en humanos produce vasodilatación manifestada por un aumento del flujo sanguíneo en el músculo esquelético $(6,10,77)$, y se sabe que aproximadamente un $40 \%$ de este aumento es dependiente de NO. En individuos obesos hay una disminución de este efecto vasodilatador (6), y las curvas dosis-respuesta para el flujo sanguíneo de los miembros en función de la concentración de insulina administrada se encuentran corridas hacia la derecha (valores mayores de insulina) en el caso de estos pacientes, asi como también en pacientes con diabetes tipo II, indicando que hay una disminución de la respuesta vasodilatadora a la insulina en casos de resistencia insulínica (6). La disminución de esta respuesta también se ha visto en pacientes con hipertensión (78), enfermedad que podría estar asociada a insulinorresistencia $(2,3)$. También se han reportado resultados en los que no se ha podido comprobar vasodilatación en respuesta a la insulina $(6,79)$, y casos en los cuales se obtuvo mayor aumento en el flujo del antebrazo en pacientes hipertensos obesos que en normotensos magros (80). Las discrepancias se atribuyen a diferencias en las técnicas utilizadas, a la gran variación biológica de los parámetros evaluados y a la diversidad en el estado de los pacientes (6).

\subsubsection{ESTUDIOS DE EFECTOS VASCULARES IN VITRO}

Como se describió en los efectos hipertensores e hipotensores de la insulina, hay varias formas por las cuales esta hormona podría afectar el nivel del calcio intracelular: estimulación de las $\mathrm{Ca}^{2+}$-ATPasas del sarcolema y del retículo sarcoplásmico, estimulación de la $\mathrm{Na}^{+} / \mathrm{K}^{+}$-ATPasa, que modifica la actividad del intercambiador $\mathrm{Na}^{+} / \mathrm{Ca}^{2+}$ y el flujo de $\mathrm{Ca}^{2+}$ a través de los canales de $\mathrm{Ca}^{2+}$ opera- 
dos por voltaje, estimulación del intercambio $\mathrm{Na}^{+} / \mathrm{H}^{+}$, y efectos de la hormona sobre canales de $\mathrm{Ca}^{2+} \mathrm{y}$ de $\mathrm{K}^{+}$.

La revisión de los resultados experimentales sugiere que los efectos vasculares in vitro de la insulina son facilitadores de la relajación del músculo liso vascular. En ratas insulinopénicas, como las diabéticas por estreptozotocina, las respuestas contráctiles de anillos de aorta estimulados con fenilefrina y serotonina están aumentadas con respecto a las de ratas controles (81). La respuesta a noradrenalina, sin embargo, no está afectada $(82,83)$.

Por otra parte, hay evidencias de que la preincubación con insulina atenúa tanto la movilización de $\mathrm{Ca}^{2+}$ intracelular como la respuesta mecánica de las células de músculo liso vascular estimuladas con diversos agonistas.

Cuando se estudiaron los aumentos transitorios de $\mathrm{Ca}^{2+}$ producidos por agonistas presores, se vio que, en general, si las células se preincubaban con insulina la cantidad de $\mathrm{Ca}^{2+}$ puesto en juego durante la contracción era menor que en los controles (43-45). Se midieron con fura-2 los aumentos transitorios de $\mathrm{Ca}^{2+}$ producidos por angiotensina-II (Ang II), noradrenalina (NA) y arginina-vasopresina (AVP) en células de arteria mesentérica de rata en cultivo. Cuando las células se colocaron en un medio con insulina y a los cinco minutos se estimularon con estos agonistas, se observó que los niveles de $\mathrm{Ca}^{2+}$ medidos disminuyeron (45). Resultados similares se encontraron para células de arteria femoral canina preincubadas con insulina durante 20 minutos o 7 dias y estimuladas con serotonina (5-HT) (44), y para células de aorta de rata y células de arteria pulmonar humana preincubadas por una hora con la hormona y estimuladas con Ang II y AVP (43). En este último estudio se midieron además las velocidades con las que el $\mathrm{Ca}^{2+}$ volvió a los niveles basales, y se vio que éstas eran mayores en las células preincubadas con insulina que en los controles. Se propuso que el aumento de la velocidad 
de recuperación del $\mathrm{Ca}^{2+}$ basal se podría deber a un aumento de la expresión de las $\mathrm{Ca}^{2+}$-ATPasas de sarcolema y de retículo sarcoplásmico, lo que está de acuerdo con los hallazgos previos de que la insulina estimula la sintesis de estas bombas (40).

Se ha encontrado, sin embargo, que la preincubación con insulina de células en cultivo derivadas de aorta de rata es capaz de aumentar la respuesta transitoria de $\mathrm{Ca}^{2+}$ citosólico inducida por $\mathrm{ET}_{1}$, aunque no se indica en este estudio si esto se acompañaria de un aumento de la contracción del músculo liso vascular (28).

De acuerdo con sus efectos sobre el calcio, se podria esperar que la insulina atenuara las respuestas mecánicas a distintos agonistas y, en efecto, se observó una disminución en las contracciones por Ang-Il y 5-HT en células musculares lisas aisladas de arteria femoral canina (44), en la contracción por noradrenalina en arteriolas de resistencia humanas (84) y en arteria femoral de conejo (85), asi como se vio vasodilatación por insulina y un corrimiento hacia la derecha en las curvas dosis-respuesta a noradrenalina en antebrazo humano (86). El grado de contracción por AVP en anillos de aorta de rata fue disminuido por insulina, mientras que en arteria mesentérica de rata la insulina potenció los efectos de AVP, proponiéndose para esto último que insulina aumenta la liberación de algún factor contrayente endotelial en estas arterias (30). Es interesante notar que la atenuación por la insulina de la respuesta vasoconstrictora a fenilefrina se encuentra disminuida en las ratas obesas Zucker (ZOR), y que esta cepa es conocida por presentar insulinorresistencia (45).

En concordancia con estos resultados in vitro se ha descripto un aumento de la respuesta vasoconstrictora a la noradrenalina (debida a un aumento de la respuesta $\alpha_{2}$ ) en pacientes con diabetes mellitus tipo I con microalbuminuria, pero 
no en diabéticos sin microalbuminuria o en individuos sanos (87). También se ha encontrado un aumento de la respuesta vasoconstrictora a Ang-II in vivo en pacientes hipertensos esenciales, estableciéndose una correlación positiva entre el aumento de esta respuesta y el grado de insulinorresistencia (88). En los hipertensos con sensibilidad normal a la glucosa la respuesta a Ang-ll fue comparable a la de los controles normotensos.

Los resultados hasta aqui presentados de los efectos de insulina sobre el sistema cardiovascular son contradictorios en algunos aspectos, o al menos no siempre unidireccionales. Podemos resumir a nuestro criterio que :

1. la insulina puede tener tanto efectos que conducirian a aumentar como efectos que tenderian a disminuir la presión arterial.

2. de estos efectos, los que parecen tener más importancia fisiopatológica son los que afectan directamente a los vasos, incluyendo la modificación de la actividad del endotelio vascular, de las bombas y de los transportes iónicos que afectan la regulación del calcio citosólico.

3. de los efectos vasculares, los que inducen vasodilatación serian predominantes in vivo, y si éstos se ven afectados por la presencia de resistencia insulinica se produciria una vasoconstricción y aumento de la presión arterial. Alternativamente, la hiperinsulinemia secundaria a resistencia insulinica podria determinar que se manifiesten más los efectos vasoconstrictores que los vasodilatadores.

4. la asociación de niveles altos de insulina, de resistencia insulínica, o de ambos 
con la hipertensión arterial está avalada por estudios epidemiológicos y experimentales in vivo o in vitro.

5. en el hombre, la hiperinsulinemia aislada no seria suficiente para inducir hipertensión arterial y para jugar un rol determinante en la elevación de la presión arterial requeriría de otros factores asociados a la raza, predisposición a obesidad, resistencia insulínica, o herencia de patología hipertensiva. 


\section{Objetivos Generales}




\section{OBJETIVOS}

Los efectos de la insulina sobre el tono vascular han sido estudiados tanto in vivo como in vitro mediante variados enfoques experimentales y en diferentes especies. El uso de células disociadas de músculo liso vascular o de células en cultivo permitió obtener información sobre los efectos de la insulina en la modificación de la concentración de $\mathrm{Ca}^{2+}$ intracelular producida por agonistas (43-45), sobre la expresión de transportadores de $\mathrm{Ca}^{2+}$ que regulan su concentración citosólica (40-43), y sobre la expresión de receptores para endotelinas $(28,29)$.

El planteo de este trabajo fue el de investigar los efectos de la insulina en el tejido vascular intacto en el cual las células de músculo liso se hallan bajo la regulación paracrina de factores derivados del endotelio. Para ello se seleccionó como principal modelo experimental a la rata debido a que es una especie donde la insulina tiene efectos hipertensores (70) y cuyos vasos o células vasculares aisladas han sido utilizadas en relación a los efectos de insulina $(28,30,39,45,81$ 83). Como vasos se eligieron uno de conductancia (aorta) y uno de resistencia (arteria de la cola) en la rata; un agonista fue testeado en segmentos de venas safenas humanas por la importancia de su rol en la regulación del tono vascular y la posibilidad de que la insulina modificara sus efectos. Los agonistas utilizados fueron todos de importancia fisiológica: noradrenalina, angiotensina II, argininavasopresina y endotelina 1. Los protocolos experimentales se diseñaron teniendo en cuenta las concentraciones de hormona y los periodos de tiempo de incubación con los que en la bibliografia se demostraban modificaciones en la concentración de $\mathrm{Ca}^{2+}$ citosólico y en la expresión de transportadores de $\mathrm{Ca}^{2+}$ inducidas 
por la insulina en células de músculo liso vascular aisladas. Para profundizar en el estudio de los efectos de la insulina sobre el retículo sarcoplásmico y sobre los canales de $\mathrm{Ca}^{2+}$ de la membrana plasmática se utilizaron también preparaciones de vasos hiperpermeabilizados por tratamiento químico y de células en cultivo derivadas de músculo liso aórtico de rata.

Los objetivos propuestos fueron establecer si la preincubación con insulina:

- modifica las contracciones inducidas por agonistas fisiológicos.

- media sus efectos a través de fosforilaciones en tirosina.

- afecta a las contracciones inducidas por endotelina 1 a través de la modificación de:

- la sintesis de óxido nítrico y de derivados de la ciclooxigenasa.

- el influjo de $\mathrm{Ca}^{2+}$ desde el medio extracelular.

- la liberación de $\mathrm{Ca}^{2+}$ desde depósitos intracelulares.

- las fosforilaciones dependientes de proteina quinasa C.

- regula la actividad del retículo sarcoplásmico.

- regula la actividad de los canales de $\mathrm{Ca}^{2+}$ de la membrana plasmática. 
ESTUDIOS MECÁNICOS Y RADIOISOTÓPICOS EN ANILLOS VASCULARES 


\section{ESTUDIOS MECÁNICOS Y RADIOISOTÓPICOS EN ANILLOS}

\section{VASCULARES}

\subsection{MÉTODOS}

\subsubsection{Materiales y equipos}

En el trabajo experimental utilizamos concentraciones de insulina bajas (40 y $160 \mu \mathrm{U} / \mathrm{ml})$ y altas $(500 \mu \mathrm{U} / \mathrm{ml})$. En la literatura se pueden encontrar valores basales de insulinemia para ratas del orden de 17 a $32 \mu \mathrm{U} / \mathrm{ml}$ y valores postprandiales de $136 \mu \mathrm{U} / \mathrm{ml}(89,90)$. Utilizamos dosis de 40 y de $160 \mu \mathrm{U} / \mathrm{ml}$, la primera cercana a los valores de ayuno y la segunda a los que se presentan luego de la ingesta. A continuación, quisimos saber si niveles de insulina cercanos a los hallados en ratas hiperinsulinémicas eran capaces de afectar las contracciones inducidas por agonistas fisiológicos. En la literatura se hallan valores de 2,5-2,9 nM para los niveles plásmáticos basales de insulina en las ratas obesas Zucker, un modelo de hiperinsulinemia (91), por lo tanto utilizamos un protocolo de $120 \mathrm{mi}$ nutos de preincubación con $500 \mu \mathrm{U} / \mathrm{ml}$ de insulina (3 nM).

Los agonistas utilizados fueron angiotensina-II (Ang II), arginina vasopresina (AVP) y endotelina-1 ( $\left.E T_{1}\right)$; las dosis utilizadas fueron del orden de las $\mathrm{DE}_{50}$ para respuesta contráctil. Se estudiaron en más profundidad los efectos de la insulina sobre las contracciones por $\mathrm{ET}_{1}$ por ser éste un agonista liberado por el endotelio de fundamental importancia en el control local de la vasculatura, y por- 
que la literatura reportaba efectos de la insulina sobre la expresión de sus receptores.

Se estudiaron los efectos de la insulina sobre tres tipos de vasos distintos: aorta y arteria de la cola de rata, y vena safena humana.

- Para obtener los vasos de rata se utilizaron machos de la cepa Wistar de 250$300 \mathrm{~g}$ de peso. Se anestesiaron con éter etilico para extraer la aorta torácica o la arteria de la cola. Luego de disecar cuidadosamente el tejido conectivo que rodea la arteria, se cortaron anillos de aproximadamente $2 \mathrm{~mm}$.

- Los vasos humanos utilizados se obtuvieron a partir de remanentes de cirugías de revascularización miocárdica realizadas en el Servicio de Cirugía Cardiovascular del Hospital San Juan de Dios de La Plata. A las venas se les disecó el tejido conectivo que las rodeaba en forma similar a los vasos de rata, y se cortaron anillos de unos $5 \mathrm{~mm}$ de longitud.

Equipo para determinaciones mecánicas: Los segmentos vasculares fueron conectados en forma isométrica a un transductor de fuerza (Letica TRI-201) e introducidos en una cámara plástica conteniendo solución de Krebs-Ringerbicarbonato (KRB) equilibrada con $5 \%$ de $\mathrm{CO}_{2}$ y $95 \%$ de $\mathrm{O}_{2}$ y termostatizada a $37^{\circ} \mathrm{C}$. La composición de la solución KRB fue la siguiente: CINa $130 \mathrm{mM}, \mathrm{ClK} \mathrm{4,7}$ $\mathrm{mM}, \mathrm{CO}_{3} \mathrm{HNa} 24 \mathrm{mM}, \mathrm{PO}_{4} \mathrm{HNa}_{2} 1,17 \mathrm{mM}, \mathrm{SO}_{4} \mathrm{Mg} 1,16 \mathrm{mM}, \mathrm{Cl}_{2} \mathrm{Ca} 1,6 \mathrm{mM}$, glucosa $11 \mathrm{mM}$. La señal del transductor fue ingresada a una plaqueta conversora analógico-digital (DT16EZ, Data translation Inc.) conectada a una computadora. Los datos almacenados se analizaron mediante un software (Labtech Notebook Pro, Laboratroy Technology Corp.) que permitió obtener registros gráficos de la fuerza desarrollada por la preparación en función del tiempo. Se les impuso a los 
preparados una tensión de reposo de $2 \mathrm{~g}$ y se los estabilizó durante una hora cambiando el KRB cada 20 minutos.

Con los preparados estabilizados se realizaron grupos de experimentos con los siguientes protocolos:

\subsubsection{Protocolos experimentales de preincubación con insulina, a dosis fi-} siológicas, interpuesta entre dos estimulaciones sucesivas con un agonista.

- experimentos mecánicos:

En estos experimentos se estudió el efecto de una dosis baja de insulina $(40 \mu \mathrm{U} / \mathrm{ml})$ sobre la taquifilaxia presentada por Angll $1 \mu \mathrm{M}$ y AVP $1 \mu \mathrm{M}$. Se realizaron dos contracciones separadas por una hora de incubación con insulina.

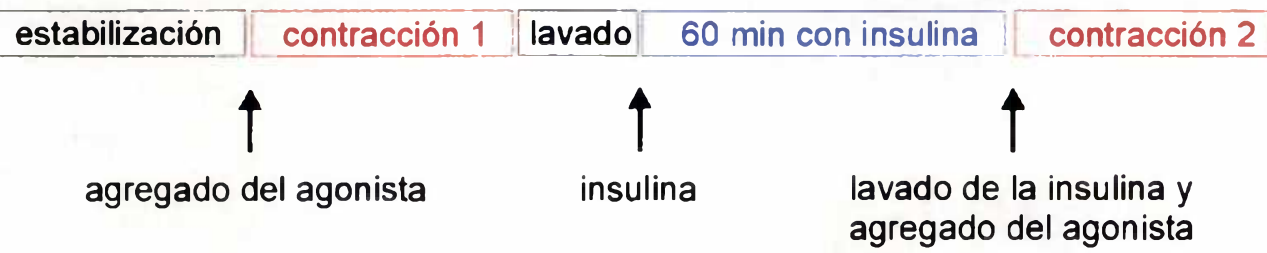

- captación de $\mathrm{Ca}^{2+}$ por el retículo sarcoplásmico:

El objetivo de esta serie de experimentos fue investigar si la preincubación de segmentos de aorta de rata con una dosis baja de insulina modificaba la captación de $\mathrm{Ca}^{2+}$ por el retículo sarcoplásmico, y tratar de correlacionar esta determinación con los resultados de los experimentos mecánicos con Angll y AVP.

La aorta fue obtenida como se describió previamente y cortada en segmentos (peso promedio $=12,1 \pm 0,25 \mathrm{mg}, \mathrm{n}=208$ ) que se agruparon por pares (dos por cada 
aorta) y se incubaron durante dos horas a $37^{\circ} \mathrm{C}$ : de cada par uno de los segmentos se incubó en KRB control y el otro en KRB con $40 \mu \mathrm{U} / \mathrm{ml}$ de insulina. Terminada la incubación se sumergieron durante $24 \mathrm{hs}$. a $4^{\circ} \mathrm{C}$ en una solución conteniendo ácido etilén glicol-bis ( $\beta$-aminoetil éter) tetraacético (EGTA) $5 \mathrm{mM}$, propionato de $\mathrm{K}^{+} 50 \mathrm{mM}$, Hepes (pH 7) $20 \mathrm{mM}$, ditiotreitol $1 \mathrm{mM}, \mathrm{Cl}_{2} \mathrm{Mg} \mathrm{0,4} \mathrm{mM}$ y sacarosa $150 \mathrm{mM}$. Este tratamiento permeabiliza la membrana plasmática y permite que las organelas intracelulares estén en contacto con las soluciones de captación conteniendo ${ }^{45} \mathrm{Ca}^{2+}$ y con las soluciones de lavado. Luego del 'pelado' químico los segmentos fueron usados para medir captación de ${ }^{45} \mathrm{Ca}^{2+}$ en retículo sarcoplásmico (RS) en función del tiempo. Pares de segmentos, uno incubado previamente sin y otro con insulina, se sumergieron en una solución de captación mantenida a $20^{\circ} \mathrm{C}$ conteniendo EGTA $0,71 \mathrm{mM}$, ${ }^{45} \mathrm{Ca}-\mathrm{EGTA} 0,29 \mathrm{mM}(0,5 \mu \mathrm{M}$ de calcio libre ), propionato de $\mathrm{K} 100 \mathrm{mM}$, Hepes $(\mathrm{pH} 7)$ $20 \mathrm{mM}$, ditiotreitol $1 \mathrm{mM}, \mathrm{Cl}_{2} \mathrm{Mg} 5,76 \mathrm{mM}$ ( $1 \mathrm{mM}$ libre ), ATPNa $20,57 \mathrm{mM}(0,5 \mu \mathrm{M}$ libre) y sacarosa $150 \mathrm{mM}$. Los tiempos de captación fueron de 2, 5, 10 y 30 minutos, al cabo de los cuales los segmentos fueron lavados durante 15 minutos en una solución mantenida a 4 - $6^{\circ} \mathrm{C}$ conteniendo EGTA $1 \mathrm{mM}$, propionato de $\mathrm{K}^{+} 100 \mathrm{mM}$, Hepes (pH 7) $20 \mathrm{mM}, \mathrm{Cl}_{2} \mathrm{Mg} 10 \mathrm{mM}$, ATPNa $25 \mathrm{mM}$ y rojo de rutenio $0,05 \mathrm{mM}$. Luego se sumergió cada segmento en $1 \mathrm{ml}$ de EDTA $1 \mathrm{mM}(\mathrm{pH}$ 7) durante 1 hora. Se midió la radiactividad remanente en el tejido en un contador de centelleo líquido.

\subsubsection{Protocolos experimentales de preincubación con insulina y estimula-} ción única con un agonista. Dosis fisiológicas de insulina y dosis hiperinsulinémicas.

Se estudió el efecto de la preincubación con dosis bajas (40 o $160 \mu \mathrm{U} / \mathrm{ml})$ o altas $(500 \mu \mathrm{U} / \mathrm{ml})$ de insulina sobre las contracciones dadas por Angll $1 \mu \mathrm{M}$, 
AVP $1 \mu \mathrm{M} \circ \mathrm{ET}_{1} 0,01 \mu \mathrm{M}$. Se estimuló con el agonista luego de una preincubación de 120 min con insulina.

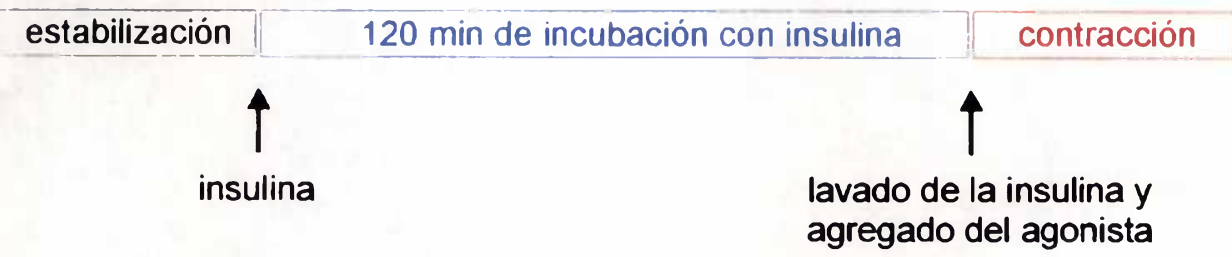

Se realizaron varios protocolos experimentales distintos en aorta y arteria de la cola de rata con sus correspondientes controles:

- sólo con insulina.

- con insulina y N $\omega$-nitro-L-arginina metil éster (L-NAME) 0,1 mM para estudiar el papel del NO en los efectos de la insulina. EI L-NAME estuvo presente durante el periodo de la incubación con insulina y durante la contracción.

- con insulina, L-NAME 0,1 mM e indometacina $10 \mu \mathrm{M}$ para estudiar el papel de los productos de la ciclooxigenasa (prostaglandinas y tromboxanos). La indometacina estuvo presente durante el período de la incubación con insulina y durante la contracción.

- con insulina y genisteína $30 \mu \mathrm{M}$ durante la preincubación para comprobar si el bloqueo de la fosforilación en tirosinas impedia que se expresaran los efectos de la insulina (sólo para anillos de aorta).

\subsubsection{Preincubación con insulina y liberación de NO inducida por ACh.}

En algunos vasos, se ha demostrado que la insulina produce un aumento en la liberación endotelial de NO. Investigamos si en nuestro modelo experimen- 
tal de aorta de rata la preincubación con $500 \mu \mathrm{U} / \mathrm{ml}$ de insulina era capaz de modificar la liberación de NO por el endotelio inducida por la acetil colina (ACh).

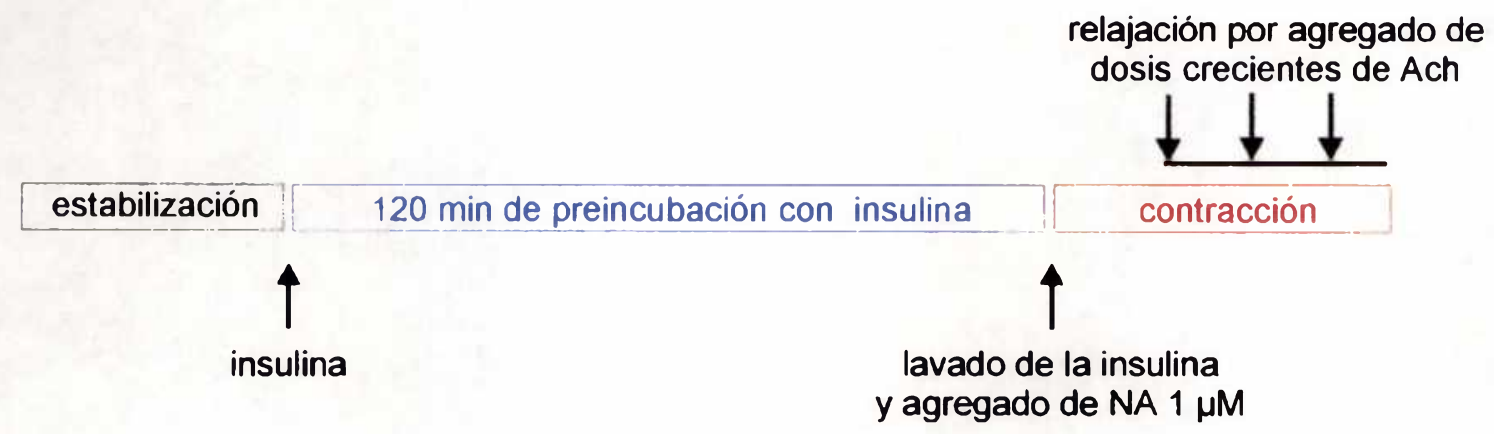

Luego de una preincubación de 120 minutos con insulina se indujo una contracción con noradrenalina (NA) $1 \mu \mathrm{M}$. Cuando la fuerza desarrollada fue máxima, se agregaron dosis crecientes de $\mathrm{ACh}\left(10^{-8}\right.$ a $\left.10^{-5} \mathrm{M}\right)$ para producir relajación inducida por la liberación de NO endotelial. Los resultados se expresan como el porcentaje de la fuerza máxima hasta el que se llega luego del agregado de cada dosis de ACh.

3.1.5 Estudio de los posibles mecanismos afectados por la preincubación con insulina para modificar contracciones inducidas por $E T_{1}$. Dosis hiperinsulinémicas.

Los efectos de la insulina sobre las contracciones por $\mathrm{ET}_{1}$ sugirieron nuevos protocolos experimentales tendientes a profundizar el estudio de estos mecanismos.

(a) participación del retículo sarcoplásmico: 
- se eliminó la participación del retículo en las contracciones por $E T_{1}$ con rianodina $10 \mu \mathrm{M}(\mathrm{Ry})$ o con tapsigargina $10 \mu \mathrm{M}$ (Taps). La rianodina produce un vaciamiento del reticulo al abrir y mantener abiertos uno de los dos tipos de canales de $\mathrm{Ca}^{2+}$ que se encuentran en su membrana, y la tapsigargina lo hace a través de inhibir la Ca-ATPasa reticular. La rianodina o la tapsigargina estuvieron presentes durante la segunda hora de preincubación y durante la contracción.

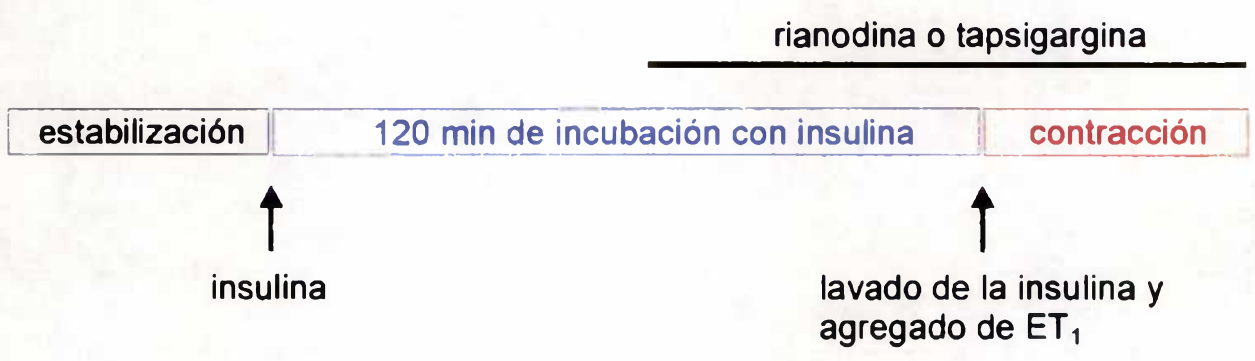

- se eliminó la participación del $\mathrm{Ca}^{2+}$ extracelular en las contracciones por $\mathrm{ET}_{1}$ incubando en ausencia de $\mathrm{Ca}^{2+}$ externo. Con estos protocolos en "cero $\mathrm{Ca}^{2+"}$ se estudió el papel del retículo en los efectos de la insulina sobre la contracción por $E T_{1}$. Los últimos 5 minutos de la preincubación y la contracción se realizaron en un $\mathrm{KRB}$ sin $\mathrm{Ca}^{2+}$, de forma que la fuerza generada se debió únicamente al $\mathrm{Ca}^{2+}$ liberado por el retículo por acción de la $\mathrm{ET}_{1}$.

estabilización 120 min de incubación con insulina


- se examinó la liberación de $\mathrm{Ca}^{2+}$ por el retículo sarcoplásmico inducida por cafeina. La contracción después de la preincubación con insulina se realizó con cafeina $3 \mathrm{mM}$. Con estos experimentos se investigó si la insulina era capaz de cambiar la cantidad de $\mathrm{Ca}^{2+}$ liberado a partir del retículo sarcoplásmico por un agonista que produce contracción sólo a través del $\mathrm{Ca}^{2+}$ de este depósito.

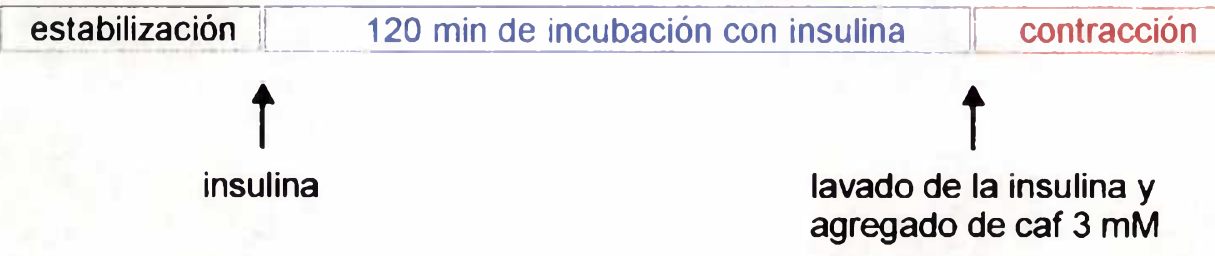

- cantidad de $\mathrm{Ca}^{2+}$ captada por el retículo sarcoplásmico: el objetivo fue comprobar si el aumento de la liberación de $\mathrm{Ca}^{2+}$ por $\mathrm{ET}_{1}$ inducido por la preincubación con una dosis alta de insulina se debia a un aumento en el contenido de $\mathrm{Ca}^{2+}$ en este depósito. Para ello se preincubaron segmentos de aorta (pe$\mathrm{so}=6,21 \pm 0,85 \mathrm{mg}, \mathrm{n}=49)$ con $0 \sin 500 \mu \mathrm{U} / \mathrm{ml}$ de insulina durante $120 \mathrm{mi}-$ nutos para luego hiperpermeabilizarlos por la técnica ya descripta. Se hicieron captaciones a 30 minutos utilizando dos tipos de soluciones de captación, una con la misma composición de la ya descripta y otra similar pero con el agregado de $10 \mu \mathrm{g} / \mathrm{ml}$ de heparina y $50 \mu \mathrm{M}$ de rojo de rutenio para inhibir la salida de $\mathrm{Ca}^{2+}$ del retículo sarcoplásmico a través de los canales sensibles a $\mathrm{IP}_{3}$ y de los sensibles a rianodina, respectivamente. Luego de la captación los anillos se lavaron durante 15 minutos con la misma técnica utilizada en los experimentos ya descriptos, se sumergieron posteriormente en EDTA $1 \mathrm{mM}$ du- 
rante 1 hora y se contó la radiactividad presente en el tejido en un contador de centelleo líquido.

(b) participación de la proteina quinasa C (PKC):

Se repitieron los experimentos en presencia de cheleritrina $30 \mu \mathrm{M}$ para inhibir la actividad de la PKC con el objeto de estudiar si la potenciación de la contracción dada por la insulina estaba mediada, al menos en parte, por esta proteina quinasa.

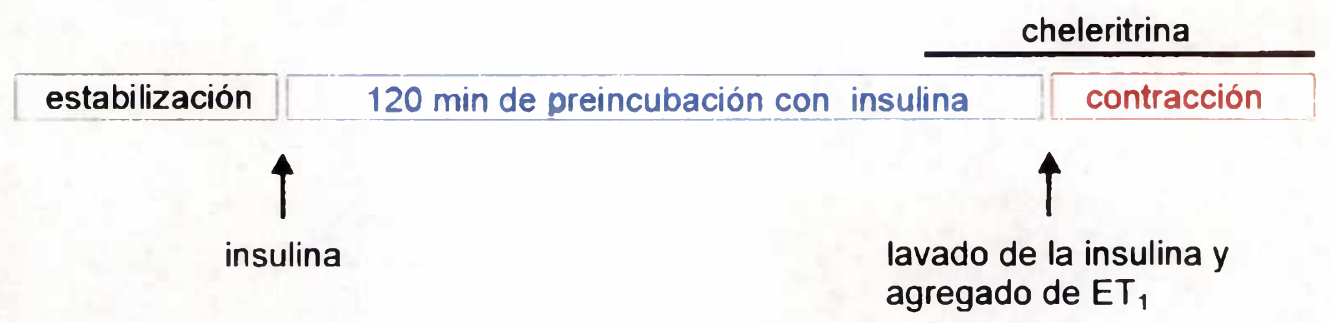

La cheleritrina se agregó durante los últimos 20 minutos de la preincubación y estuvo presente durante la posterior contracción.

(c) participación del $\mathrm{Ca}^{2+}$ externo:

La contracción por $E T_{1}$ luego de la incubación con insulina se realizó en una solución de KRB marcada con ${ }^{45} \mathrm{Ca}^{2+}$ de forma de medir simultáneamente la fuerza y la entrada de $\mathrm{Ca}^{2+}$ desde el espacio extracelular. 


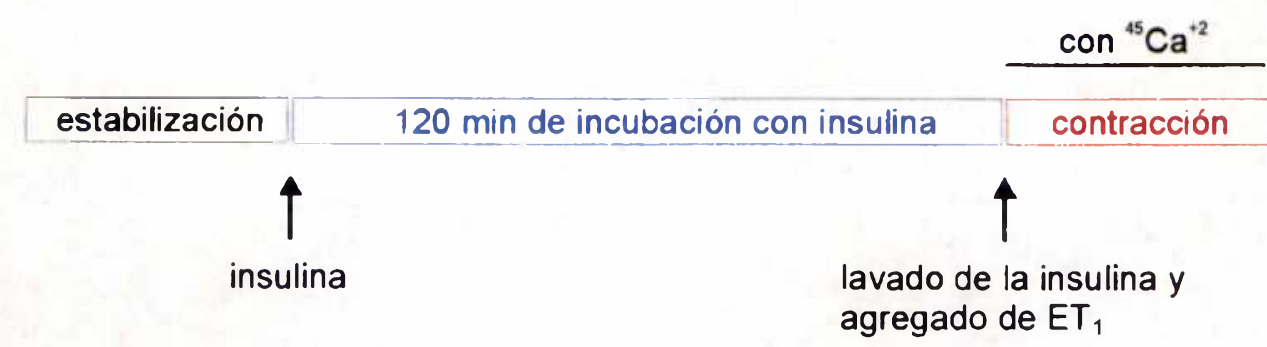

A los 20 minutos de la estimulación se sacó el anillo de la cámara y se le lavó el ${ }^{45} \mathrm{Ca}^{2+}$ que hubiera quedado en el espacio extracelular tratándolo durante 45 minutos con una solución de la siguiente composición (en $\mathrm{mM}$ ): $\mathrm{Cl}_{2} \mathrm{Ca}$ 1,6; $\mathrm{PO}_{4} \mathrm{HNa} 1,17 ; \mathrm{CIK} 4,7 ; \mathrm{SO}_{4} \mathrm{Mg}$ 1,16; HEPES 25 (pH 7,4); CINa 50; $\mathrm{Cl}_{3} \mathrm{La} 80$. Se dejó el anillo toda la noche a $4^{\circ} \mathrm{C}$ en OHNa $1 \mathrm{M}$ para disgregar el tejido y se dosó el ${ }^{45} \mathrm{Ca}^{2+}$ presente en la muestra mediante un contador de centelleo líquido.

(d) Participación de derivados del ácido araquidónico:

Los experimentos con indometacina sugirieron que en la arteria de la cola de la rata la $E T_{1}$ podría estar liberando un agente vasoconstrictor derivado del ácido araquidónico. Para confirmar si se trataba de tromboxano $A_{2}\left(T X A_{2}\right)$ se repitieron los experimentos con SQ $25.5481 \mu \mathrm{M}$, un antagonista especifico de los receptores de $\mathrm{TXA}_{2}$.

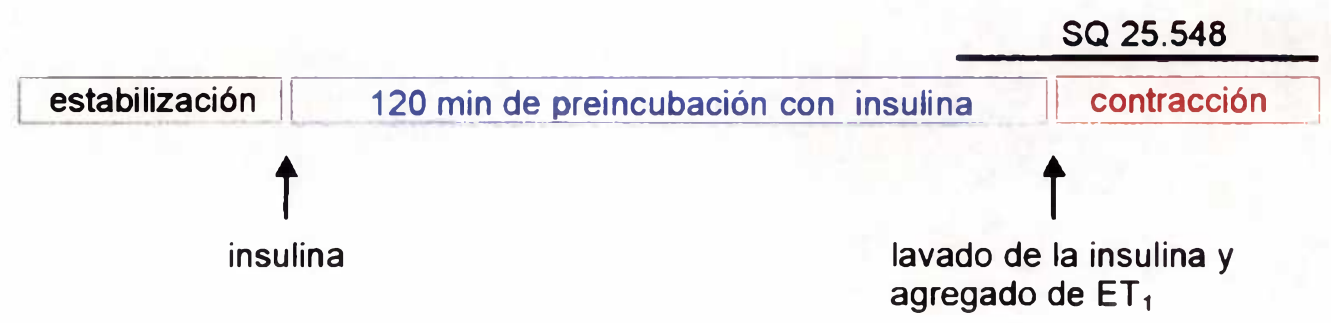


EI SQ 25.548 estuvo presente durante los últimos 20 min de la incubación y durante la posterior contracción.

(e) tiempo necesario para que se expresen los efectos de la insulina:

Se estudió si un tiempo breve era suficiente para que se manifestasen los efectos de la insulina sobre las contracciones producidas por ET 1 . La insulina se agregó sólo 15 minutos antes de estimular al anillo con $E T_{1}$, y la contracción se llevó a cabo en presencia de la insulina.

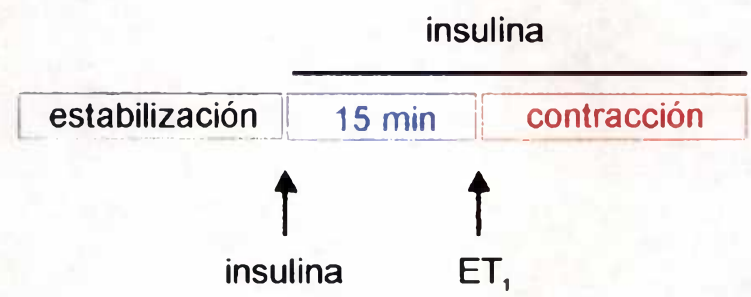

\subsubsection{Parámetros mecánicos medidos. Análisis estadistico.}

Los parámetros medidos en los registros de la actividad mecánica fueron:

- fuerza máxima desarrollada por el preparado desde la línea de base (Fmáx).

- tiempo medio de contracción ( $t_{1 / 2}$ contr): tiempo necesario para desarrollar la mitad de la fuerza máxima, un índice de la velocidad del desarrollo de la fuerza (medido sólo en el caso de $E T_{1}$ ).

- tiempo de relajación al tercio ( $\mathrm{t}_{1 / 3}$ relaj): tiempo necesario para relajar un tercio de la fuerza máxima.

- tiempo de semirrelajación ( $t_{1 / 2}$ relaj): tiempo necesario para relajar la mitad de la fuerza máxima. 
- Velocidad media de relajación al tercio de la relajación ( $v_{1 / 3}$ relaj): un tercio de la fuerza máxima/tiempo necesario para relajar un tercio de la fuerza máxima.

- Velocidad media de relajación al medio de la relajación ( $\mathrm{V}_{1 / 2}$ relaj): mitad de la fuerza máxima/tiempo necesario para relajar la mitad de la fuerza máxima.

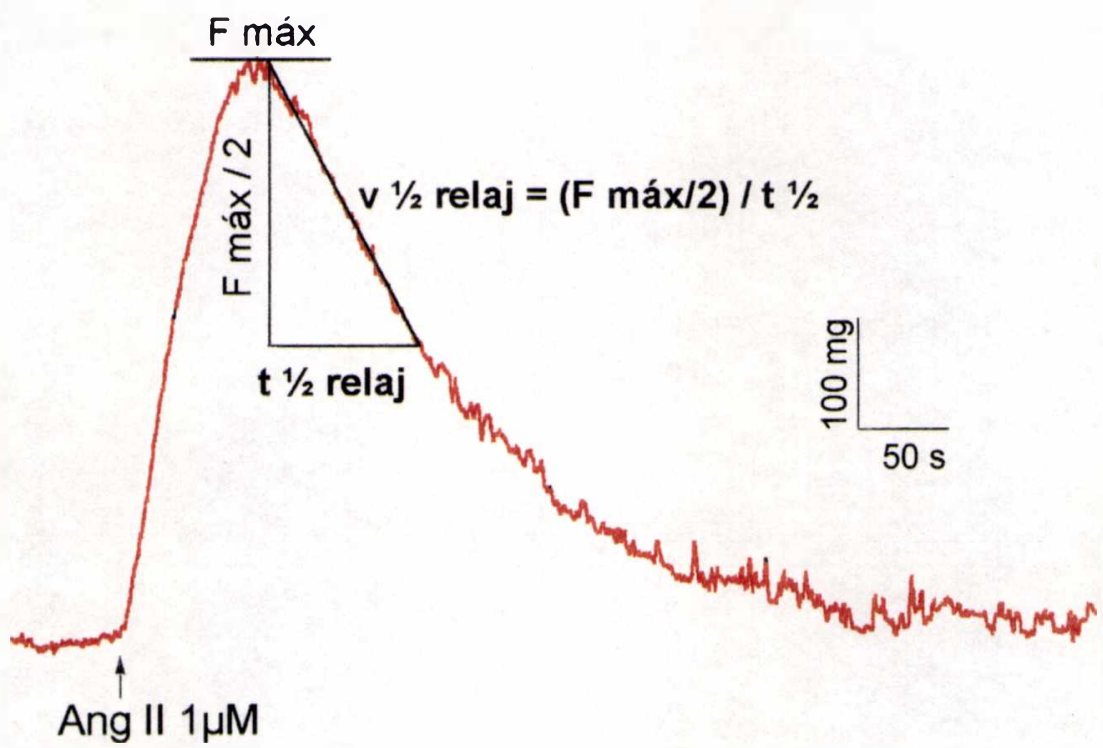

Fig 2: contracción típica producida por Ang II donde se indican los parámetros medidos.

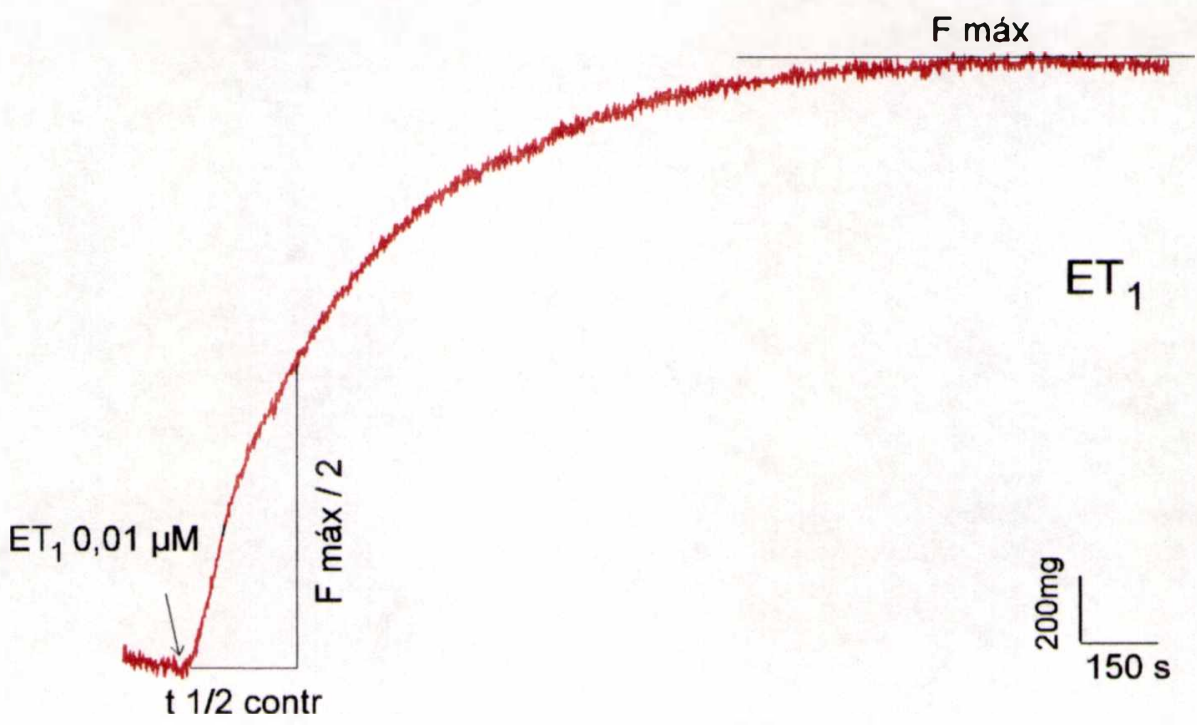

Fig 3 : contracción tipica dada por $E T_{1}$. Se indican en el dibujo los parámetros medidos 
Los resultados de los experimentos con dos contracciones sucesivas por Ang II o AVP se expresan como diferencias $(\Delta)$ entre el valor del parámetro de la contracción post incubación y el valor del mismo en la primera contracción.

Ej: $\Delta$ Fmáx $=F$ máx post incubación - Fmáx pre incubación

Los resultados de los experimentos con una sola estimulación por Ang II, AVP o $E T_{1}$ se expresan como valores absolutos normalizados por la superficie del anillo abierto determinada mediante un calibre digital $\left(\mathrm{mg} / \mathrm{mm}^{2}\right)$ en el caso de la aorta de rata, o por el peso del mismo $(\mathrm{mgF} / \mathrm{mgP})$ en el caso de la arteria de la cola de rata. En los experimentos con determinación simultánea de fuerza y captación de $\mathrm{Ca}^{2+}$ los resultados de fuerza se expresan como porcentaje de una contracción previa inducida por CIK $80 \mathrm{mM}$.

En los experimentos radioisotópicos, los resultados se expresan en pmoles de $\mathrm{Ca}^{2+}$ captado por $\mathrm{mg}$ de tejido húmedo.

Los valores experimentales presentados como resultados corresponden a promedios \pm 1 error estándar de la media.

Se utilizó el test de " $t$ " de Student para muestras independientes, o apareadas, cuando se compararon valores promedio de una intervención con su correspondiente control en la misma preparación. Para comparar grupos múltiples se realizaron análisis de varianza empleando del test de Newman-Keuls. En todos los casos las diferencias se consideraron estadisticamente significativas para un valor de $p<0,05$ 


\subsection{RESULTADOS}

3.2.1 Preincubación con insulina, a dosis fisiológicas, interpuesta entre dos estimulaciones sucesivas con un agonista.

- experimentos mecánicos: en aorta de rata, Ang II y AVP

En aorta de rata, las segundas contracciones de Ang II en el grupo control fueron siempre menores que las primeras, un fenómeno conocido como taquifilaxia. El tratamiento con $40 \mu \mathrm{U} / \mathrm{ml}$ de insulina fue capaz de atenuar la taquifilaxia: al comparar los experimentos con insulina con los experimentos control se observó una disminución significativa en la caida de la fuerza máxima $(p<0.02)$ y un aumento significativo en la velocidad de relajación $(P<0.005)$. No se encontraron diferencias significativas entre los $\Delta v$ contracción o entre los $\Delta t \frac{1}{2}$ de relajación (Fig 4).
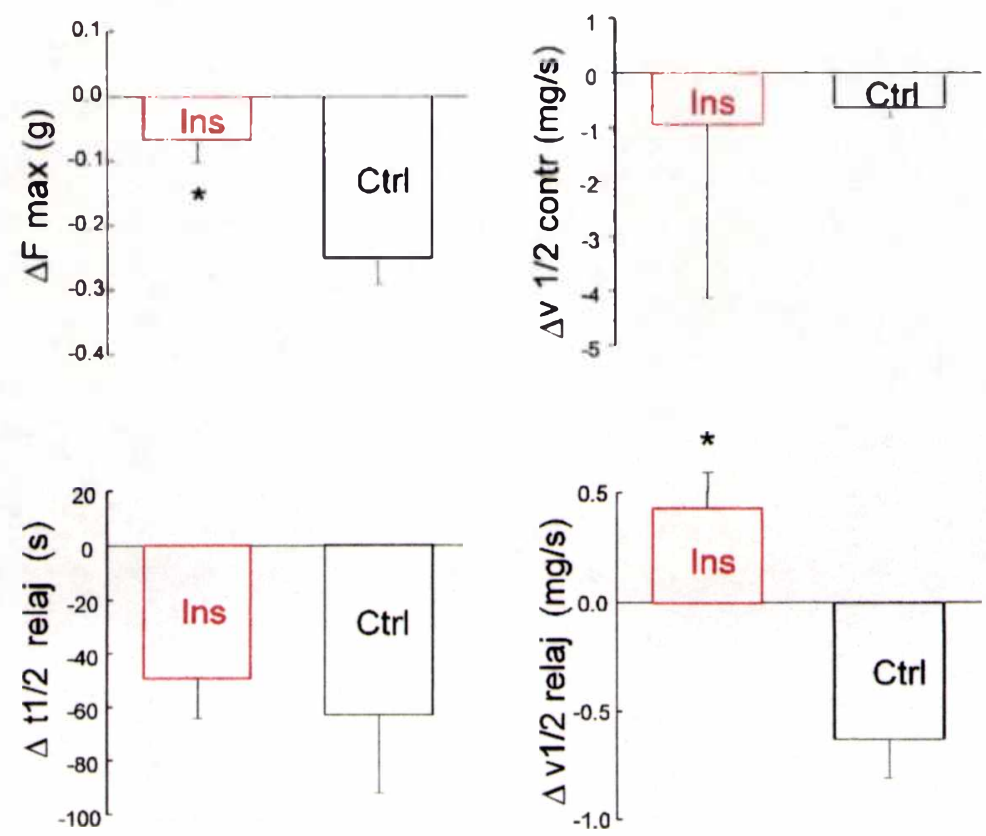

Fig 4: parámetros de las respuestas a Ang II en aorta de rata. " indica diferencia significativa $(p<0,05)$ respecto al grupo control. Cada grupo experimental tiene $n=5$. 
Las respuestas a AVP también presentaron taquifilaxia (Fig 5).

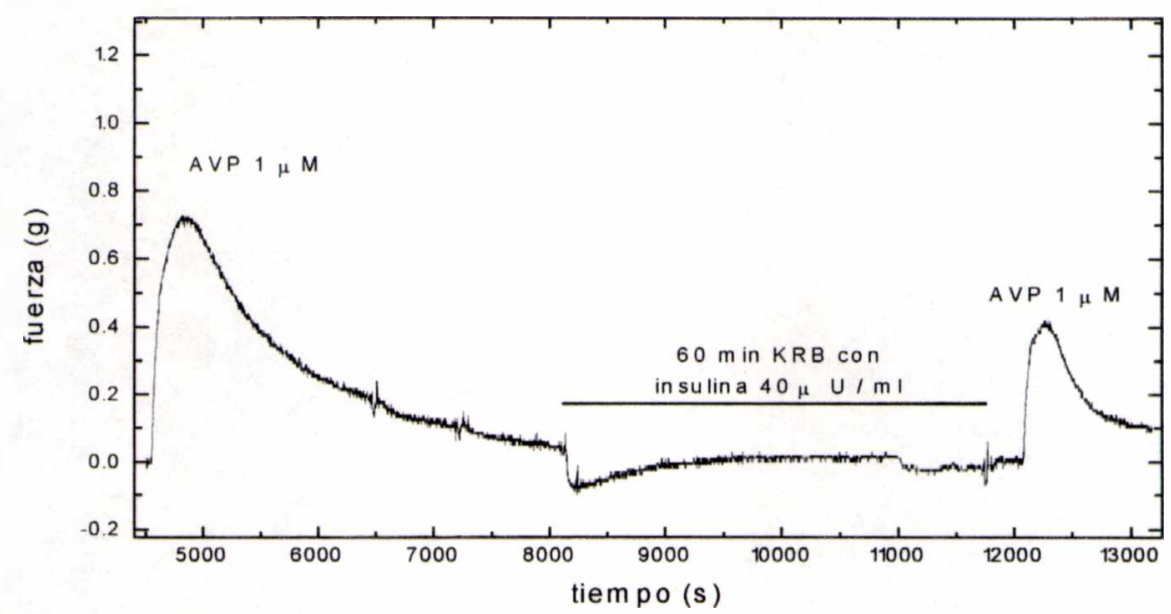

Fig 5 : registro de un experimento típico del grupo insulina con AVP en anillo de aorta de rata.

La preincubación con $40 \mu \mathrm{U} / \mathrm{ml}$ de insulina produjo una disminución significativa de la taquifilaxia (aumento de la fuerza máxima) de la segunda contracción evocada por AVP. No hubo, sin embargo, cambios en los parámetros de relajación ( $t_{1 / 2}$ de relajación o velocidades de relajación) (Fig 6).
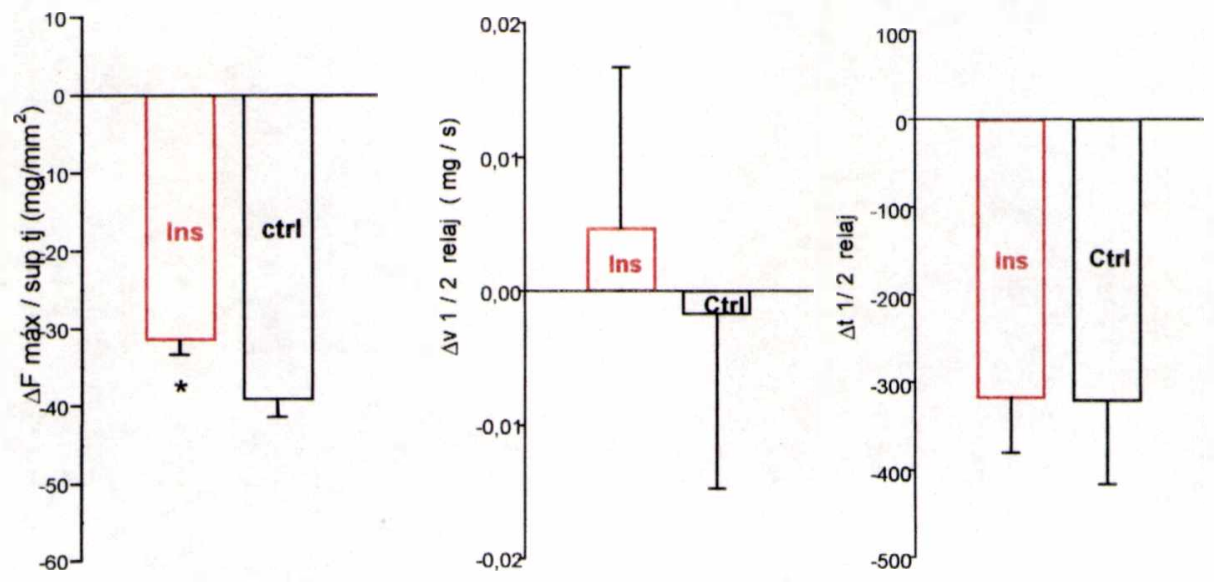

Fig 6: parámetros de las respuestas a AVP en aorta de rata y su modificación por la preincubación con $40 \mu \mathrm{U} / \mathrm{ml}$ de insulina. * indica diferencia significativa $(p<0,05)$ respecto del grupo control. Controles: $n=13-18$, insulina: $n=6-12$. 
- experimentos mecánicos: en vena safena humana, Ang II.

La respuesta a Ang II en anillos de vena safena humana fue diferente a la observada en aorta de rata. Los anillos se dividieron en dos grupos según proviniesen de pacientes hipertensos o normotensos. En estos vasos el $48 \%$ de las respuestas a Angll presentaron contracciones espontáneas superpuestas a la fase de relajación de una magnitud cercana al $10 \%$ del valor de la fuerza pico.

La fuerza de la segunda contracción por Angll no fue distinta de la primera (los $\Delta \mathrm{F}$ máx no fueron significativamente distintos de cero), es decir, no se observó taquifilaxia. La preincubación con $40 \mu \mathrm{U} / \mathrm{ml}$ de insulina no modificó el valor de la fuerza máxima desarrollada por Ang II en ninguno de los dos grupos, así como tampoco modificó la frecuencia de aparición de contracciones espontáneas.
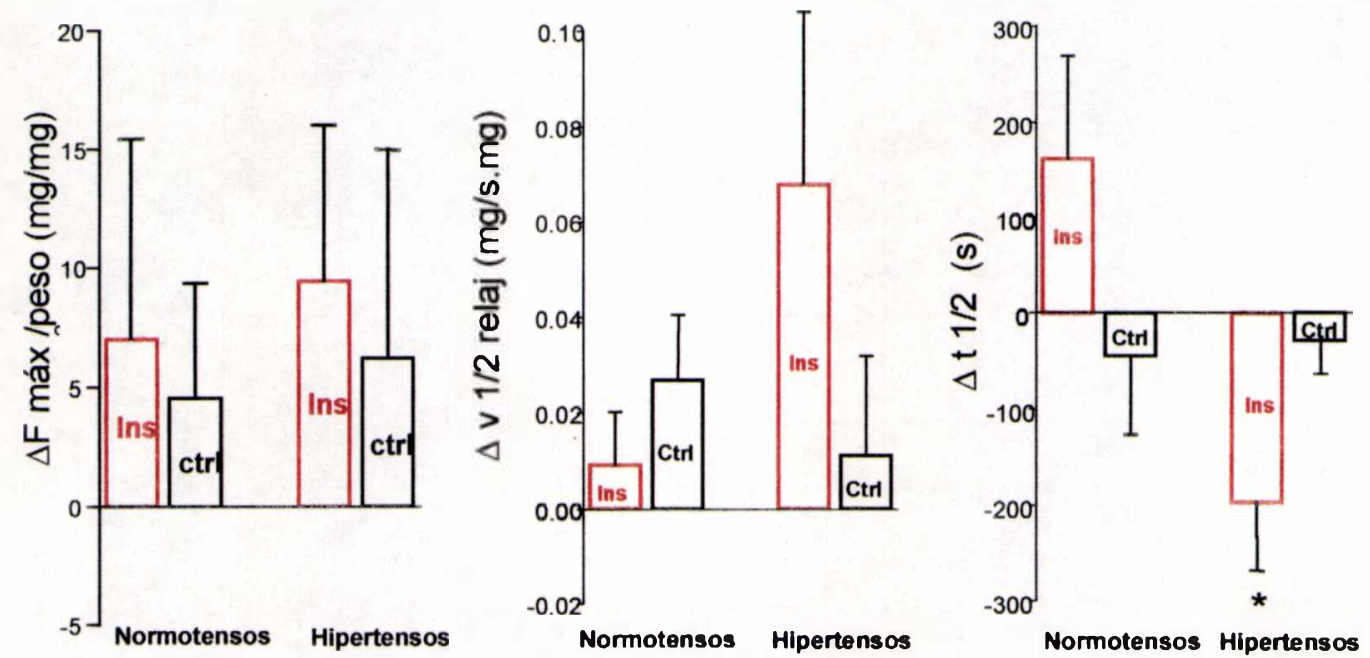

Fig 7: parámetros de las respuestas a Ang II en vena safena humana. * indica diferencia significativa $(p<0,05)$ respecto al grupo control de hipertensos y respecto al grupo insulina de normotensos. Hipertensos: control $n=9$, insulina $n=10$; normotensos: control $n=5$, insulina $n=5$. 
En el grupo de hipertensos la preincubación con insulina disminuyó significativamente el $\mathrm{t}_{1 / 2}$, siendo la disminución del $\Delta \mathrm{t}_{1 / 2}$ significativamente mayor que en el grupo control y en el grupo normotenso con insulina (Fig 7).

Los parámetros obtenidos de las contracciones pre-incubación, tanto del grupo control como del que luego fue tratado con insulina, se utilizaron también para obtener información sobre las posibles diferencias en la conducta frente a Angll de los anillos provenientes de normotensos o de hipertensos.
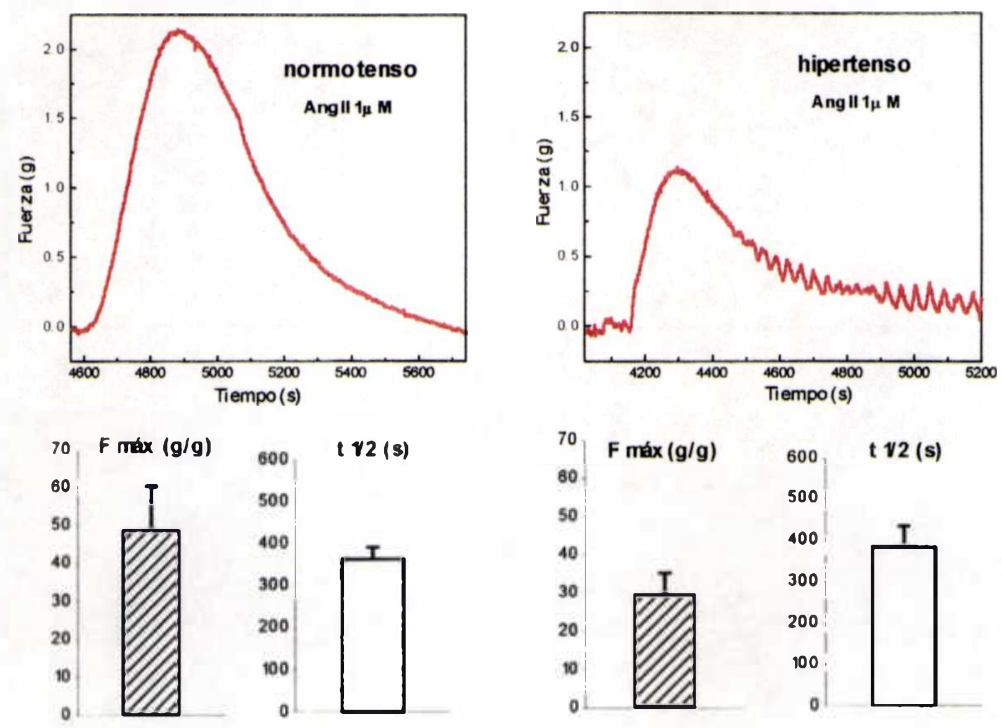

Fig 8 : Registros tipicos de contracciones dadas por Ang II en venas safenas humanas de normotensos e hipertensos (panel superior), y promedios de $F$ máx y $t^{t} 1 / 2$ relajación para dichas contracciones (panel inferior). Normotensos: $n=17-19$, hipertensos: 10-12.

En anillos de vena safena humana se observó una tendencia a que la fuerza de las primeras contracciones por Ang II fuesen mayores en los normotensos que en los hipertensos, pero la diferencia no alcanzó significación estadística ( Fig 8).

- captación de ${ }^{45} \mathrm{Ca}^{2+}$ en retículo sarcoplásmico de segmentos de aorta preincubados con dosis fisiológicas de insulina e hiperpermeabilizados por tratamiento químico. 
La siguiente tabla presenta los valores de la captación de ${ }^{45} \mathrm{Ca}^{2+}$ en anillos de aorta de rata expresados en pmol de $\mathrm{Ca}^{2+} / \mathrm{mg}$ de tejido húmedo como promedios \pm 1 error estándar. Se compararon diferencias de captación en cada par de segmentos de aorta uno incubado previamente sin y otro con $40 \mu \mathrm{U} / \mathrm{ml}$ de insulina (deltas).

\begin{tabular}{|c|c|c|c|c|}
\hline & $\mathbf{2}$ min & $\mathbf{5}$ min & $\mathbf{1 0}$ min & $\mathbf{3 0}$ min \\
\hline control & $38,48 \pm 2,34$ & $44,86 \pm 2,39$ & $91,25 \pm 8,19$ & $134,93 \pm 9,58$ \\
insulina & $39,11 \pm 2,58$ & $49,22 \pm 3,48$ & $85,75 \pm 4,26$ & $121,69 \pm 7,12$ \\
$\Delta=$ Ins-Ctrl & $0,73 \pm 3,03$ & $4,34 \pm 2,74$ & $-5,58 \pm 9,14$ & $-11,99 \pm 7,35$ \\
$\mathbf{n}$ & 30 & 31 & 14 & 19 \\
\hline
\end{tabular}

Con estos datos se realizaron curvas de captación de ${ }^{45} \mathrm{Ca}^{2+}$ (Fig 9).

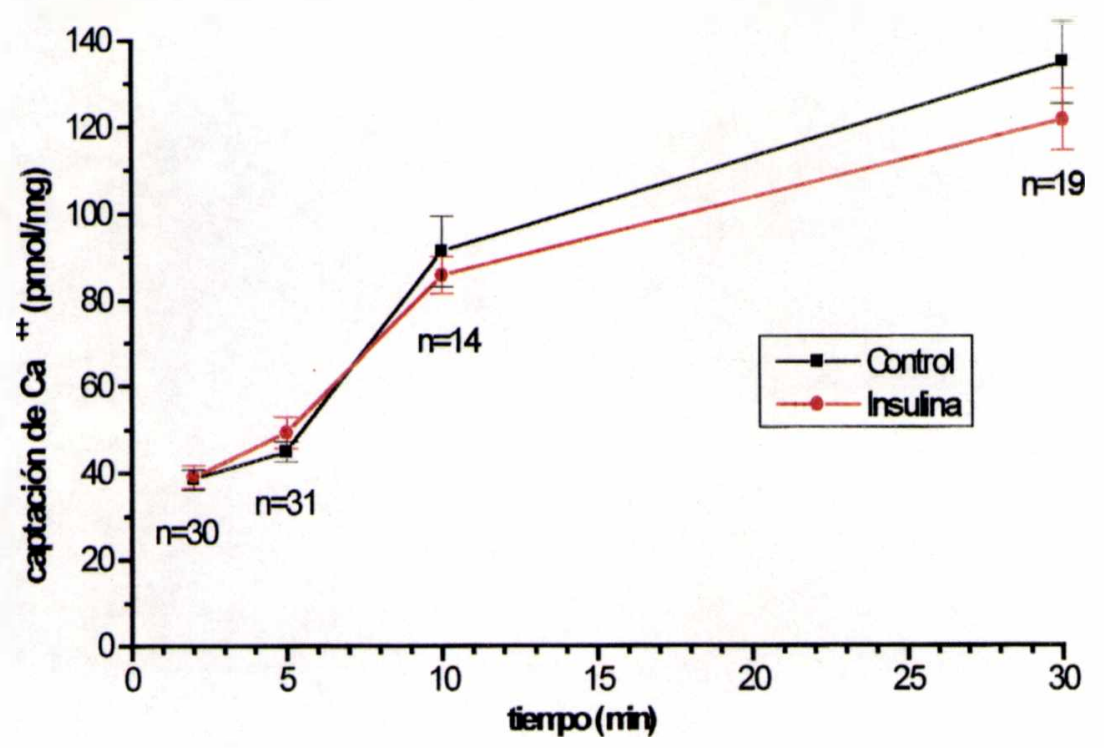

Fig 9: curva de captación de ${ }^{45} \mathrm{Ca}^{2+}$ en segmentos de aorta de rata hiperpermeabilizados por tratamiento con EGTA. 
La captación de ${ }^{45} \mathrm{Ca}^{2+}$ se realizó a concentración de $0,5 \mu \mathrm{M}$ de $\mathrm{Ca}^{2+}$, valor comparable al del $\mathrm{Ca}^{2+}$ citosólico del músculo liso vascular durante una contracción. Al exponer los segmentos de aorta "pelados" a esta concentración de $\mathrm{Ca}^{2+}$ en presencia de ATP se observó una acumulación progresiva de $\mathrm{Ca}^{2+}$ en función del tiempo, con tendecia a ser mayor a los 5 y menor a los 30 minutos de captación en los segmentos pretratados con insulina con respecto al grupo control. Al aparear los valores de captación de los segmentos tratados y no tratados con la hormona se observó una ganancia neta de $\mathrm{Ca}^{2+}(p<0,05)$ a los 5 minutos con respecto a los valores a los 30 minutos (Fig 10).

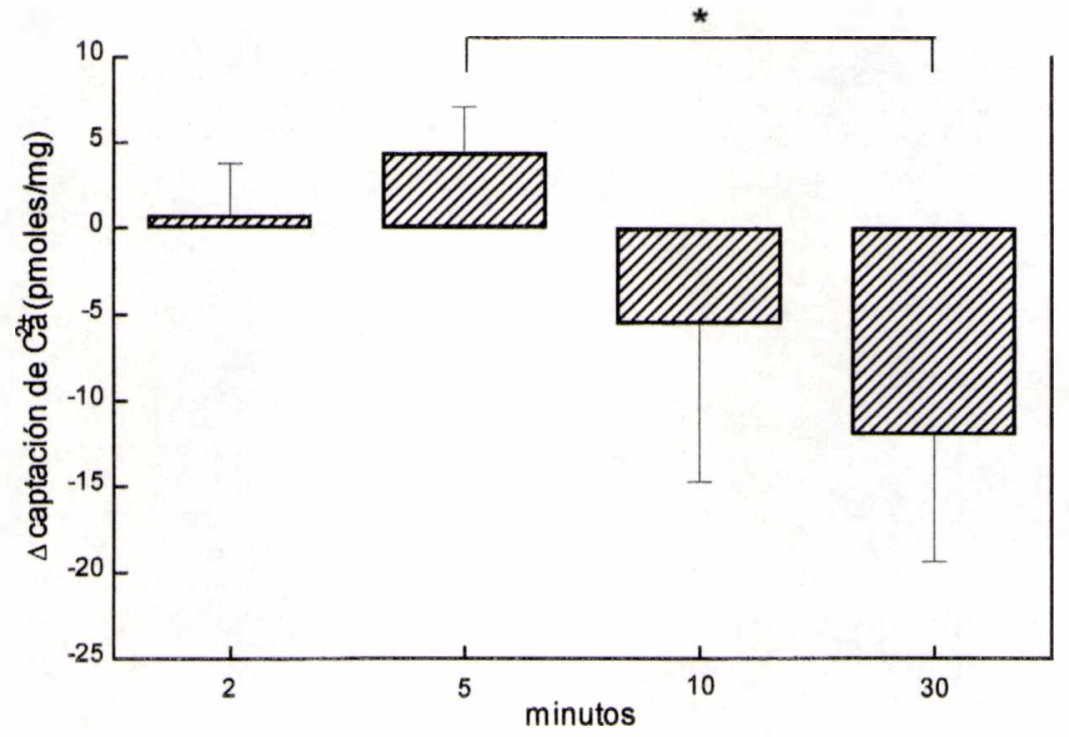

Fig 10: deltas (insulina - control) de captación de de ${ }^{45} \mathrm{Ca}^{2+}$ en segmentos de aorta de rata hiperpermeabilizados por tratamiento con EGTA. * indica diferencia significativa $(p<0,05)$ entre los dos grupos.

3.2.2 Preincubación con insulina y estimulación única con un agonista.

- Dosis fisiológicas de insulina en aorta de rata (Ang II, AVP, y ET 1 ). Determinaciones mecánicas. 
Hubo un aumento espontáneo en el tono de reposo de los anillos en los experimentos control con una sola estimulación durante las 2 hs de preincubación antes de agregar el agonista $\left(4,4 \pm 1,4 \mathrm{mg} / \mathrm{mm}^{2}, \mathrm{n}=23\right)$. En los experimentos donde la preincubación se hizo en presencia de L-NAME, hubo un aumento en el tono de reposo significativamente mayor $\left(12,6 \pm 2,7 \mathrm{mg} / \mathrm{mm}^{2}, \mathrm{n}=26, p<0,05\right)$, indicando que el NO es uno de los factores involucrados en el mantenimiento del tono de reposo en estos preparados. La incubación con 40 o $160 \mu \mathrm{U} / \mathrm{ml}$ de insulina no modificó significativamente los aumentos de la tensión de reposo en los grupos sin L-NAME (Ins 40: 4,2 $\pm 1,0 \mathrm{mg} / \mathrm{mm}^{2}, \mathrm{n}=15$; Ins $160: 8,5 \pm 1,7 \mathrm{mg} / \mathrm{mm}^{2}$ $\mathrm{n}=21$ ) o con L-NAME (Ins 40: $14,9 \pm 2,8 \mathrm{mg} / \mathrm{mm}^{2}, \mathrm{n}=18$; Ins $160: 12,1 \pm 2,9 \mathrm{mg} / \mathrm{mm}^{2}$, $\mathrm{n}=20$ )
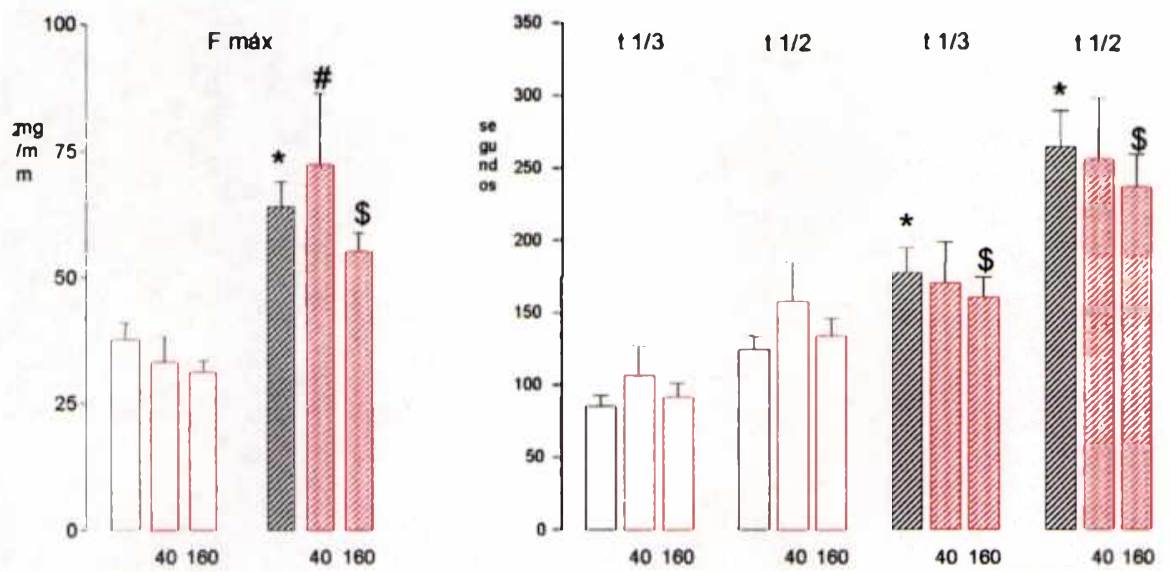

Fig 11: Fuerza máxima y $t_{1 / 3}$ y $t_{1 / 2}$ de relajación de las respuestas a Ang II en anillos de aorta de rata sin (barras vacias) y con (barras rayadas) inhibición de la sintesis de NO por L-NAME. Controles: barras negras ( $n=$ entre 16 y 21 en cada grupo), grupos con insulina: barras rojas ( $n=$ entre 8 y15 en cada grupo). " indica diferencia significativa $(p<0,05)$ respecto del grupo control, \# respecto del grupo insulina $40 \mu \mathrm{U} / \mathrm{ml}$, y $\$$ respecto del grupo insulina 160 $\mu \mathrm{U} / \mathrm{ml}$. 
En contraste a los experimentos con dos estimulaciones sucesivas, cuando se realizó una sola contracción por Angll luego de 2 hs de preincubación con dosis bajas de insulina, la hormona no produjo modificaciones ni en la $\mathrm{F}$ max ni en los parámetros de relajación (Fig 11).

La inhibición de la sintesis de NO con L-NAME potenció significativamente la fuerza desarrollada y enlenteció las relajaciones. La insulina no tuvo efectos adicionales a los del L-NAME.

En las contracciones únicas por AVP se observó una respuesta similar a la vista en el caso de Ang II: la preincubación con insulina no afectó la F máx, asi como no alteró las relajaciones espontáneas de las contracciones (Fig 12).
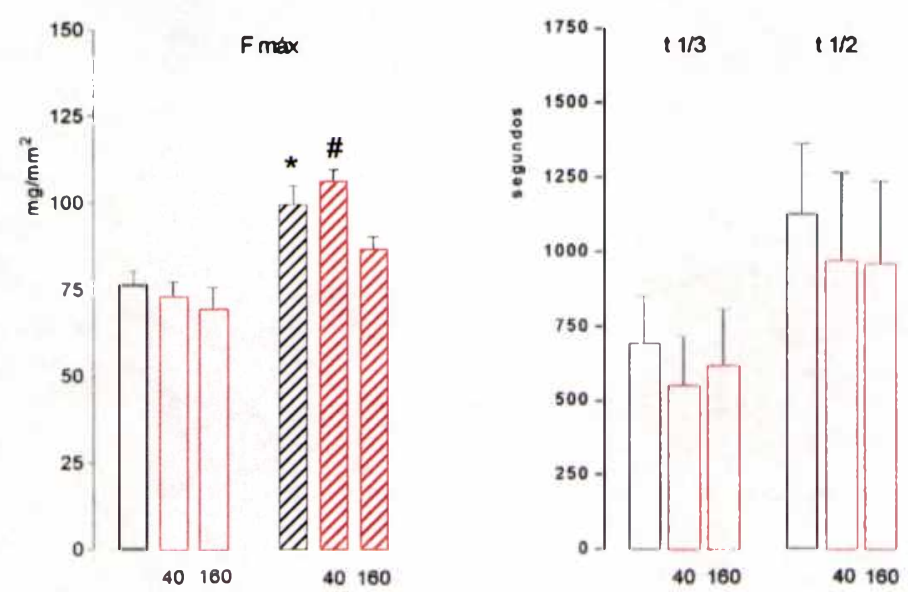

Fig 12: Fuerza máxima y $t_{1 / 3}$ y $t_{1 / 2}$ de relajación de las respuestas a AVP en anillos de aorta de rata sin L-NAME (barras vacias) y con L-NAME (barras rayadas). Controles: barras negras ( $n=$ entre 13 y 18 en cada grupo), grupos con insulina: barras rojas ( $n=$ entre 6 y 12 en cada grupo). " indica diferencia significativa $(p<0,05)$ respecto del grupo control, \# indica diferencia significativa $(p<0,05)$ respecto del grupo insulina $40 \mu \mathrm{U} / \mathrm{ml}$. 
EI L-NAME produjo un aumento de la fuerza, y la dosis menor de insulina (40 $\mu \mathrm{U} / \mathrm{ml})$ no modificó esta respuesta; sin embargo, al preincubar con L-NAME y $160 \mu \mathrm{U} / \mathrm{ml}$ no se pudo demostrar un aumento de la $\mathrm{F}$ máx, indicando que a estas concentraciones la insulina tiene un efecto relajante en presencia de L-NAME.

Al utilizar L-NAME para inhibir la sintesis de NO, la relajación espontánea de las contracciones se enlenteció notablemente, y en algunos casos desapareció, por lo cual los parámetros de relajación en presencia de L-NAME no fueron cuantificados.

Al utilizar el agonista $\mathrm{ET}_{1}$ se produjo una situación similar a la del AVP: la preincubación con insulina en ausencia de L-NAME no tuvo efectos significati$\operatorname{vos}($ Fig 13).
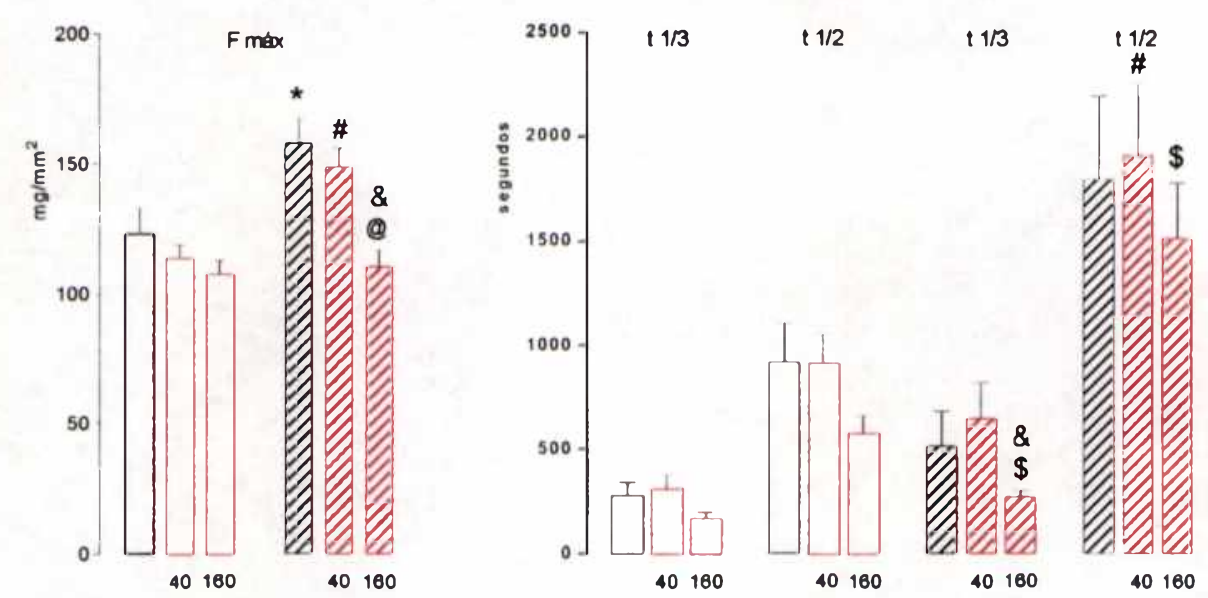

Fig 13: Fuerza máxima de las respuestas a $E T_{1}$ y $t_{1 / 3}$ y $t_{1 / 2}$ de relajación (inducidos por cafeina) en anillos de aorta de rata sin L-NAME (barras vacias) y con L-NAME (barras rayadas). Controles: barras negras ( $n=9-12)$, grupos con insulina: barras rojas $(n=7-11)$. Se indican diferencias significativas $(p<0,05)$ respecto del grupo control $(*)$, del grupo insulina $40 \mu \mathrm{U} / \mathrm{ml}$ 
(\#), del grupo insulina $160 \mu \mathrm{U} / \mathrm{ml}$ sin L-NAME (\$), del grupo control con L-NAME (@), y del grupo insulina $40 \mu \mathrm{U} / \mathrm{ml}$ con L-NAME (\&).

Pero cuando se utilizó L-NAME, la preincubación con $160 \mu \mathrm{U} / \mathrm{ml}$ de insulina hizo que el preparado desarrollara significativamente menos $F$ máx que el grupo control con L-NAME, poniendo de manifiesto que hubo liberación de un factor vasodilatador que se opuso a los efectos de la inhibición del NO.

La inhibición del NO enlenteció las relajaciones por cafeína, y los aumentos del $t_{1 / 2}$ fueron significativos en los grupos preincubados con insulina. Por el contrario, se observó en el grupo preincubado con $160 \mu \mathrm{U} / \mathrm{ml}$ de insulina que el $t_{1 / 3}$ fue significativamente menor al del grupo preincubado con $40 \mu \mathrm{U} / \mathrm{ml}$ de insulina y a su control sin L-NAME, un resultado coincidente con la aparición de efectos relajantes de la hormona a esta dosis, como se ve en los resultados de la F máx.

- Dosis hiperinsulinémicas en aorta de rata y en arteria de la cola de rata (AVP y ET 1 ). Determinaciones mecánicas.

La preincubación de anillos de aorta de rata con una dosis de insulina similar a la hallada en ratas con hiperinsulinemia $(500 \mu \mathrm{U} / \mathrm{ml})$ no produjo modificaciones en la velocidad del desarrollo de la fuerza (medido como $t_{1 / 2}$ de contracción) ni en el valor máximo alcanzado en contracciones por AVP (Fig 14). Cuando se inhibió la síntesis del NO se observó un efecto relajante de la insulina similar al descripto con la dosis de $160 \mu \mathrm{U} / \mathrm{ml}$. 

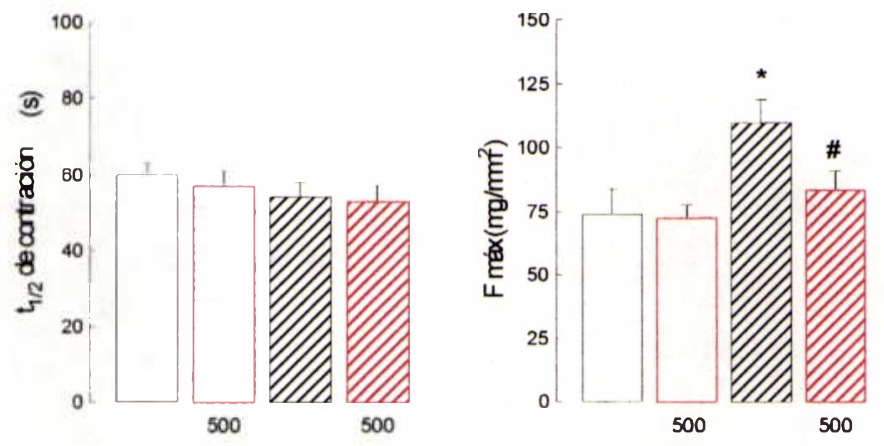

Fig 14: $t_{1 / 2}$ de contracción y fuerza máxima de las respuestas a AVP en anillos de aorta de rata con L-NAME (barras rayadas) y sin L-NAME (barras sin rayas) preincubadas con $500 \mu \mathrm{U} / \mathrm{ml}$ de insulina. Control (barras negras), $n=7$; insulina (barras rojas), $n=7$; control con L-NAME (barras negras rayadas), $n=8$, insulina con L-NAME (barras rojas rayadas), $n=8$. Se indican diferencias significativas $(p<0,05)$ respecto del grupo control sin L-NAME (*) y del grupo LNAME sin insulina (\#).

La dosis alta de insulina produjo cambios sobre la velocidad de desarrollo de las contracciones por $\mathrm{ET}_{1}$ que no se habian observado con las dosis menores (Fig 15). La preincubación con $500 \mu \mathrm{U} / \mathrm{ml}$ de insulina aceleró la velocidad del desarrollo de la fuerza contráctil. La inhibición del NO aumentó más esta velocidad, y la insulina potenció aun más dicho efecto. Por otra parte, el efecto relajante de la insulina en presencia de L-NAME también se produjo con esta dosis elevada, como lo muestra la falta de potenciación de $\mathrm{F}$ máx en presencia de LNAME e insulina. 


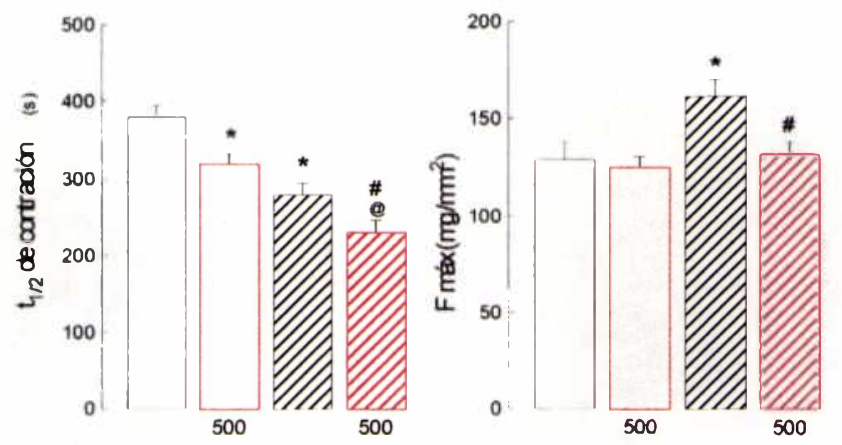

Fig 15: $t_{1 / 2}$ de contracción y fuerza máxima de las respuestas a $E T_{1}$ en anillos de aorta de rata preincubados con $500 \mu \mathrm{U} / \mathrm{ml}$ de insulina con L-NAME (barras rayadas) y sin L-NAME (barras $\sin$ rayas). Control (barras negras), $n=17$; insulina (barras rojas), $n=11$; control con $L$ NAME (barras negras rayadas), $n=14$, insulina con L-NAME (barras rojas rayadas), $n=11$. Se indican diferencias significativas $(p<0,05)$ respecto del grupo control $\left(^{*}\right)$, del grupo insulina $500 \mu \mathrm{U} / \mathrm{ml}$ sin L-NAME (\#) y del grupo control con L-NAME (@).

A continuación ensayamos los efectos de la preincubación con insulina sobre una arteria de resistencia, la arteria de la cola de la rata (Fig 16). A diferencia de los visto en la aorta, la insulina a la dosis de $500 \mu \mathrm{U} / \mathrm{ml}$ produjo un aumento de la $\mathrm{F}$ máx desarrollada por $\mathrm{ET}_{1}$. La inhibición de la síntesis del $\mathrm{NO}$ con L-NAME no tuvo un efecto significativo sobre la $\mathrm{F}$ máx en este preparado, pero sí impidió que la insulina produjera la potenciación de la $\mathrm{F}$ máx. 


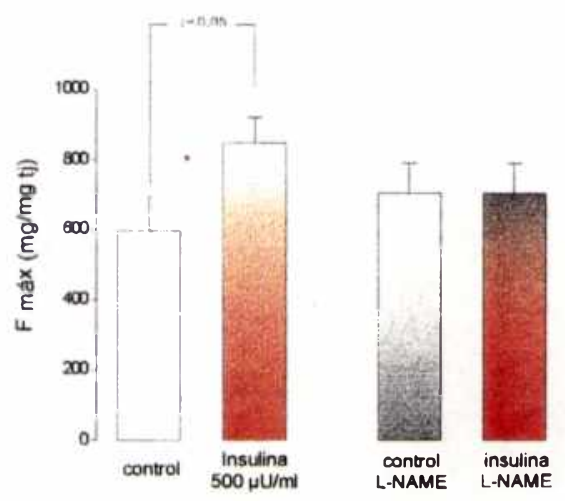

Fig 16: Fuerza máxima de las respuestas a $\mathrm{ET}_{1}$ en anillos de arteria de la cola de rata preincubados con $500 \mu \mathrm{U} / \mathrm{ml}$ de insulina. Cada grupo experimental tiene $n=14$.

A diferencia de lo observado en los anillos de aorta, el $t_{1 / 2}$ de contracción no fue afectado por la preincubación con la hormona (Fig 17).
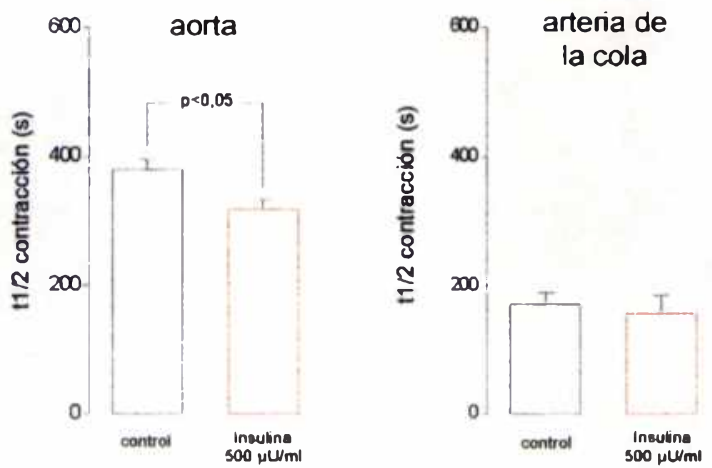

Fig 17: comparación de los efectos de la insulina sobre el $t_{1 / 2}$ de las contracciones por ET, en anillos de aorta y de arteria de la cola de rata preincubados con $500 \mu \mathrm{U} / \mathrm{ml}$ de insulina. Aorta: controles (barras negras $\sin$ rayas), $n=17$, insulina (barras rojas $\sin$ rayas), $n=11$. Arteria de la cola: cada grupo experimental tiene $n=14$.

- Inhibición de ciclooxigenasas con indometacina:

Los efectos relajantes de la insulina en presencia de L-NAME, tanto a la dosis baja $(160 \mu \mathrm{U} / \mathrm{ml})$ como a la dosis alta $(500 \mu \mathrm{U} / \mathrm{ml})$ desaparecieron luego de la preincubación con indometacina, lo que sugiere que eran debidos a un meta- 
bolito de la ciclooxigenasa, probablemente $\mathrm{PGI}_{2}$ liberada por el endotelio vascular (Fig 18)

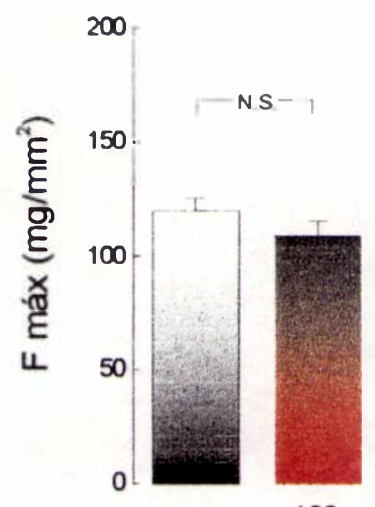

160 Indometacina ET,

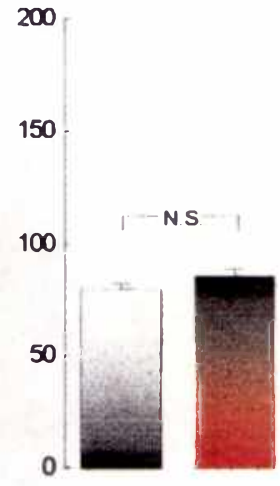

160

Indometacina AVP

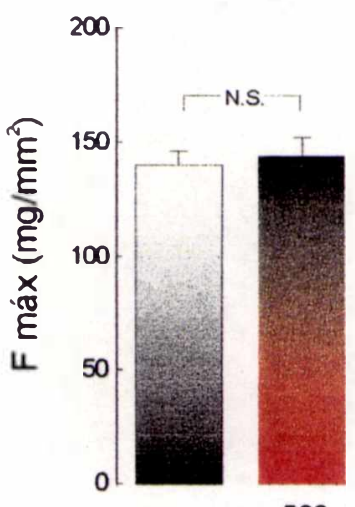

500

Indometacina ET,

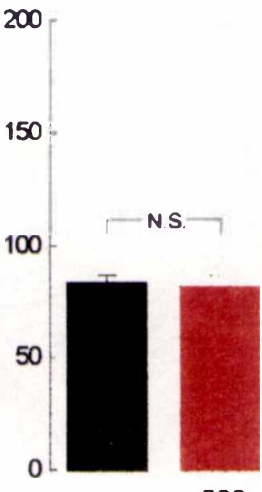

500 Indometacina AVP

Fig 18: Fuerzas máximas inducidas por $\mathrm{ET}_{1}$ y por AVP en presencia de L-NAME e indometacina en anillos de aorta de rata preincubados con $160 \circ 500 \mu \mathrm{U} / \mathrm{ml}$ de insulina. Controles (barras negras): $E T_{1} n=5$ (de 3 ratas), $A V P n=7$ (de 6 ratas); insulina (barras rojas): $E T_{1} n=5$ (de 3 ratas), AVP $n=7$ (de 6 ratas).

En la arteria de la cola de rata el aumento observado de la Fmáx dado por la insulina podria deberse a la estimulación de la liberación o de la acción de un factor contrayente derivado del endotelio, posiblemente un derivado del ácido araquidónico, por lo que también estos experimentos se repitieron en presencia de indometacina (Fig 19). 


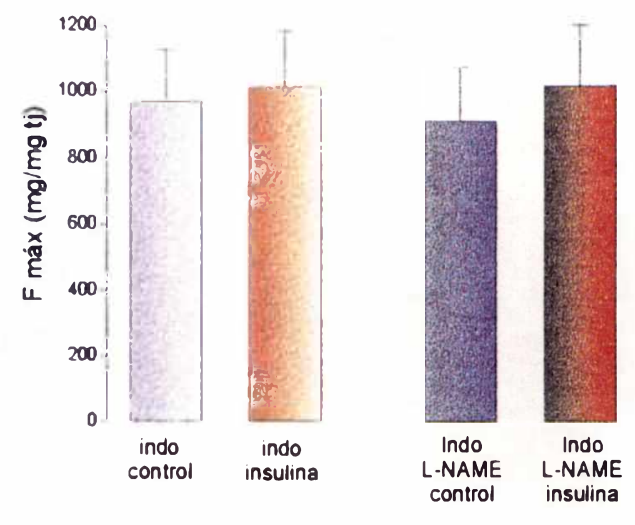

Fig 19: Fuerzas máximas inducidas por $\mathrm{ET}_{1}$ en anillos de arteria de la cola de rata preincubados con $500 \mu \mathrm{U} / \mathrm{ml}$ de insulina en presencia de indometacina, con o sin L-NAME. Control indometacina, $n=16$; insulina indometacina, $n=16$; control indometacina con L-NAME, $n=16$; insulina indometacina con I-NAME, $n=14$.

La desaparición del aumento de F máx producido por la insulina al inhibir las ciclooxigenasas con indometacina sugiere que dicho factor contrayente podria ser el TXA

\section{- Bloqueo de tirosin quinasas con qenisteina:}

El tratamiento con genisteína alargó significativamente el $t_{1 / 2}$ de contracción de la $E T_{1}$ (con genisteina: $656 \pm 58$ s vs sin genisteina: $399 \pm 35 s, n=10$, $p<0.05$ ); el mismo efecto se observó en presencia de L-NAME (con genisteína: $486 \pm 23 s$ vs sin genisteina: $279 \pm 15 s, n=22 p<0.05)$. La $F$ máx también fue disminuida por el tratamiento con genisteina (con genisteina: $97 \pm 8 \mathrm{mg} / \mathrm{mm} 2$ vs sin genisteina: $\left.152 \pm 11 \mathrm{mg} / \mathrm{mm}^{2}, \mathrm{n}=10 \mathrm{p}<0.05\right)$; un efecto similar se observó en presencia de L-NAME, aunque en este caso las diferencias no alcanzaron significación estadistica (con genisteina: $135 \pm 11 \mathrm{mg} / \mathrm{mm} 2$ sin genisteina: 159 \pm 11 $\mathrm{mg} / \mathrm{mm} 2$, N.S.). 
Luego del tratamiento con genisteína, la insulina $500 \mu \mathrm{U} / \mathrm{ml}$ no fue capaz de modificar el $t_{1 / 2}$ de contracción ni en presencia ni en ausencia de L-NAME (Fig. 20, panel izquierdo). La genisteína bloqueó parcialmente los efectos de la insulina sobre la F máx: aunque el L-NAME fue capaz de potenciar significativamente la F máx, este efecto fue significativamente menor que en los controles (Fig. 20, panel derecho).
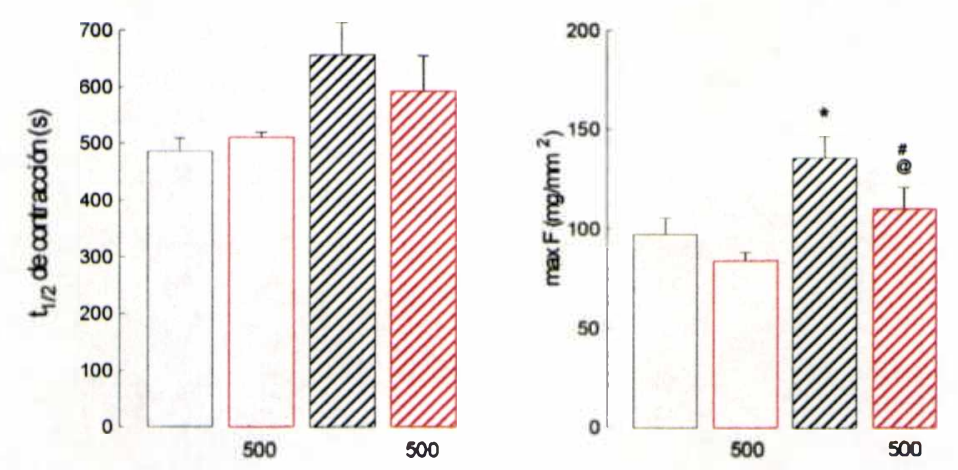

Fig 20: $t_{1 / 2}$ de contracción y $F$ máx de contracciones por $E T$, preincubadas con genisteina en presencia (barras rayadas) o en ausencia de L-NAME (barras sin rayas). Controles (barras negras): $\sin$ L-NAME, $n=5$; con L-NAME, $n=12$. Insulina $500 \mu \mathrm{U} / \mathrm{ml}$ (barras rojas): $\sin \mathrm{L}$ NAME, $n=6$; con L-NAME, $n=12$. Los simbolos *, @ y \# indican diferencias significativas $(p<0,05)$ con respecto a los grupos control, insulina y control con L-NAME, respectivamente.

En las contracciones con AVP y L-NAME la genisteina no afectó el $t_{1 / 2}$ de contración (con genisteina: $43 \pm 3 s, n=16$ de 6 ratas, vs sin genisteina: $53 \pm 4$, $n=8$, N.S.). La $F$ máx en presencia de L-NAME tampoco fue afectada por la genisteina (con genisteina: $59 \pm 5 \mathrm{mg} / \mathrm{mm} 2, \mathrm{n}=16$ de 6 ratas, vs sin genisteina: $49 \pm 5$ $\mathrm{mg} / \mathrm{mm} 2, \mathrm{n}=8, N$.S.). Luego de la inhibición de las tirosín quinasas con genistei- 
na, la preincubación con insulina no fue capaz de disminuir significativamente la F max en las contracciones por AVP (L-NAME con insulina: $50 \pm 4 \mathrm{mg} / \mathrm{mm} 2, \mathrm{n}=16$ de 6 ratas, vs L-NAME control: $59 \pm 5 \mathrm{mg} / \mathrm{mm} 2, \mathrm{n}=16$ de 6 ratas, N.S.).

\subsubsection{Preincubación con insulina y liberación de NO inducida por ACh.}

El objetivo de estos experimentos fue el de comprobar si la preincubación con insulina era capaz de aumentar la capacidad de la ACh de liberar NO a partir de las células endoteliales. Para ello, se relajaron con dosis crecientes de ACh contracciones de noradrenalina (NA) evocadas luego de la preincubación con insulina. Los resultados se expresan como el porcentaje de la $F$ máx de NA que se relaja el preparado luego de cada dosis de ACh.

\begin{tabular}{|c|c|c|c|c|}
\hline & ACh $10^{-8} M$ & ACh $10^{-7} M$ & ACh $10^{-6} M$ & ACh $10^{-5} M$ \\
\hline Control $(n=11)$ & $22,7 \pm 6,6 \%$ & $48,5 \pm 7,3 \%$ & $72,8 \pm 7,5 \%$ & $87,1 \pm 7,0 \%$ \\
Insulina $(n=9)$ & $31,2 \pm 7,7 \%$ & $63,9 \pm 9,2 \%$ & $93,2 \pm 12,5 \%$ & $102,5 \pm 12,8 \%$ \\
\hline
\end{tabular}

Se puede ver que la insulina no tuvo un efecto estadisticamente significativo sobre la liberación de NO inducida por ACh, aunque se puede observar una tendencia a que los anillos preincubados con la insulina se relajen más que los no preincubados. No se observaron diferencias en las $F$ máx desarrolladas por NA en los preparados control $\left(60,8 \pm 10,1 \mathrm{mg} / \mathrm{mm}^{2}\right)$ y los preincubados con insulina $\left(68,1 \pm 14,9 \mathrm{mg} / \mathrm{mm}^{2}\right)$. 
3.2.4 Estudio de los posibles mecanismos afectados por la preincubación con insulina (dosis hiperinsulinémica) para modificar las contracciones inducidas por $\mathrm{ET}_{1}$.

(a) participación del retículo sarcoplásmico:

- experimentos con rianodina y tapsigargina:

Se estudiaron los efectos de la rianodina (Ry) y la tapsigargina (Taps) sobre la disminución inducida por insulina del $t_{1 / 2}$ de contracción por $E T_{1}$.

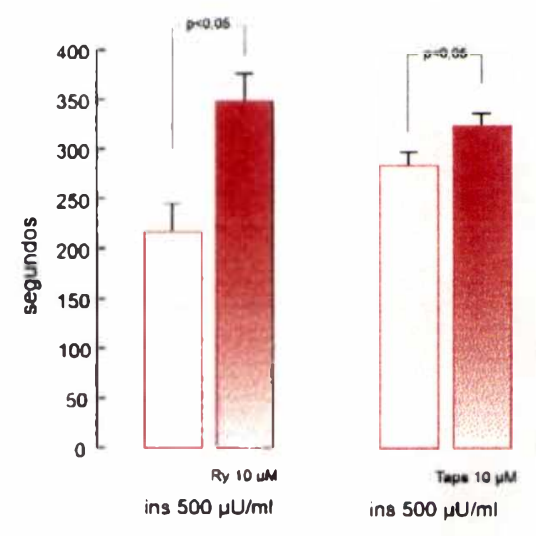

Fig 21: Efectos de la rianodina y de la tapsigargina sobre la disminución del $\mathrm{t}_{1 / 2}$ de contracción inducido por insulina en contracciones por $\mathrm{ET}_{1}$. Todos los experimentos se llevaron a cabo en presencia de L-NAME. Rianodina: controles, $n=17$; insulina, $n=7$; tapsigargina: controles, $n=15$; insulina, $n=6$.

Ambas drogas producen un vaciamiento del retículo sarcoplásmico. La rianodina mantiene abiertos uno de los dos tipos de canales que se encuentran en su membrana, facilitando que se vacie este depósito; la tapsigargina actúa inhibiendo la Ca-ATPasa del retículo impidiendo que éste capte el $\mathrm{Ca}^{2+}$, y como resultado el depósito es vaciado de $\mathrm{Ca}^{2+}$. Por lo tanto, en las contracciones por $\mathrm{ET}_{1}$ obtenidas en presencia de estas drogas se encuentra ausente la componente 
dependiente del retículo sarcoplásmico. Con la dosis mayor de insulina utilizada (500 $\mu \mathrm{U} / \mathrm{ml}$ ) se observó que la hormona no fue capaz de seguir disminuyendo el $t_{1 / 2}$ de contracción en presencia tanto de rianodina como de tapsigargina, lo que indica que la liberación de $\mathrm{Ca}^{2+}$ por parte del retículo sarcoplásmico está implicada en el aumento de la velocidad de contracción generado por la insulina (Fig 21). Por el contrario, se observó un alargamiento significativo del $t_{1 / 2}$ de contracción en presencia de insulina.

- experimentos en ausencia de $\mathrm{Ca}^{2+}$ externo:

Para corroborar la necesidad de un retículo sarcoplásmico funcionante en la manifestación del aumento del desarrollo de fuerza por $\mathrm{ET}_{1}$ inducido por la insulina se realizaron experimentos en los que las contracciones de $\mathrm{ET}_{1}$ se hicieron en ausencia de $\mathrm{Ca}^{2+}$ externo, de forma que todo el desarrollo de fuerza contráctil se debiera exclusivamente al $\mathrm{Ca}^{2+}$ liberado por los depósitos intracelulares (Fig 22).
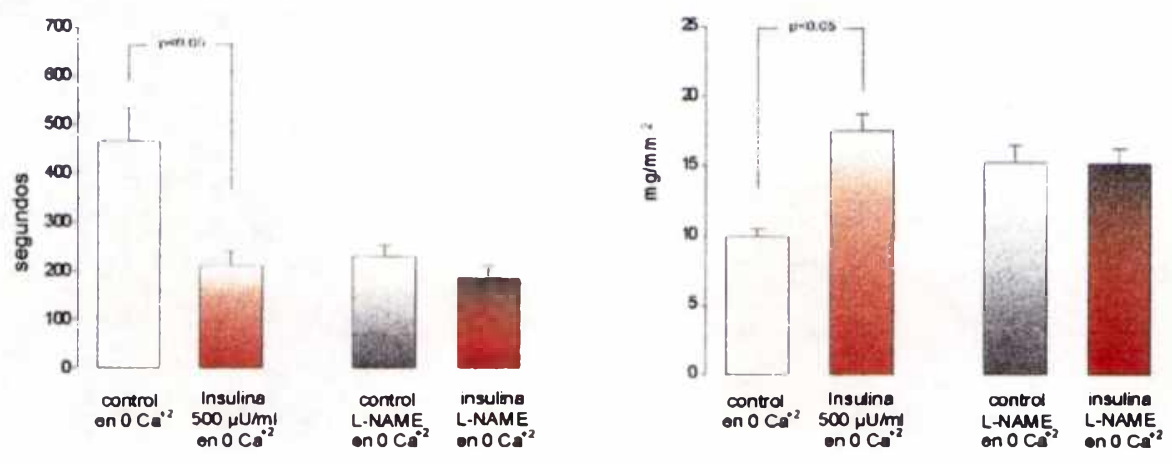

Fig 22: Fmáx y $t_{1 / 2}$ de contracción desarrollados por la liberación de $\mathrm{Ca}^{2+}$ a partir de depósitos intracelulares inducida por $\mathrm{ET}, 0,01 \mu \mathrm{M}$ en anillos de aorta en KRB $\sin \mathrm{Ca}^{2+}$. Los anillos fueron preincubados o no con insulina, y con o sin inhibición de la sintesis de NO con LNAME. Cada grupo experimental tiene $n=8$. 
Las contracciones inducidas por $\mathrm{ET}_{1} 0,01 \mu \mathrm{M}$ en ausencia de $\mathrm{Ca}^{2+}$ externo siguen siendo potenciadas por la insulina, como lo demuestran el aumento en la Fmax y la disminución del $t_{1 / 2}$ de contracción producidos por la preincubación con la hormona.

En presencia de L-NAME, la inhibición de la síntesis de NO, potencia las contracciones inducidas por $\mathrm{ET}_{1}$ (aumento de Fmax) en ausencia de calcio externo. La insulina no produce una potenciación adicional en las contracciones por $E T_{1}$ cuando la sintesis de NO está inhibida.

- liberación de $\mathrm{Ca}^{2+}$ del reticulo sarcoplásmico inducida por cafeína:

La preincubación con $500 \mu \mathrm{U} / \mathrm{ml}$ de insulina no afecta las contracciones inducidas por cafeína $3 \mathrm{mM}$ (Fig 23). La inhibición de la síntesis de NO no modifica la Fmax. desarrollada por cafeina y la preincubación con insulina tampoco modifica las contracciones en presencia de L-NAME.

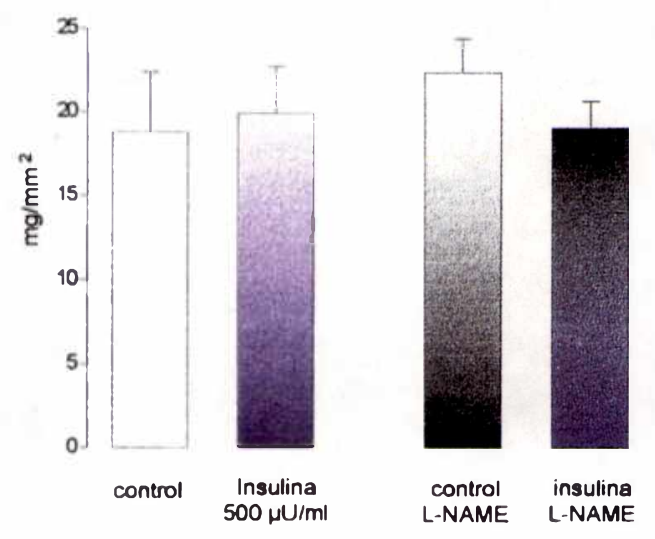

Fig 23: Fmáx desarrollada por la liberación de $\mathrm{Ca}^{2+}$ a partir del reticulo sarcoplásmico inducida por cafeina $3 \mathrm{mM}$ en anillos de aorta preincubados o no con insulina y con o sin inhibición 
de la sintesis de NO con L-NAME. Controles: $\sin$ L-NAME, $n=7$; con L-NAME, $n=14$. Insulina: $\sin L-N A M E, n=7$; con L-NAME, $n=14$.

- captación de $\mathrm{Ca}^{2+}$ por el retículo sarcoplásmico:

La preincubación con insulina $500 \mu \mathrm{U} / \mathrm{ml}$ no modificó la cantidad de $\mathrm{Ca}^{2+}$ captado a los 30 minutos por los depósitos intracelulares del segmento vascular (Fig 24).
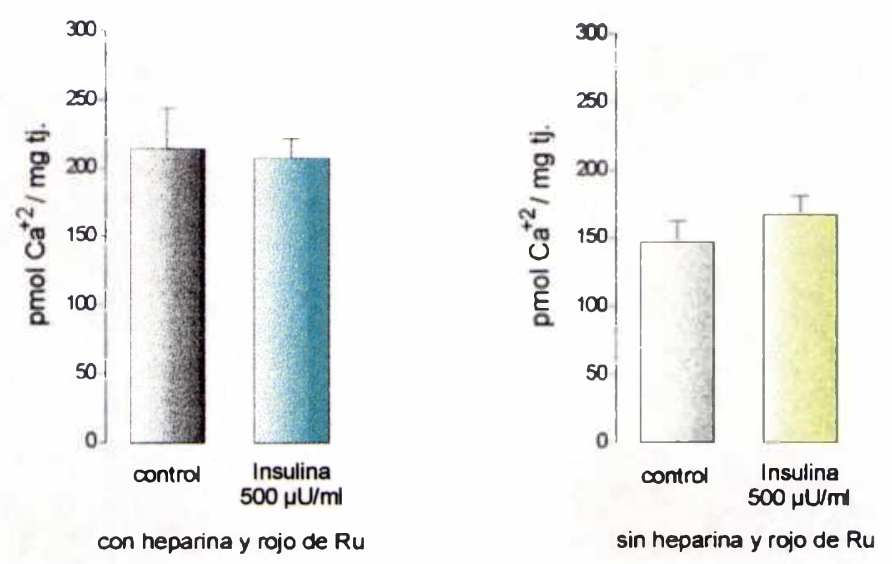

Fig 24: cantidad de $\mathrm{Ca}^{2+}$ captada por el retículo sarcoplásmico, en anillos de aorta de rata hiperpermeabilizados por tratamiento quimico, en soluciones de captación con heparina y rojo de rutenio (control $n=16$, insulina $n=17$ ) o sin heparina y rojo de rutenio (control $n=8$, insulina $n=8)$.

El bloqueo de los canales de $\mathrm{Ca}^{2+}$ del retículo sarcoplásmico con heparina (canales sensibles a $\mathrm{IP}_{3}$ ) y con rojo de rutenio (canales de $\mathrm{Ca}^{2+}$ sensibles a rianodina) produjo un aumento en la captación de ${ }^{45} \mathrm{Ca}^{2+}$ (Fig 24, panel izquierdo vs panel derecho), lo que indica que en ausencia de los bloqueantes el $\mathrm{Ca}^{2+}$ captado es parcialmente perdido a través de estos canales. La preincubación con insulina tampoco modificó la cantidad de $\mathrm{Ca}^{2+}$ acumulada en el retículo en estas condiciones. 
(b) participación de la PKC:

Cuando la actividad de la PKC fue inhibida con cheleritrina $30 \mu \mathrm{M}$, la preincubación con insulina a concentración de $500 \mu \mathrm{U} / \mathrm{ml}$ perdió su capacidad de disminuir el $t_{1 / 2}$ de contracción de la $E T_{1}$, indicando que esta proteína quinasa está implicada de alguna forma en los efectos de la hormona (Fig 25).

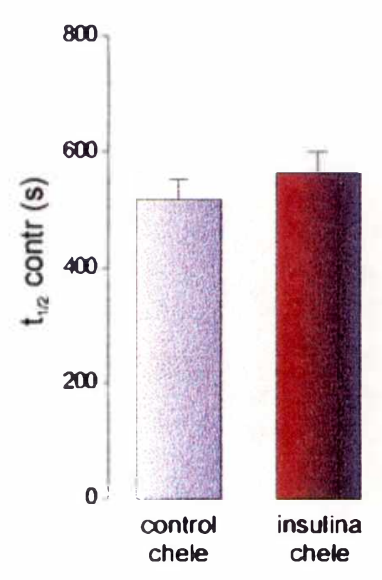

Fig 25: $t_{1 / 2}$ de contracción por $E T_{1}$ en presencia de cheleritrina en anillos de aorta de rata preincubados o no con insulina. Cada grupo experimental tiene $n=13$.

(c) participación del $\mathrm{Ca}^{2+}$ externo:

En los experimentos en los que se midieron simultáneamente fuerza desarrollada y captación de ${ }^{45} \mathrm{Ca}^{2+}$ en anillos intactos de aorta no hubo diferencias en la cantidad de $\mathrm{Ca}^{2+}$ captado a los 20 minutos por los anillos preincubados y no preincubados con insulina, lo que sugiere que la disminución de la $\mathrm{F}$ máx observada al tratar la aorta de rata con esta hormona no se debe a una atenuación de la entrada de $\mathrm{Ca}^{2+}$ a partir del medio extracelular (Fig 26). 

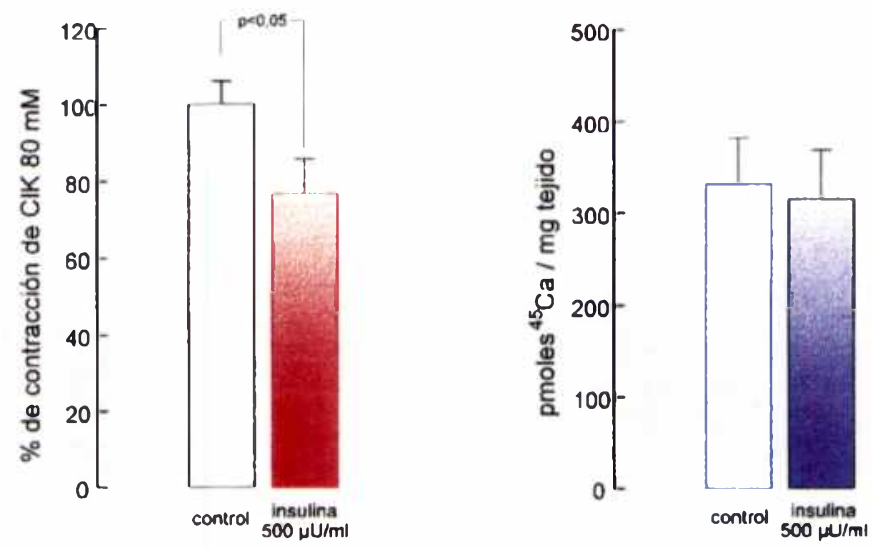

Fig 26: Fuerzas máximas inducidas por $\mathrm{ET}_{1}$ y captación simultánea de ${ }^{45} \mathrm{Ca}^{2+}$ en presencia de $\mathrm{L}$ NAME en anillos de aorta de rata. Controles $n=18$, insulina $n=22$. NOTA: la Fmáx se expresa en función de una contracciones control de CIK $80 \mathrm{mM}$ para evitar el tomar las dimensiones de los anillos impregnados $\operatorname{con}{ }^{45} \mathrm{Ca}^{2+}$.

(d) participación de derivados vasoconstrictores del ácido araquidónico:

En la arteria de la cola de rata, la indometacina suprimió el efecto potenciador de la preincubación con $500 \mu \mathrm{U} / \mathrm{ml}$ de insulina sobre las contracciones por $\mathrm{ET}_{1}$.

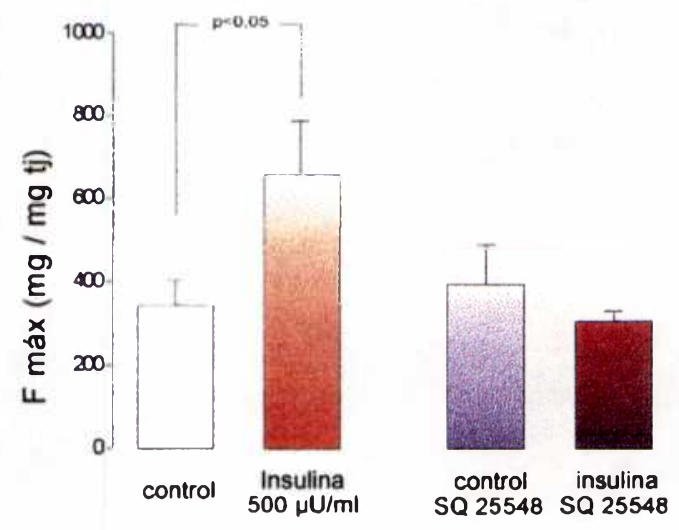

Fig 27: Efectos de la insulina sobre la Fmáx desarrollada por anillos de arteria de la cola de la rata. en ausencia o en presencia de un inhibidor de los receptores de TXA . Cada grupo experimental tiene $n=6$. 
En presencia de un inhibidor especifico de los receptores de $\mathrm{TXA}_{2}$ (SQ 25.548), la insulina tampoco fue capaz de potenciar la fuerza contráctil de la $E T_{1}$, lo que confirma que este prostanoide es el responsable de este efecto (Fig 27).

(e) tiempo necesario para que se expresen los efectos de la insulina:

La exposición a insulina por un corto plazo previo y durante la estimulación con $\mathrm{ET}_{1}$ no logró afectar ni el $\mathrm{t}_{1 / 2}$ de contracción ni la $\mathrm{F}$ máx desarrollada (Fig 28). Se pueden sacar dos conclusiones de estos experimentos: que la presencia de insulina durante la contracción de $\mathrm{ET}_{1}$ no la modifica, y que se necesita un tiempo mayor a 15 min de exposición previa a la hormona para observar sus efectos.
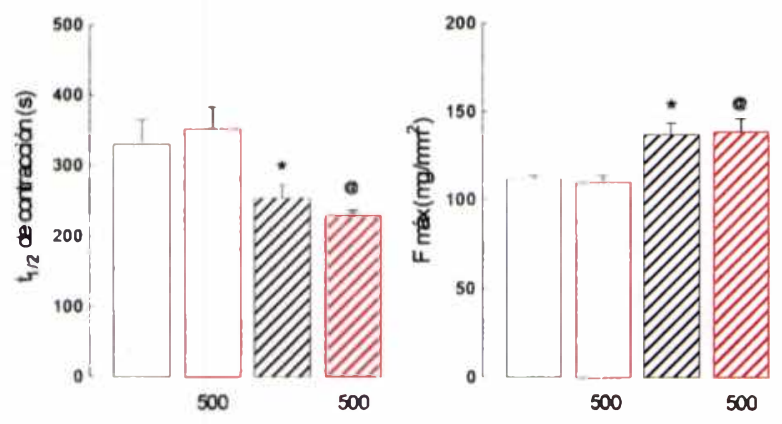

Fig 28: $t_{1 / 2}$ de contracción y $F$ máx de contracciones por $E T_{1}$ realizadas en presencia de insulina. Los experimentos se realizaron con L-NAME o sin L-NAME. Controles sin L-NAME: barras negras $\sin$ rayas $(n=6)$; controles con L-NAME: barras negras rayadas $(n=6)$; Insulina 500 $\mu \mathrm{U} / \mathrm{ml}$ sin L-NAME: barras rojas sin rayas $(n=6)$; insulina con L-NAME: barras rojas rayadas $(n=6)$. Los simbolos * $y @$ indican diferencias significativas $(p<0,05)$ con respecto a los grupos control e insulina sin L-NAME, respectivamente. 


\subsection{ANÁLISIS Y DISCUSIÓN DE LOS RESULTADOS}

La preincubación con insulina a concentraciones fisiológicas y/o hiperinsulinémicas modificó la función del músculo liso vascular en los diferentes protocolos experimentales en los que se utilizaron segmentos vasculares intactos o hiperpermeabilizados por tratamiento químico. El análisis y discusión de los resultados se desarrolla siguiendo la secuencia de presentación en Métodos y Resultados.

Dos estimulaciones sucesivas con Ang II o AVP :

\section{- experimentos mecánicos}

Los efectos de la insulina sobre un tejido vascular intacto, con células endoteliales, podrían diferir de los resultados obtenidos en células de músculo liso dispersas, y los primeros experimentos que presentamos examinan cuáles son las consecuencias de preincubar con insulina sobre las contracciones inducidas por diversos agonistas fisiológicos en anillos vasculares intactos.

Cuando se realizan dos contracciones sucesivas con Ang II o con AVP en anillos de aorta de rata, la segunda contracción es siempre de menor magnitud que la primera, un fenómeno conocido como taquifilaxia. La incubación con $40 \mu \mathrm{U} / \mathrm{ml}$ de insulina entre estas dos contracciones atenuó la taquifilaxia, ya que las diferencias entre las segundas y las primeras contracciones por Ang II o por AVP fueron menores que en el caso de los controles. En el caso de la Ang II, además, las segundas contracciones se relajaron más rápidamente que las prime- 
ras en el grupo tratado con insulina ( $\Delta \mathrm{v}_{1 / 2}$ de relajación positivo), cosa que no ocurria en los controles ( $\Delta \mathrm{v}_{1 / 2}$ de relajación negativo). Se demostró previamente que la preincubación con insulina aumenta la expresión y la actividad de las CaATPasas en las células de músculo liso vascular en cultivo (40); la manifestación fisiológica de este efecto sería un aumento de la velocidad a la cual el $\mathrm{Ca}^{2+}$ citosólico es bombeado desde el citosol hacia el medio extracelular o hacia el retículo sarcoplásmico. En concordancia con esto, se observaron en células de músculo liso aisladas aumentos transitorios de $\mathrm{Ca}^{2+}$ inducidos por Ang II y AVP más pequeños luego de la preincubación con insulina $(43,45)$, y atenuación de las contracciones por Ang II en células aisladas (44). En nuestros experimentos, el aumento de la velocidad de relajación de las contracciones por Ang II inducido por la insulina podría explicarse gracias a esta estimulación de la función de las CaATPasas; nuestros resultados de captación de $\mathrm{Ca}^{2+}$ por el retículo sarcoplásmico, donde pudimos demostrar que la insulina producía un aumento de la captación de $\mathrm{Ca}^{2+}$ a tiempos cortos (5 minutos) comparado con tiempos largos (30 minutos), apoyan la participación del retículo sarcoplásmico en este efecto relajante de la insulina.

La insulina no fue capaz de afectar las respuestas a Ang II o a AVP cuando se realizó una contracción única con dichos agonistas, precedida de la preincubación con la hormona.

Se ha reportado que la sintetasa de NO del endotelio (eNOS) es estimulada por varias sustancias vasoactivas fisiológicas como acetilcolina, bradiquinina, angiotensina II, vasopresina, histamina, norepinefrina, serotonina, endotelina-1 y trombina. Todos los agonistas actúan a través de aumentar el $\mathrm{Ca}^{2+}$ citosólico en el endotelio que unido a calmodulina resulta en activación de la eNOS; el aumento rápido de esta actividad enzimática no requiere de sintesis proteica (92). Dado 
que las estimulaciónes con Angll y AVP producen contracciones que están atenuadas por la liberación simultánea de NO (93-95), utilizamos L-NAME como un inhibidor de la eNOS para evaluar si este compuesto vasorrelajante estaba enmascarando un posible efecto vasoconstrictor de la insulina sobre las respuestas de los anillos de aorta a estos agonistas. Como se esperaba, el tratamiento con LNAME produjo un aumento del $75 \%$ en la $\mathrm{F}$ máx de las respuestas control a Ang II, y de un $30 \%$ en la F máx de las respuestas control a AVP. Además, la relajación espontánea fue disminuida en el caso de Ang II, y muy disminuída o totalmente eliminada en el caso de AVP. La preincubación con $40 \mu \mathrm{U} / \mathrm{ml}$ de insulina no tuvo un efecto adicional al del L-NAME sobre la $F$ máx o los parámetros de relajación de las contracciones por Ang II o AVP, por lo que en contracciones únicas por estos agonistas no se pudieron demostrar efectos de la insulina similares a los vistos en una doble estimulación.

Las discrepancias entre los resultados de contracciones únicas y los de dos contracciones sucesivas podrian explicarse en base a la naturaleza del proceso de la taquifilaxia. Se ha descripto que la internalización o la fosforilación de los receptores de Ang II seria responsable de la taquifilaxia, y que cerca del $25 \%$ de los receptores endocitados podrian reciclarse nuevamente hacia la membrana plasmática (96). La internalización de receptores también ha sido observada en el caso de AVP, y se ha demostrado en células aisladas de aorta de rata que los receptores internalizados pueden retornar luego a la membrana plasmática (97), o sea que la endocitosis también podria estar involucrada en la taquifilaxia a AVP. Una posible explicación para la disminución de la taquifilaxia inducida por la insulina seria el suponer que el tratamiento con la hormona luego de una primera contracción podría haber acelerado su retorno desde el citosol a la membrana celular, y de esa manera aumentar la respuesta a una segunda estimulación con 
el agonista. Hay trabajos que demostraron un efecto similar de la insulina en músculo esquelético aumentando la traslocación de las subunidades de la $\mathrm{Na}^{+} / \mathrm{K}^{+}$ATPasa desde el citosol a la membrana plasmática $(98,99)$.

A diferencia de lo ocurrido en las aortas de rata, la fuerza de la segunda contracción por Ang II en vena safena humana no fue distinta de la primera, o sea que no se observó taquifilaxia, aunque hay experimentos en la bibliografia en los que se ha podido demostrar la presencia de taquifilaxia a Angll en anillos de vena safena humana denudados de endotelio (100). La preincubación con insulina no produjo modificaciones en la $F$ máx en el grupo de venas de pacientes normotensos ni en el grupo de venas de pacientes hipertensos, lo que estaría avalando la hipótesis de que el efecto de la insulina se manifiesta sólo cuando hay taquifilaxia a Ang II. Sin embargo, en el grupo hipertenso la preincubación con 40 $\mu U / \mathrm{ml}$ de insulina aumentó la velocidad de relajación de las segundas contracciones por Ang II, siendo la disminución del $t_{1 / 2}$ de relajación significativamente diferente del de los hipertensos sin insulina y del grupo normotenso con insulina; este resultado permite sugerir una mayor relevancia de los mecanismos modificados por insulina en las relajaciones de venas de pacientes hipertensos. Se sabe que en aortas de ratas hipertensas espontáneas (SHR) la captación de $\mathrm{Ca}^{2+}$ y la actividad de la Ca-ATPasa de la membrana plasmática es menor que en la de sus controles normotensos (ratas WKY) $(101,102)$. Es posible, entonces, que el aumento de la relajación producido por la preincubación con insulina en los hipertensos se deba a una estimulación del secuestro de $\mathrm{Ca}^{2+}$ por el retículo sarcoplásmico producido por la hormona. No está claro, sin embargo, por qué los hipertensos sin insulina no presentan diferencias con los normotensos (que si se equiparan con las ratas WKY deberian tener valores de relajación mayores a los 
de los hipertensos), o por qué la insulina no modifica los valores de los parámetros de normotensos.

- experimentos radioisotópicos:

Los resultados obtenidos en los minutos iniciales permiten sugerir que la insulina a dosis bajas estimula la captación de $\mathrm{Ca}^{2+}$ por el retículo sarcoplásmico, lo cual favorecería la relajación del vaso. No se pudo demostrar, sin embargo, que se altere el valor de captación máxima, de forma que estos resultados estarian en contra de la propuesta de que la insulina determina que haya un depósito con mayor cantidad de $\mathrm{Ca}^{2+}$ para ser liberado ante la estimulación con agonistas y asi favorecer la contracción del preparado. Una posibilidad es que el pretratamiento con insulina, además de aumentar la expresión de la Ca-ATPasa reticular, modifique la expresión o la actividad de los canales de $\mathrm{Ca}^{2+}$ del retículo sarcoplásmico, de forma que además de aumentar la captación de $\mathrm{Ca}^{2+}$ incrementara el eflujo, lo que impediria demostrar un aumento de la cantidad de $\mathrm{Ca}^{2+}$ total retenido por el retículo. Sin embargo, como se observó en los datos de captación luego de la preincubación con dosis altas de insulina (discutidos más adelante), el bloqueo de los canales del retículo durante la captación no hizo surgir un efecto de la insulina enmascarado por un aumento simultáneo del eflujo de $\mathrm{Ca}^{2+}$.

- una sola estimulación con Ang II, AVP o ET 1 :

- dosis bajas de insulina con y sin inhibición de la sintesis de NO:

Se sabe que la insulina puede contribuir a la vasorrelajación inducida por la 
liberación de NO a partir del endotelio. La vasodilatación mediada por la insulina en la vasculatura del antebrazo humano parece depender de la liberación tanto de NO como de prostaglandinas (33). Arteriolas aisladas de músculo esquelético de rata fueron relajadas por la insulina de forma dependiente del NO (32), y se ha visto que dosis de insulina 1.000 - 10.000 veces mayores que las usadas en nuestros estudios produjeron aumentos en el $\mathrm{Ca}^{2+}$ citosólico endotelial en la aorta de rata, seguido de una disminución del tono de reposo (103).

Durante el periodo de preincubación determinamos si dosis fisiológicas de insulina eran capaces de relajar el tono de reposo de anillos intactos de aorta de rata, ya sea a través del NO o de un mecanismo independiente del mismo. Alternativamente, probamos si la inhibición del NO era capaz de poner de manifiesto un rol presor de esta hormona. Utilizando 40 o $160 \mu \mathrm{U} / \mathrm{ml}$ de insulina no pudimos demostrar una disminución en el tono de reposo de anillos aórticos. E tratamiento con L-NAME aumentó el tono unas tres veces, indicando que el NO ejerce una inhibición tónica del mismo. La preincubación con insulina no tuvo un efecto adicional al del L-NAME. Esto sugiere que, en nuestras condiciones experimentales, dosis fisiológicas de insulina no afectan el tono de reposo de anillos de aorta de rata, ya sea por mecanismos dependientes o independientes del NO.

Como ya se ha dicho, a diferencia de lo encontrado para dos estimulaciones sucesivas con Ang II o AVP, la preincubación con 40 o con $160 \mu \mathrm{U} / \mathrm{ml}$ de insulina no modificó las contracciones desarrolladas por una sola estimulación con Ang II en aorta de rata. El tratamiento con L-NAME aumentó significativamente la fuerza desarrollada por la Ang II en el grupo control, y también disminuyó su velocidad de relajación, lo que confirma que durante la estimulación con este agonista hay una liberación simultánea de NO por parte del endotelio y/o las 
propias células del MLV que tiende a disminuir la fuerza generada y a acelerar la recuperación de los valores de reposo. El tratamiento con 40 o con $160 \mu \mathrm{U} / \mathrm{ml}$ de insulina en presencia de L-NAME produjo una tendencia (aunque no significativa) a desarrollar menos fuerza durante la estimulación con Ang II que cuando se aplicó solamente L-NAME. Esto podría deberse a que la insulina actúe activando algún mecanismo de relajación independiente del NO.

Al igual que lo ocurrido para el caso de Ang II, ninguna de las dos dosis bajas de insulina tuvo efecto sobre el desarrollo de la fuerza producida por AVP en el caso de una sola contracción en aorta de rata.

EI L-NAME potenció siginificativamente las contracciones por AVP, por lo que también en el caso de este agonista se pudo comprobar la liberación simultánea de NO que atenúa la contracción. La dosis menor de insulina no modificó las respuestas en presencia de L-NAME, pero en el grupo tratado con $160 \mu \mathrm{U} / \mathrm{ml}$ de insulina el L-NAME no fue capaz de potenciar la F máx. Esto, que ya se habia observado como una tendencia en el caso de la Ang II, indica que a estas dosis la insulina es capaz de estimular la liberación o la acción de un factor relajante distinto del NO cuyo efecto no puede apreciarse en los grupos sin L-NAME, debido probablemente a la presencia simultánea del potente vasorrelajante NO.

Al unirse a receptores de tipo $E T_{A}$, la $E T_{1}$ produce contracción del músculo liso vascular, mientras que su unión a receptores $E T_{B 1}$ en las células endoteliales estimula la liberación de $\mathrm{NO}$ y de $\mathrm{PGI}_{2}$, que promueven la vasorrelajación (104). La preincubación con insulina de células de músculo liso vascular aisladas produce un aumento de la expresión de los receptores $\mathrm{ET}_{\mathrm{A}}$ (27); esto, a su vez, podria potenciar la respuesta contráctil de los miocitos a la ET 1 . Sin embargo, nuestros resultados muestran que la insulina no afecta la $\mathbf{F}$ máx de las contracciones 
producidas por este agonista en aorta de rata. Es de hacer notar que en un preparado como el nuestro, que contiene endotelio intacto, la insulina podría aumentar también la expresión de receptores $\mathrm{ET}_{\mathrm{B} 1}$ en las células endoteliales, la activación de los cuales estimula la síntesis de factores relajantes, enmascarando esto la respuesta debida al aumento de receptores $\mathrm{ET}_{\mathrm{A}}$ en el músculo liso del vaso. Para confirmar esta hipótesis se repitieron los experimentos agregando LNAME con el objetivo de inhibir la sintesis de NO. De los resultados experimentales se ve que la falta del factor relajante endotelial potenció significativamente la fuerza máxima desarrollada por $\mathrm{ET}_{1}$ tanto en el grupo control como en el tratado con $40 \mu \mathrm{U} / \mathrm{ml}$ de insulina, pero éstos no difirieron entre sí, por lo que tampoco en estas condiciones se puso de manifiesto un efecto derivado del aumento de la sintesis de los receptores $\mathrm{ET}_{\mathrm{A}}$. Por el contrario, los valores de $\mathrm{F}$ máx del grupo incubado con $160 \mu \mathrm{U} / \mathrm{ml}$ de insulina en presencia de L-NAME fueron significativamente menores que los del grupo con L-NAME sin insulina, lo que permite sugerir que, como ya se dijo para AVP, la insulina activaría algún mecanismo atenuador de la contracción que sólo puede ser observado cuando se ha inhibido la sintesis del NO. Cuando los experimentos se repitieron en presencia de indometacina, un inhibidor de la síntesis de prostaglandinas y tromboxanos a través de la ruta de la ciclooxigenasa, el efecto relajante de la insulina sobre las contracciones por $\mathrm{ET}_{1}$ y por AVP desapareció, por lo que es posible sugerir que la atenuación de la contracción observada se debia a la estimulación por parte de la insulina de la liberación y/o de la acción de un agente vasodilatador derivado del ácido araquidónico, como la $\mathrm{PGI}_{2}$.

Estudios con radioligandos demostraron que la $\mathrm{ET}_{1}$ es un ligando irreversible ya que la vida media de la disociación del complejo ligando/receptor es mayor 
de 100 hs. (105). Por esta razón las contracciones por $\mathrm{ET}_{1}$ se relajaron farmacológicamente con cafeína. La insulina no modificó las relajaciones inducidas por cafeína en las contracciones por $\mathrm{ET}_{1}$; se observó una disminución de la relajación en los tres grupos tratados con L-NAME, con significación estadística sólo en los anillos pretratados con insulina $40 \mu \mathrm{U} / \mathrm{ml}$, lo que sugiere que la relajación por cafeína tiene un componente dependiente del endotelio, similar al descripto en las relajaciones inducidas por esta sustancia de contracciones producidas por fenilefrina (106).

- dosis alta de insulina con y sin inhibición de la sintesis de NO:

Varios trabajos han sugerido la participación de la $\mathrm{ET}_{1}$ en la producción de hipertensión arterial (107). En ratas con hipertensión arterial por hiperinsulinemia se ha demostrado una correlación positiva significativa entre niveles de $\mathrm{ET}_{1}$ en el tejido vascular y niveles de presión sanguínea (108).

Se discuten a continuación los resultados obtenidos utilizando dosis de insulina similares a las encontradas en ratas con hiperinsulinemia.

La $\mathrm{F}$ máx inducida por $\mathrm{ET}_{1}$ ○ AVP en aorta de rata no fue afectada por la preincubación con la hormona a dosis hiperinsulinémicas, un resultado similar al ya hallado con dosis menores de insulina. Por otro lado, apareció un efecto de la insulina hasta ahora no observado: la preincubación con $500 \mu \mathrm{U} / \mathrm{ml}$ de insulina potenció la velocidad de desarrollo de la fuerza en las contracciones por $\mathrm{ET}_{1}$ (disminuyó el $\mathrm{t}_{1 / 2}$ de contracción). Este efecto de la insulina pudo ser bloqueado por el tratamiento con genisteína, como se hubiera esperado para un mecanismo mediado por la actividad tirosín quinasa del receptor de insulina o del receptor del IGF 
La inhibición de la sintesis de NO con L-NAME potenció la F máx de las contracciones por $\mathrm{ET}_{1}$ y por AVP en forma similar a lo ya observado en experimentos previos. La ausencia de NO aumentó la velocidad de desarrollo de la fuerza por $\mathrm{ET}_{1}$, y la estimulación de este parámetro por la preincubación con insulina fue más notoria que en presencia de NO. Se demostró, además, que este efecto de la insulina dependía de fosforilaciones en tirosina ya que fue inhibido por la presencia de genisteína.

De forma similar a lo ya dicho para la dosis de $160 \mu \mathrm{U} / \mathrm{ml}$, la preincubación con $500 \mu \mathrm{U} / \mathrm{ml}$ de insulina puso de manifiesto un efecto relajante cuando la sintesis de NO estaba inhibida: las contracciones por $E_{1}$ y $A V P$ alcanzaron valores menores que en ausencia de insulina $(\sim 20 \%$ y $\sim 25 \%$ respectivamente).

Los efectos relajantes de la insulina sobre las contracciones por AVP fueron sensibles a la inhibición de tirosín quinasas con genisteína, confirmando que éstos se producen a través de la unión de la insulina a su propio receptor o al receptor de $\mathrm{IGF}_{1}$. Por otro lado, en el caso de las contracciones por $\mathrm{ET}_{1}$ los efectos de la insulina sobre la F máx se bloquearon sólo parcialmente por la genisteína, mientras que, como ya se dijo, los efectos sobre el $t_{1 / 2}$ de contracción se bloquearon completamente. Esto no implica necesariamente que las acciones de la insulina no sean totalmente dependientes de fosforilaciones en tirosina, ya que se ha descripto que la genisteina puede no ser capaz de bloquear todos los efectos tirosín-quinasa dependientes de la insulina (109).

La inhibición de la ciclooxigenasa con indometacina eliminó la atenuación 
de las contracciones por $\mathrm{ET}_{1}$ y por AVP producida por la insulina $500 \mu \mathrm{U} / \mathrm{ml}$ en presencia de L-NAME, lo que confirma las observaciones con $160 \mu \mathrm{U} / \mathrm{ml}$, y sugiere que la $\mathrm{PGI}_{2}$ estaria involucrada en los efectos de la hormona. En el caso de la $E T_{1}$, los experimentos en los cuales se midió simultáneamente la captación de ${ }^{45} \mathrm{Ca}^{2+}$ por el tejido sugieren que la atenuación de la fuerza observada no se debió a una disminucion del influjo de $\mathrm{Ca}^{2+}$ desde el medio extracelular.

No está claro el por qué no pudimos observar vasodilatación sin inhibición de la sintesis de NO. Una posibilidad es que el NO sea el principal responsable de la vasodilatación dependiente de endotelio en este vaso, de manera que el componente vasorrelajante dependiente de las prostaglandinas fuera muy pequeño $o$ inexistente en presencia de NO. A favor de esta hipótesis es el hecho de que las prostaglandinas podrian actuar en algunos tejidos a través del GMPc (110), el mismo segundo mensajero utilizado por el NO, de forma que si los efectos del GMPc fueran activados en forma máxima por la $\mathrm{ET}_{1}$ o la AVP a través del NO, un aumento en la síntesis o acción de la $\mathrm{PGI}_{2}$ podría pasar desapercibido. Otra posibilidad seria que, como se ha observado en músculo liso de útero de ratas tratadas con progesterona (111), el NO inhibiera la sintesis de prostaglandinas, de forma que los efectos de la insulina sobre $\mathrm{PGl}_{2}$ se observarian mejor en presencia de L-NAME.

La insulina estimula la liberación de prostaglandinas in vivo en el antebrazo humano, pero de una forma dependiente de NO (33), mientras que nosotros observamos un efecto independiente del NO. La vasodilatación inducida por la insulina en arterias retinales de cerdo (46) y en arterias de cremáster de rata (32) es dependiente del NO, y en estos vasos el tratamiento con indometacina no tuvo efectos, o sea que la relajación inducida por la hormona no estaba mediada por 
prostaglandinas. Es evidente, entonces, que hay diferencias entre especies y naturaleza del vaso en los efectos relajantes de la insulina, y también es posible que dichos efectos dependan del tipo de agonista utilizado para producir la contracción. Nuestros datos muestran efectos relajantes de la preincubación con insulina a dosis normo e hiperinsulinémicas sobre aorta de rata contraida con $\mathrm{ET}_{1}$ o AVP, no mediados por NO, pero sí por $\mathrm{PGI}_{2}$.

La relajación dependiente de endotelio parece estar afectada tanto en la diabetes mellitus insulino-dependiente (DMID) como en la diabetes mellitus no insulino-dependiente (DMNID) $(112,113)$. Se encontró que en el caso de pacientes con DMNID las vasorrelajaciones inducidas por acetil colina o por metacolina estaban disminuidas, y esto se debía a una disfunción endotelial, ya que la relajación con nitroprusiato era normal (114); sin embargo, otros investigadores han hallado alteraciones en la respuesta del músculo liso vascular a los vasodilatadores $(115,116)$. El rol de los productos de la ciclooxigenasa en la diabetes, tanto vasodilatadores como vasoconstrictores, no ha sido completamente aclarado, pero parece ser que no siempre son afectados por esta patologia. Hay resultados en la literatura que sugieren que no contribuyen al deterioro de la vasodilatación observado en la diabetes $(117,118)$, pero también se ha descripto que los metabolitos vasoconstrictores de la ciclooxigenasa podrian ser en parte responsables de esta alteración $(119,120)$. Teniendo en cuenta todos estos datos, el aumento inducido por la insulina de la liberación de prostanoides vasodilatadores que nosotros observamos podría ser relevante en el caso de pacientes hiperinsulinémicos con una producción o una respuesta anormal al NO, pero con una actividad normal de la ruta de la ciclooxigenasa.

Los resultados obtenidos en la arteria de la cola de rata difieren de los de 
la aorta en el hecho de que se pudo observar un aumento de la F máx inducido por la preincubación con insulina en las contracciones por ET1. Dado el antecedente en aorta de rata, es probable que esto se deba a que la insulina fue capaz de estimular la expresión o la respuesta de los receptores para $\mathrm{ET}_{1}$ en las células musculares lisas de la arteria de la cola de rata, o alternativamente producir un aumento en la liberación o en la acción de algún factor vasoconstrictor endotelial. El tratamiento con indometacina eliminó estos efectos vasocosntrictores de la insulina en la arteria de la cola, lo que sugiere que éstos se debian a un factor contrayente derivado del metabolismo del ácido araquidónico, probablemente $\mathrm{TXA}_{2}$.

- liberación de NO inducida por ACh:

La infusión de insulina en humanos es capaz de producir vasodilatación de las arteriolas del músculo esquelético de los miembros inducida por liberación endotelial de NO, lo que se evidencia por un aumento del flujo sanguíneo (31). Este efecto también ha sido comprobado in vitro en arteriolas aisladas (32). En aorta de rata, hay antecedentes que indican que la insulina es capaz de producir liberación de NO. El agregado agudo de dosis crecientes de insulina (1 a $120 \mathrm{mU} / \mathrm{ml}$ ) produjo una relajación dosis dependiente de contracciones por NA, un efecto que fue atenuado por la eliminación del endotelio o la inhibición de la síntesis de NO (103).

En nuestro preparado no pudimos demostrar que la insulina produjera un aumento de la liberación de NO inducida por la $A C h$, aunque hubo una tendencia a que los anillos preincubados con la hormona se relajasen más. Es posible que la diferencia se deba a que la dosis de insulina utilizada en nuestros estudios es la 
mitad de la dosis menor con la cual se ha reportado el efecto relajante al agregar insulina sobre contracciones previas (103). Además, es posible que la preincubación con la hormona no haya afectado los mecanismos puestos en juego en forma aguda por la insulina. Por último, es también probable que el efecto de la insulina sobre la liberación de NO no sea muy importante en una arteria de conducción como la aorta.

- estudio detallado de los efectos de la insulina sobre contracciones por $\mathrm{ET}_{1}$ :

La $\mathrm{ET}_{1}$ activa varios mecanismos celulares para producir la contracción del músculo liso vascular (121). La acción primaria de $\mathrm{ET}_{1}$ a concentraciones nanomolares es activar la fosfolipasa C (PLC) (122) induciendo aumento del inositol trifosfato $\left(\mathrm{IP}_{3}\right)$ que libera $\mathrm{Ca}^{2+}$ del retículo sarcoplásmico; este mecanismo produce un desarrollo de fuerza fásico inicial que es seguido por una contracción sostenida mediada por la entrada de $\mathrm{Ca}^{2+}$ externo y por la activación de la PKC vía el diacilglicerol (DAG); este compuesto producido por la activación de PLC y fosfolipasa $\mathrm{D}(\mathrm{PLD})$ promueve la contracción aumentanto la sensibilidad al $\mathrm{Ca}^{2+}$ de las proteinas contráctiles (123). El esquema de la Figura 29 señala los mecanismos estudiados luego de la preincubación con insulina para determinar si son responsables de los efectos que esta hormona tiene sobre las contracciones inducidas por $\mathrm{ET}_{1}$. También se indican los tres factores vasoactivos derivados del endotelio que fueron investigados como posibles mediadores de estos efectos de la insulina. 


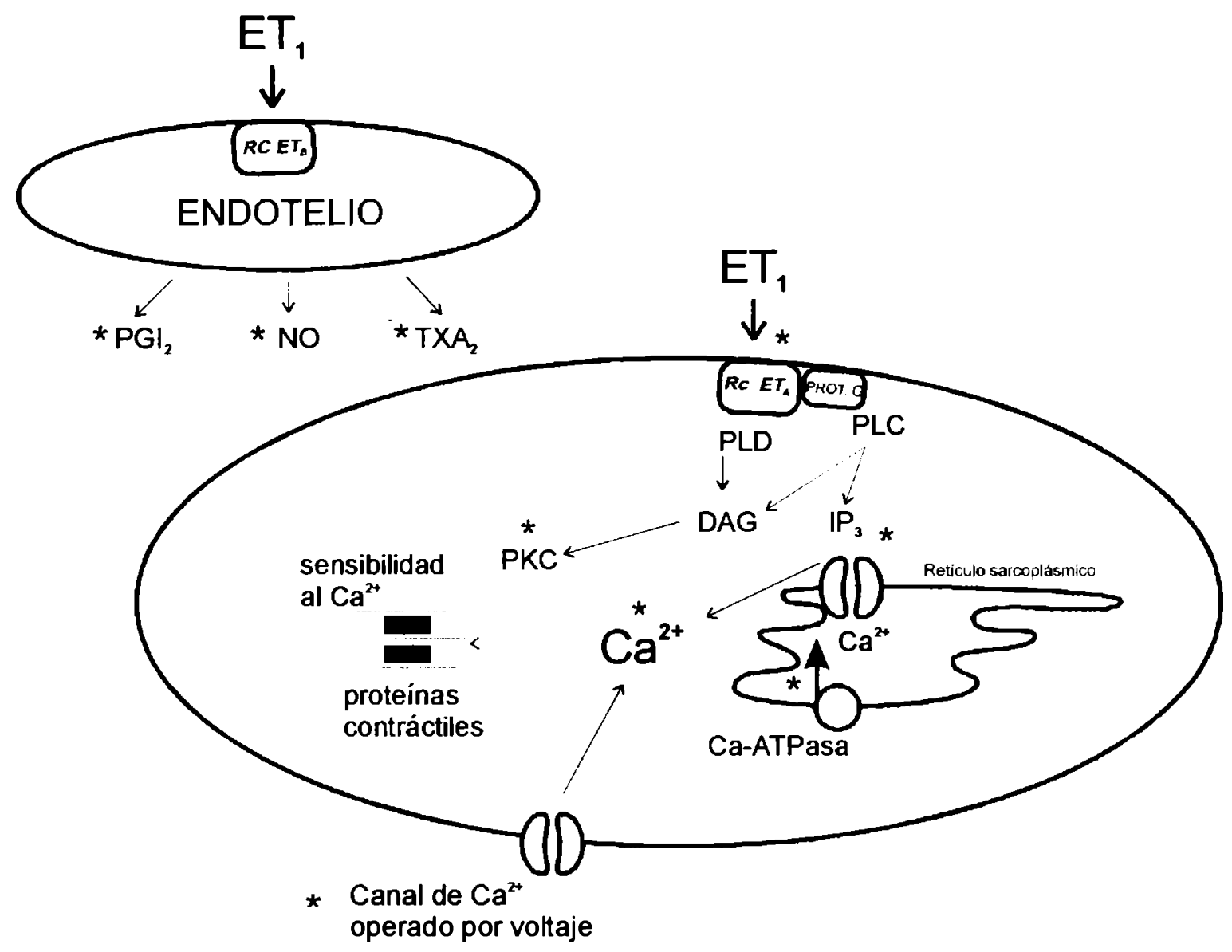

Fig 29: El esquema señala (") los mecanismos que participan en las contracciones producidas por $E T_{1}$ que fueron investigados en este trabajo como posibles mediadores de los efectos de insulina en la modificación de la respuesta del músculo liso vascular a este agonista.

La $E T_{1}$ también activa la fosfolipasa $A_{2}$ que produce la formación de metabolitos del ácido araquidónico, incluídos los leucotrienos, las prostaglandinas y los tromboxanos. Estos efectos son mediados por activación de receptores $E T_{A}$ y $E T_{B}$ acoplados a proteina $\mathrm{G}$ o directamente por aumento del $\mathrm{Ca}^{2+}$ intracelular (124).

Se estudió la participación de algunos de estos mecanismos (marcados con asterisco en la Figura 29) en los efectos potenciadores de las contracciones por $\mathrm{ET}_{1}$ producidos por la preincubación con dosis altas de insulina: aumento de la velocidad de relajación en aorta, y aumento de la fuerza desarrollada en la arte- 
ria de la cola.

En lo que respecta a los efectos de concentraciones hiperinsulinémicas sobre las contracciones por $\mathrm{ET}_{1}$ en la aorta de rata, una posible explicación para nuestros resultados sería el suponer que la insulina estimula las rutas de transducción de señales de la $E T_{1}$, en la cual ya se ha descripto la participación de tirosín quinasas $(125,126)$. Nuestros datos experimentales están de acuerdo con el hecho de que la fosforilación en restos de tirosina es uno de los mecanismos utilizados en el acoplamiento excitación-contracción de la ET muestra la disminución tanto de la F máx como de la velocidad del desarrollo de la fuerza en las preparaciones control tratadas con genisteina. Sin embargo, la exposición aguda a la insulina, que también deberia haber estimulado una ruta dependiente de fosforilaciones en tirosina, no afectó las contracciones inducidas por $E T_{1}$. Este resultado, por lo tanto, no es compatible con el concepto de una interacción directa entre las rutas de transducción de señales de la insulina y de la $E T_{1}$. El hecho de que se necesite un tiempo más prolongado para que se expresen los efectos de la hormona sugiere que éstos estarian mediados por la síntesis de nuevas proteinas. Se sabe que la preincubación con insulina estimula la expresión de receptores para $\mathrm{ET}$ del tipo $\mathrm{ET}_{\mathrm{A}}$ en células de músculo liso vascular en cultivo (27), y un mayor número de receptores podría explicar el que la insulina aumentase la velocidad de desarrollo de la fuerza contráctil. Sin embargo, si la insulina aumentara el número de receptores $\mathrm{ET}_{\mathrm{A}}$, deberiamos haber tenido también un aumento de la $\mathrm{F}$ máx luego de la preincubación, a no ser que esta respuesta estuviera enmascarada por un efecto relajante simultáneo de la insulina. Con nuestros experimentos no se puede discernir si la insulina produce un aumento de la expresión de los receptores para $\mathrm{ET}_{1}$ o si estimula la sintesis de otras 
proteínas involucradas en la regulación de la contracción del músculo liso vascular. Tenemos sí evidencias de que la liberación de $\mathrm{Ca}^{2+}$ desde depósitos intracelulares participa en el aumento que la insulina induce sobre la velocidad de desarrollo de la fuerza en contracciones por $\mathrm{ET}_{1}$.

El tratamiento con rianodina o con tapsigargina elimina la participación en la contracción del $\mathrm{Ca}^{2+}$ proveniente del retículo sarcoplásmico. En estas condiciones, la insulina no fue capaz de aumentar la velocidad de las contracciones por $E T_{1}$. En cambio, en los experimentos realizados en ausencia de $\mathrm{Ca}^{2+}$ externo se muestra que la insulina si es capaz de potenciar tanto la velocidad de desarrollo de la fuerza por $\mathrm{ET}_{1}$ como la $\mathrm{F}$ máx, siendo en este caso la contracción dependiente sólo de la liberación de $\mathrm{Ca}^{2+}$ desde el retículo sarcoplásmico. Estos datos indican que la preicubación con la hormona aumentó la liberación de $\mathrm{Ca}^{2+}$ a partir de depósitos intracelulares inducida por la ET 1 . Este efecto no dependería de un aumento en la cantidad de $\mathrm{Ca}^{2+}$ acumulado en el retículo sarcoplásmico por acción de la insulina, ya que nuestros resultados muestran que las contracciones por cafeína $3 \mathrm{mM}$ no son potenciadas por la preincubación con insulina, como tampoco lo es la captación máxima de ${ }^{45} \mathrm{Ca}^{2+}$ por el retículo sarcoplásmico en segmentos vasculares preincubados con la hormona. Tomados en conjunto, estos resultados permiten sugerir que el aumento de la velocidad de contracción para $E T_{1}$ dado por la preincubación con insulina se debería a una potenciación de la capacidad de dicho agonista para producir la salida de $\mathrm{Ca}^{2+}$ desde los depósitos intracelulares, ya sea mediante algún efecto sobre su ruta de transducción de señales, por la liberación de algún otro factor contrayente por parte del endotelio, o por una combinación de ambas posibilidades.

La inhibición de la sintesis de NO potencia las contracciones inducidas por $\mathrm{ET}_{1}$ en ausencia de $\mathrm{Ca}^{2+}$ externo, pero la insulina no tiene un efecto adicional 
sobre las mismas. Este resultado sugiere que: (a) en ausencia de NO la respuesta debida a la liberación de calcio intracelular es máxima y la insulina no puede incrementarla más, o (b) la presencia de NO es necesaria para que el efecto de insulina per se o a través de factores derivados del endotelio se manifiesten. Esta última alternativa sería coincidente con la eliminación del efecto potenciador de la insulina sobre contracciones de $\mathrm{ET}_{1}$ que observamos en la arteria de la cola de la rata cuando la sintesis de NO está inhibida.

En células de músculo liso de aorta de rata en cultivo se midió la variación en el nivel de $\mathrm{Ca}^{2+}$ intracelular inducida por $\mathrm{ET}_{1}$ a la misma concentración utilizada en nuestros experimentos. La preincubación con insulina $100 \mathrm{nM}$ (dosis 33 veces mayor que la de $500 \mu \mathrm{U} / \mathrm{ml}$ ) durante 24 hs. aumentó el pico de $\mathrm{Ca}^{2+}$ inducido por $E T_{1}$ y el efecto fue atribuído a la mayor expresión de receptores $E T_{A}$ producido por la preincubación con la hormona (29). Por otra parte, en células de músculo liso aisladas de arteria coronaria de cerdo y preincubadas con dosis fisiológicas de insulina (300 pM) durante 20 minutos, se describió una disminución del aumento de $\mathrm{Ca}^{2+}$ intracelular al estimular con $\mathrm{ET}_{1}$ 0,01 $\mu \mathrm{M}$. Si bien el resultado es opuesto al descripto por nosotros con dosis hiperinsulinémicas y preincubación durante dos horas, el mismo trabajo demuestra que los efectos de insulina son mediados por la reducción en la liberación de $\mathrm{Ca}^{2+}$ de depósitos intracelulares ya que se detectan en ausencia de $\mathrm{Ca}^{2+}$ externo; por otra parte demuestra que la preincubación con insulina no afecta los aumentos transitorios de $\mathrm{Ca}^{2+}$ inducidos por cafeína ni el contenido de $\mathrm{Ca}^{2+}$ de los depósitos intracelulares (28). Es decir, la insulina produce dos efectos opuestos sobre $\mathrm{el} \mathrm{Ca}^{2+}$ intracelular que moviliza la $E T_{1}$, pero ambos coinciden en que son mediados por la liberación de $\mathrm{Ca}^{2+}$ desde el retículo sarcoplásmico, no son dependientes de la carga de calcio del depósito ni de los canales sensibles a cafeina. La propuesta es que la insulina modifica la 
producción de $\mathrm{IP}_{3}$ o el efecto de $\mathrm{IP}_{3}$ sobre los canales del retículo sarcoplásmico para alterar la respuesta a $\mathrm{ET}_{1}(29)$.

En aorta de rata las contracciones por $\mathrm{ET}_{1}$ son atenuadas por inhibidores de PKC como la staurosporina, la floretina y el H-7 (127). Usamos cheleritrina para estudiar si la PKC estaba involucrada en el efecto potenciador de las contracciones por $\mathrm{ET}_{1}$ dependiente de la preincubación con insulina. La inhibición de la actividad de la PKC suprimió el aumento en la velocidad de desarrollo de fuerza lo cual sugiere que mecanismos regulados por fosforilaciones dependientes de esta quinasa son mediadores de los efectos de insulina.

En la arteria de la cola de rata observamos un efecto potenciador de la fuerza dado por la insulina, y comprobamos que éste desaparecía en presencia de indometacina, sugiriendo un efecto dependiente de un vasoconstrictor derivado del ácido araquidónico, como el $\mathrm{TXA}_{2}$. El inhibidor específico de los receptores de $\mathrm{TXA}_{2}, \mathrm{SQ} 25.548$, permitió confirmar que este prostanoide era el responsable del aumento de la fuerza contráctil producido por la insulina. La preincubación con la hormona podria haber generado un aumento de la capacidad de la $E T_{1}$ de liberar $\mathrm{TXA}_{2}$, un aumento de la cantidad de receptores para este vasoconstrictor en el músculo liso, o ambos. El origen más probable del $\mathrm{TXA}_{2}$ es la célula endotelial, aunque nuestros experimentos no nos permiten diferenciar si este factor efectivamente proviene del endotelio o si la insulina estimula la producción de prostanoides por parte de la propia célula muscular lisa.

EI NO juega un papel importante en los efectos de la insulina en la arteria de la cola. Cuando se inhibió la síntesis de este compuesto con el L-NAME, no se observó el aumento de la fuerza contráctil producido por la insulina, lo que indica que la presencia de NO es necesaria para que se produzca el aumento en la liberación o la acción del $\mathrm{TXA}_{2}$. En células de músculo liso uterino en cultivo se ha 
observado una interacción entre el NO y los prostanoides: la presencia de NO fue necesaria para que en células uterinas obtenidas de ratas estrogenizadas se produjera la prostaglandina vasoconstrictora PGE, ya que la inhibición del NO produjo una disminución en su síntesis, mientras que donores exógenos de NO como el nitroprusiato de sodio la aumentaron (111). También se ha probado que el NO es necesario para que en células de músculo liso vascular se produzca la liberación de prostaglandina $E_{2}\left(P G E_{2}\right)$ inducida por la interleuquina-1 (128). 


\section{ESTUDIOS ELECTROFISIOLÓGICOS EN CÉlulas DeRIVAdas de Músculo Liso \\ VASCULAR EN CULTIVO}




\section{ESTUDIOS ELECTROFISIOLÓGICOS EN CÉLULAS DE MÚS- CULO LISO EN CULTIVO.}

\subsection{ANTECEDENTES Y OBJETIVOS}

Como se describió en la introducción, se sabe que la insulina es capaz de afectar de varias formas a las células de músculo liso vascular; sin embargo sus efectos sobre los canales de $\mathrm{Ca}^{2+}$ de la membrana plasmática no han sido completamente aclarados. Varios trabajos han estudiado el papel de la insulina sobre estos canales en forma indirecta, por ejemplo, mediante la medida de los efectos de la hormona sobre los aumentos transitorios de $\mathrm{Ca}^{2+}$ en el citosol inducidos por agonistas (43-45), o a través de determinar su modificación por diversos bloqueantes de los canales de $\mathrm{Ca}^{2+}(46,47)$. Sin embargo, los trabajos que midieron directamente las corrientes con técnicas electrofisiológicas son escasos.

Mediante la técnica de patch-clamp es posible medir las corrientes que circulan a través de los canales iónicos presentes en la membrana plasmática de una célula aislada. Nuestro objetivo fue utilizar esta técnica para estudiar los efectos de la insulina sobre las corrientes que fluyen a través de los canales de $\mathrm{Ca}^{2+}$ voltaje activados de tipo $\mathrm{L}\left(\mathrm{I}_{\mathrm{Ca}(\mathrm{L})}\right)$ en músculo liso vascular, con el objetivo de correlacionar estos resultados con los obtenidos en los experimentos mecánicos. Se realizaron experimentos en células de músculo liso aórtico en cultivo preincubándolas durante 2 o 24 hs con $500 \mu \mathrm{U} / \mathrm{ml}$ de insulina; también se investigaron los efectos agudos de la insulina sobre las corrientes registradas.

\subsection{METODOLOGÍA}


Se utilizaron células A7r5, una línea celular derivada de músculo liso vascular de aorta de rata, cultivadas en medio de Eagle modificado por Dulbecco (DMEM) a $37^{\circ} \mathrm{C}$ en una atmósfera con $5 \%$ de $\mathrm{CO}_{2}$. El medio de cultivo contenia $10 \%$ de suero fetal bovino (SFB), $100 \mathrm{U} / \mathrm{ml}$ de penicilina-G y $100 \mu \mathrm{g} / \mathrm{ml}$ de sulfato de estreptomicina. Como se explica luego, algunos de los experimentos se llevaron a cabo en células confluentes (que cubrian el $100 \%$ de la superficie de la caja de cultivo), mientras que para otros experimentos se repicaron células en DMEM con sólo $0,5 \%$ de SFB y se utilizaron antes de que fueran confluentes (que cubrieran no más de $15-20 \%$ de la superficie de cultivo). El día de cada experimento, las células fueron tratadas durante 2 minutos con una solución de tripsina al $0,05 \%$ para separarlas. Luego de esto se dejaron a $37^{\circ} \mathrm{C}$ con $5 \%$ de $\mathrm{CO}_{2}$ en DMEM sin SFB hasta el momento de utilizarlas (1-5 hs después) para mantenerlas separadas y para detener el ciclo celular, que podría haber causado variaciones en las $\mathrm{I}_{\mathrm{Ca}(\mathrm{L})}$.

Los experimentos se llevaron a cabo con la configuración de célula entera (whole-cell) en modo de fijación del voltaje (voltage clamp). Las células aisladas se colocaron en una cámara montada sobre la platina de un microscopio invertido que fue perfundida constantemente con una solución "extracelular" de la siguiente composición (en mM): $\mathrm{Cl}_{2} \mathrm{Ba} 5$, cloruro de tetraetilamionio (TEA-Cl) 130, HEPES $10(\mathrm{pH} 7,4), \mathrm{Cl}_{2} \mathrm{Mg} \mathrm{1,4-aminopiridina} 5$ y glucosa 10. Con tubos capilares de vidrio se fabricaron micropipetas con una punta de unos 2-4 $\mu \mathrm{m}$ de diámetro. Un alambre de $\mathrm{Ag}-\mathrm{ClAg}$ conectado al sistema registrador se introdujo en la micropipeta que se llenó con una solución "intracelular" de la siguiente composición (en mM): OHCs 104, CICs 40,5, L-glutamato 80, Cl 2 Mg 1,0, EGTA 10, HEPES 10 (pH $7,2)$ y $A T P N a, 5,0$. La composición de las soluciones del baño y del microelectrodo fueron las adecuadas para registrar corrientes a través de canales de $\mathrm{Ca}^{2+}$; se 
utilizó $\mathrm{Ba}^{2+}$ como transportador de carga para tener una corriente mayor, y para evitar la inhibición de los canales por el $\mathrm{Ca}^{2+}$ intracelular. Mediante movimientos realizados con un micromanipulador se tocó la superficie celular con la punta del microelectrodo y se efectuó una suave succión para generar una unión de alta resitencia eléctrica ("sello") entre el vidrio de la pipeta y la membrana celular. Mediante una succión adicional se rompió la porción de membrana bajo la punta de la pipeta, logrando así una comunicación eléctrica con el citoplasma celular (configuración de whole-cell).

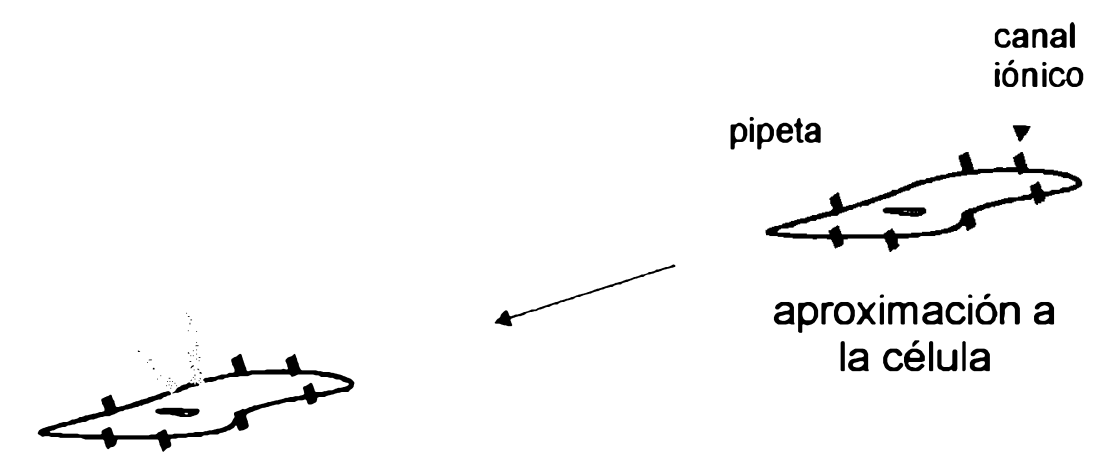

formación del sello

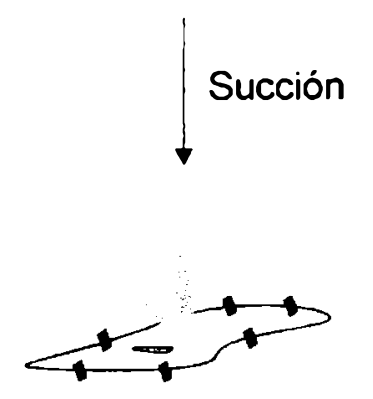

"Whole-cell"

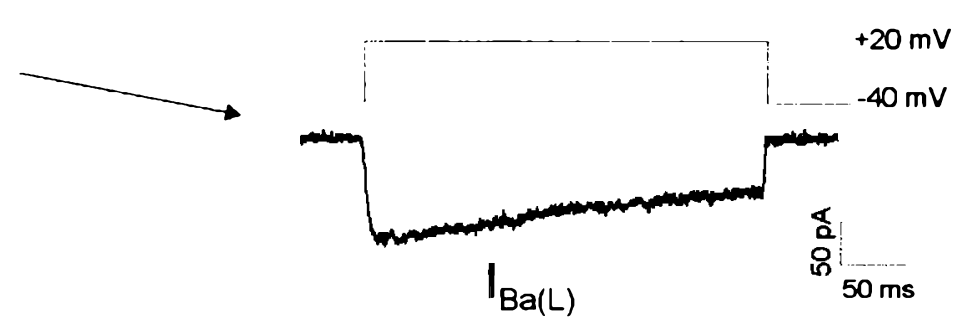

registro de la corriente

Fig 30: Esquema de la obtención de la configuración de "whole-cell" para medir corrientes a través de los canales iónicos en la membrana plasmática. 
Se indujeron y registraron corrientes a través de los canales de $\mathrm{Ca}^{2+}$ mediante la aplicación a la célula de pulsos de corriente despolarizante de $300 \mathrm{~ms}$ de duración desde un potencial de reposo fijo (holding potential) de $-40 \mathrm{mV}$ hasta distintos potenciales finales dependiendo del protocolo experimental. El potencial de reposo utilizado excluye la participación de canales de $\mathrm{Ca}^{2+}$ de tipo $\mathrm{T}$, asi que los canales de tipo $L$ se consideran responsables de la corriente. La corriente capacitiva y la corriente de fuga (leak) se sustrajeron de los registros mediante un protocolo P/4. Se filtraron las corrientes con una frecuencia de $1 \mathrm{kHz}$ y se adquirieron a una frecuencia de $2,5 \mathrm{kHz}$. El valor de la capacitancia de la membrana plasmática se calculó a partir de la corriente generada por un pulso triangular, y los resultados de los experimentos se expresaron como densidad de corriente (valor de la corriente / capacitancia de la membrana) para minimizar la variabilidad debida a las diferencias en el tamaño de las células. Con los valores de densidad de corriente al pico se construyeron curvas corriente-potencial (curvas I-V). El análisis estadístico se realizó mediante análisis de varianza (ANOVA) utilizando el test LSD de Fisher, aceptando una $p<0,05$ para establecer significación estadistica.

\subsection{RESULTADOS}

- Exposición aguda a la insulina:

Los experimentos se realizaron luego de que la corriente se estabilizó (generalmente 1-2 minutos luego de romper la membrana). Se obtuvo una curva I-V control y luego algunas células se perfundieron con solución de baño conteniendo 
$500 \mu \mathrm{U} / \mathrm{ml}$ de insulina, mientras que otras se siguieron perfundiendo con la solución control. Se obtuvieron corrientes aplicando pulsos despolarizantes de $300 \mathrm{~ms}$ hasta $+20 \mathrm{mV}$ desde un potencial de reposo de $-40 \mathrm{mV}$ cada 2 minutos. La corriente a través de los canales $\mathrm{Ca}_{\mathrm{L}}$ disminuyó gradualmente, un fenómeno conocido como "run-down" (129).
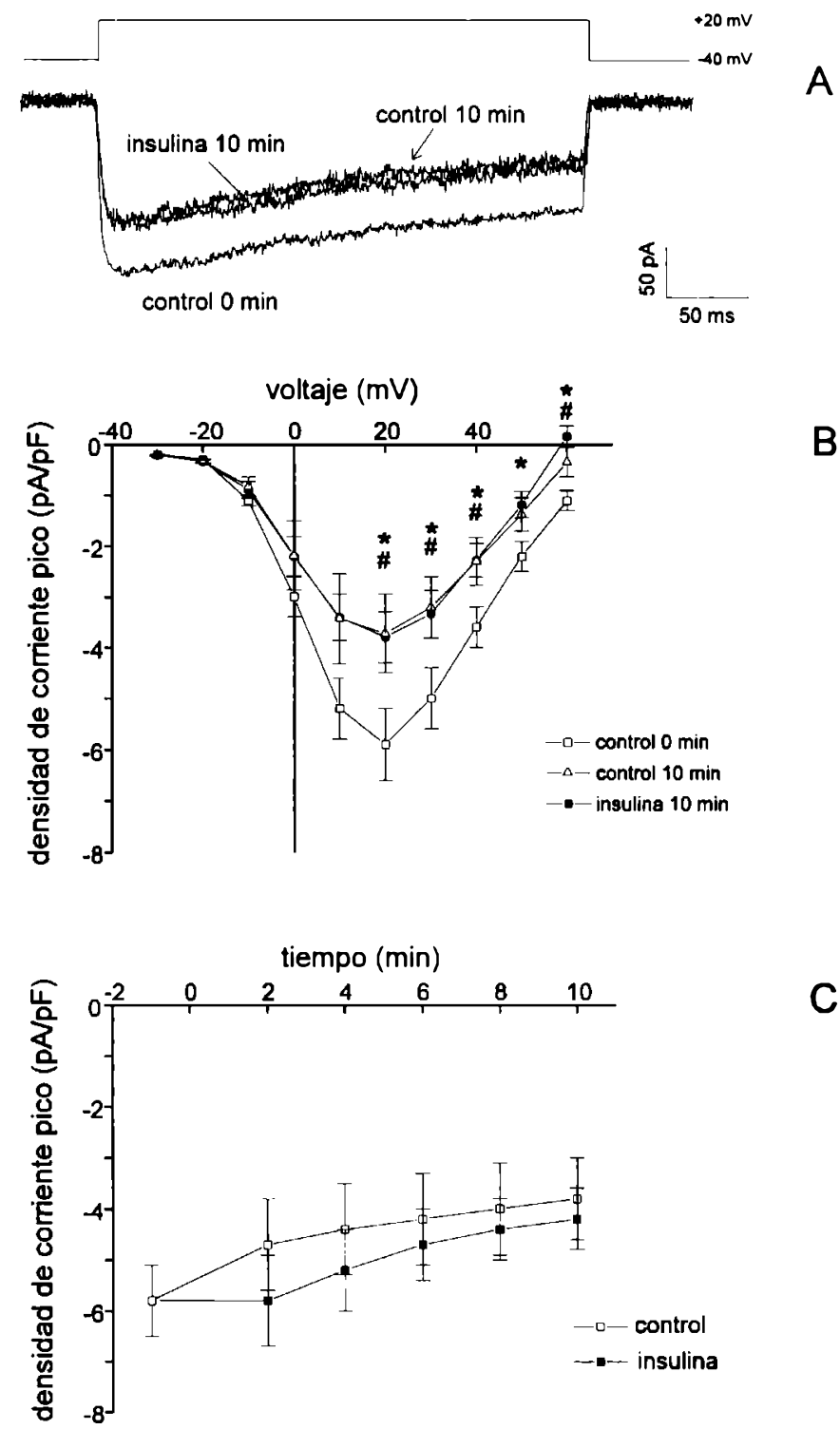

B

C

Fig 31: registros típicos $(A)$ y datos promediados $(C)$ de corrientes a través de canales $C a_{L}$ antes y $10 \mathrm{~min}$ después de la perfusión con $500 \mu \mathrm{U} / \mathrm{ml}$ de insulina. Curvas I-V control y obtenidas luego de los 10 minutos de perfusión con insulina (B). Control antes de 0 min: $n=20$, control 2-10 minutos: $n=9$, insulina $2-10$ minutos: $n=11$. 
Estudiamos si la insulina era capaz de modificar la velocidad de dicha atenuación comparando el run-down observado en las células tratadas con la hormona con el medido en las células control. Luego de 10 minutos de perfusión se obtuvo una segunda curva I-V (Fig 31). Se ve que los 10 minutos de perfusión con insulina no tuvieron ningún efecto sobre el run-down de las corrientes registradas.

- Incubación con insulina por plazos prolongados:

A continuación de los efectos agudos se estudiaron los efectos de un tratamiento más prolongado con insulina. La preincubación de células confluentes por 2 o por 24 hs con $500 \mu \mathrm{U} / \mathrm{ml}$ de insulina en DMEM con $10 \%$ de SFB no modificó las corrientes por los canales $\mathrm{Ca}_{\mathrm{L}}$, ya que las curvas $\mathrm{I}-\mathrm{V}$ post incubación no fueron diferentes de sus respectivos controles. En la figura 32 se ven los datos obtenidos preincubando por 24 hs.

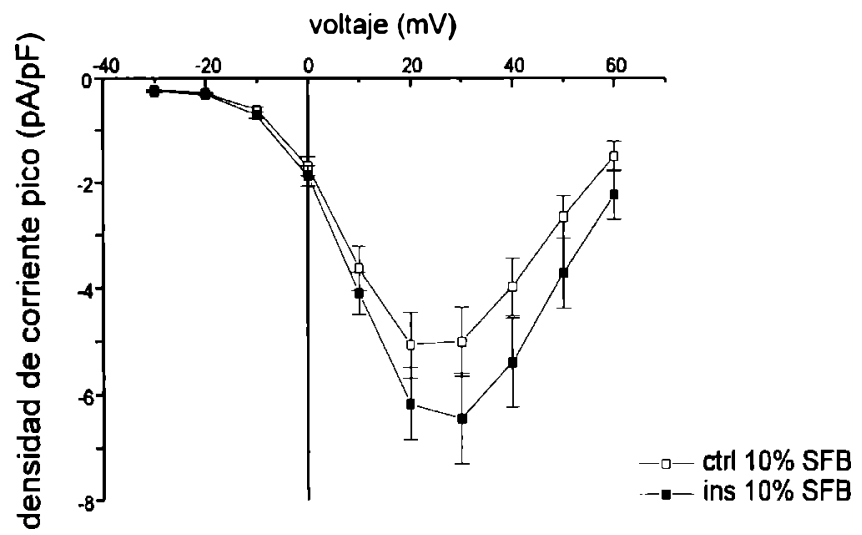

Fig 32: Curvas I-V luego de 24 hs de incubación con $(n=13) \circ \sin (n=14)$ insulina en un medio con $10 \%$ de SFB 
Existia la posibilidad de que los factores de crecimiento presentes en el SFB enmascararan los efectos de la insulina, por lo que los experimentos se repitieron utilizando un medio de cultivo pobre en SFB. Se repicaron células confluentes en placas de DMEM con sólo $0,5 \%$ de SFB, y se utilizaron 24 hs después. Las células no eran confluentes y ocupaban sólo el 10-20\% de la superficie de la placa. Como se ve en la figura 33 , luego de 24 hs en este medio pobre en factores de crecimiento, la densidad de corriente a través de los canales $C a_{L}$ disminuyó. Cuando las células se repicaron en un medio con $0,5 \%$ de SFB con 500 $\mu \mathrm{U} / \mathrm{ml}$ de insulina, la atenuación de las corrientes no se produjo.
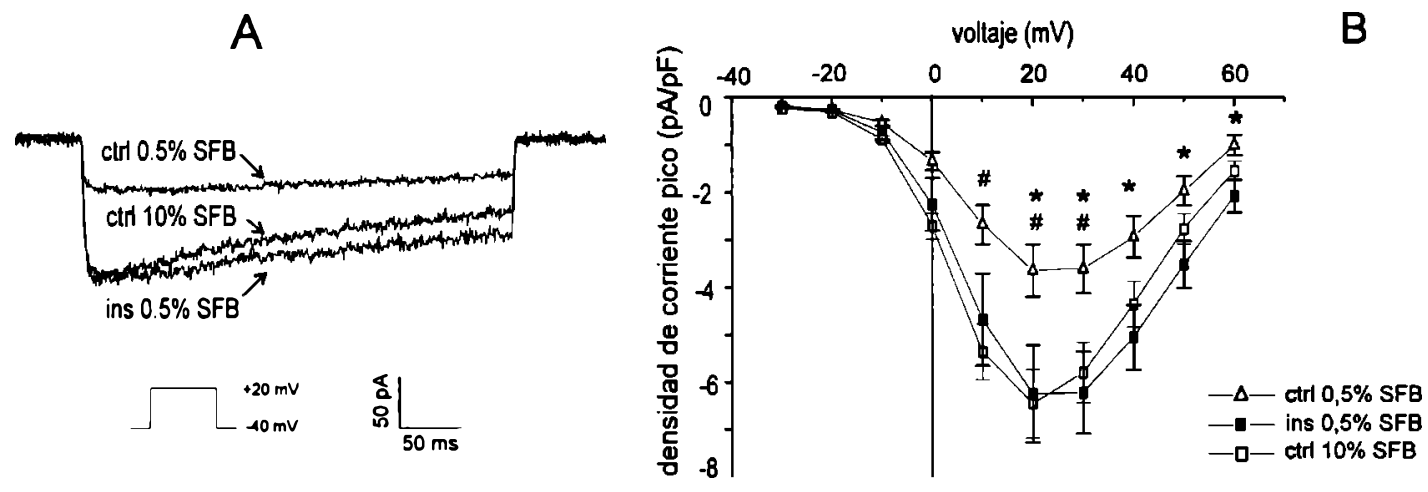

Fig 33: Registros típicos (A) y curvas I-V (B) controles en un medio con $10 \%$ SFB ( $n=14)$ y luego de 24 hs de incubación con $(n=15)$ o $\sin (n=13)$ insulina en un medio con $0,5 \%$ de SFB.

A continuación se utilizó genisteina para bloquear la actividad de tirosín quinasa del receptor de insulina. Como se sabe que la genisteina afecta las corrientes de $\mathrm{Ca}^{2+}$ se estudiaron también los efectos de preincubar con esta droga. Se repicaron células confluentes en DMEM con $0,5 \%$ de SFB, con o sin genisteína $30 \mu \mathrm{M}$, y se midieron las corrientes después de 24 hs. Este inhibidor de tirosín 
quinasas previno la disminución de las corrientes observadas en los controles de forma similar a la insulina (Fig 34).
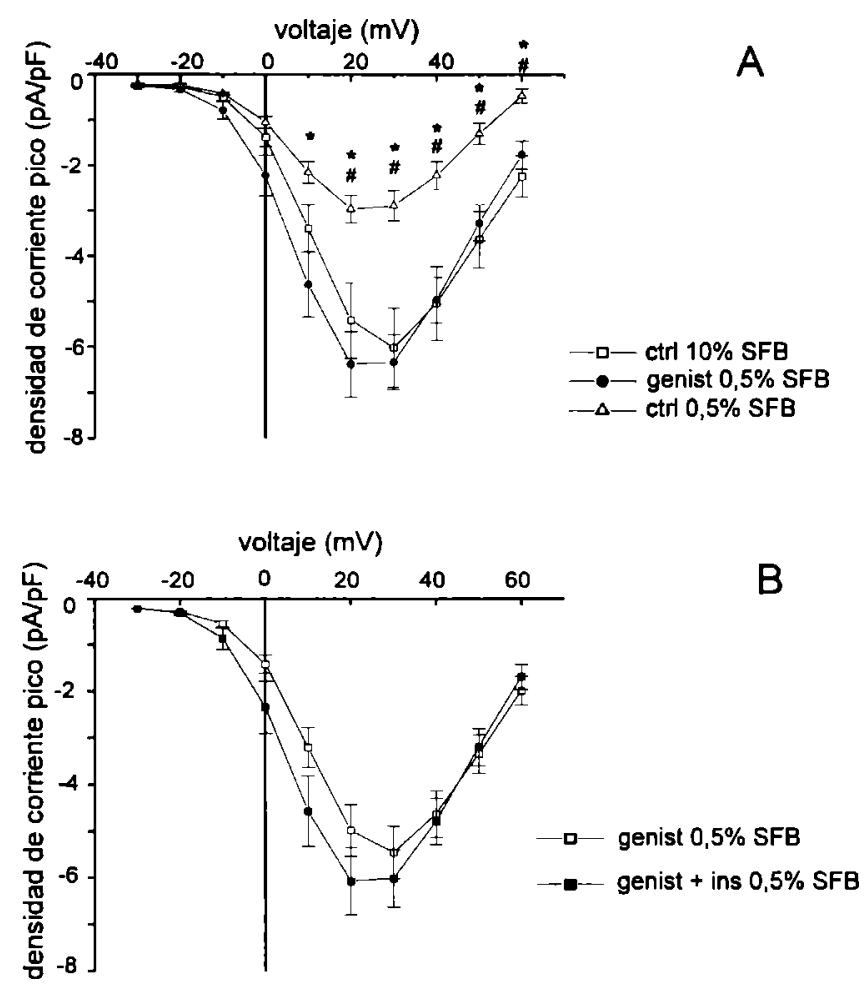

Fig 34: (A) Curvas I-V controles en un medio con $10 \%$ SFB $(n=7)$ y luego de 24 hs de incubación $\operatorname{con}(n=8)$ o $\sin (n=7)$ genisteina en un medio con $0,5 \%$ de SFB. (B) Curvas I-V luego de 24 hs de incubación con genisteína $(n=12)$ o con genisteina e insulina $(n=11)$ en un medio con $0,5 \%$ de SFB.

La curva I-V para las células preincubadas durante 24 hs con insulina y genisteina en DMEM con $0,5 \%$ SFB no fue distinta a la de las células control tratadas sólo con genisteina. Como los efectos que la genisteina tenía per se no difirieron de los de la insulina, no podemos asegurar si nuestros resultados se deben a que la genisteína no bloqueó el receptor de insulina o al hecho de que los efectos de la insulina y de la genisteina sobre los canales $\mathrm{Ca}_{\llcorner}$no son aditivos. 


\subsection{ANÁLISIS Y DISCUSIÓN DE LOS RESULTADOS}

Los datos presentes en la bibliografía sobre el efecto de la insulina sobre los canales de $\mathrm{Ca}^{2+}$ operados por voltaje del músculo liso vascular son escasos. En uno de los trabajos se informa que el tratamiento de células A7r5 durante 90 minutos con $100 \mathrm{mU} / \mathrm{ml}$ (una dosis 200 veces mayor a la nuestra) produjo un corrimiento hacia la derecha de los primeros puntos de la curva I-V de una corriente entrante dependiente de $\mathrm{Ca}^{2+} \sin$ afectar el valor del máximo de corriente (130). En este mismo estudio se mostró que la insulina era capaz de atenuar los aumentos transitorios de $\mathrm{Ca}^{2+}$ y la corriente entrante inducidos por AVP en forma dosis dependiente. Hay también algunos datos sobre experimentos en otros tejidos diferentes: en células de corazón embrionario de pollo, $80 \mu \mathrm{U} / \mathrm{ml}$ de insulina no afectaron la amplitud de la $\mathrm{I}_{\mathrm{Ca}(L)}(131)$, mientras que dosis más elevadas (166 $\mu \mathrm{U} / \mathrm{ml}$ y $1666 \mu \mathrm{U} / \mathrm{ml}$ ) fueron capaces de inhibir una $\mathrm{I}_{\mathrm{Ca}(L)}$ en pinealocitos de rata (132).

Nosotros obtuvimos resultados de la influencia de la insulina sobre las corrientes transportadas por $\mathrm{Ba}^{2+}$ a través de canales $\mathrm{Ca}_{\llcorner}$en células $\mathrm{A} 7 \mathrm{r} 5$, línea derivada de músculo liso aórtico de rata. La perfusión de estas células con insulina durante 10 minutos no modificó las curvas I-V ni la disminución tiempo dependiente del pico de la corriente (run-down); por lo tanto, no se pudieron observar efectos inmediatos de la insulina sobre estas células. Esto no excluye, sin embargo, que en un vaso intacto la insulina module agudamente los canales de $\mathrm{Ca}^{2+}$ voltaje operados en forma indirecta, por ejemplo, a través de los canales de $\mathrm{K}^{+}$y su efecto sobre el potencial de membrana (48).

La insulina es también un importante factor de crecimiento en muchos tejidos y el músculo liso vascular no es una excepción. Esto puede contribuir a la 
hipertrofia vascular en casos de hiperinsulinemia, uno de los posibles nexos entre la insulina y la hipertensión arterial. Células de músculo liso aórtico de rata cultivadas en un medio con $1 \%$ de SFB e insulina crecieron más rápidamente y llegaron antes a la fase estacionaria de crecimiento que células control (en un medio con $1 \%$ de SFB pero sin insulina) (133). Sin embargo, el número final de células en un medio suplementado con $10 \%$ de SFB fue siempre mayor al número en el medio con $1 \%$ de SFB e insulina, por lo que estos autores concluyen que el SFB contiene otros factores de crecimiento importantes necesarios para los miocitos vasculares. Un resultado similar se obtuvo con células derivadas de vasos de resistencia mesentéricos de rata, donde la insulina también tuvo un efecto proliferativo, pero nuevamente menor a aquel producido por $10 \%$ de SFB (134). En este último estudio se encontró también que los efectos de la insulina sobre los miocitos aórticos fue mayor que sobre las células de arterias mesentéricas, o sea que parece haber heterogeneidad en cuanto al origen del vaso en los efectos tróficos de la insulina. Se ha demostrado que en células de aorta de rata en cultivo la insulina produce un aumento en la producción del RNAm del angiotensinógeno, y que los efectos estimuladores del crecimiento inducidos por la hormona se pueden reducir por el bloqueo de los receptores de Ang II. Por lo tanto, la insulina es capaz de inducir el crecimiento del músculo liso, al menos en parte, a través de la activación de un sistema renina-angiotensina local (135).

Nosotros observamos que esta actividad promotora del crecimiento inducida por la insulina afecta a los canales de $\mathrm{Ca}^{2+}$ en las células A7r5. Cuando las células se dejaron por 24 hs en un medio pobre en suero ( $0,5 \%$ SFB), la corriente de $\mathrm{Ba}^{2+}$ a través de los canales $\mathrm{Ca}_{\llcorner}$era significativamente menor que la obtenida en las células cultivadas con $10 \%$ de SFB. Esto sugiere que los efectos promotores del crecimiento del SFB potencian la densidad de corriente de los canales 
Ca $a_{L}$ El agregado de insulina a este medio pobre en suero previno la atenuación de las corrientes. La insulina parece haber reemplazado la actividad promotora del crecimiento que se había perdido al bajar la concentración de SFB del medio. Sin embargo, los efectos del SFB y de la insulina no fueron aditivos, ya que la preincubación durante 2 o 24 hs con esta hormona en un medio rico en suero (10\% de SFB) no modificó la densidad de corriente de los canales Ca. A partir de nuestros resultados no podemos asegurar cuál es el mecanismo utilizado por la insulina para prevenir la atenuación de las corrientes, pero la hipótesis más plausible es la de una estimulación de la expresión de dichos canales, sobre todo sabiendo que la insulina produce un aumento de la expresión de varios mecanismos de transporte iónico en el músculo liso vascular (Fig 35).

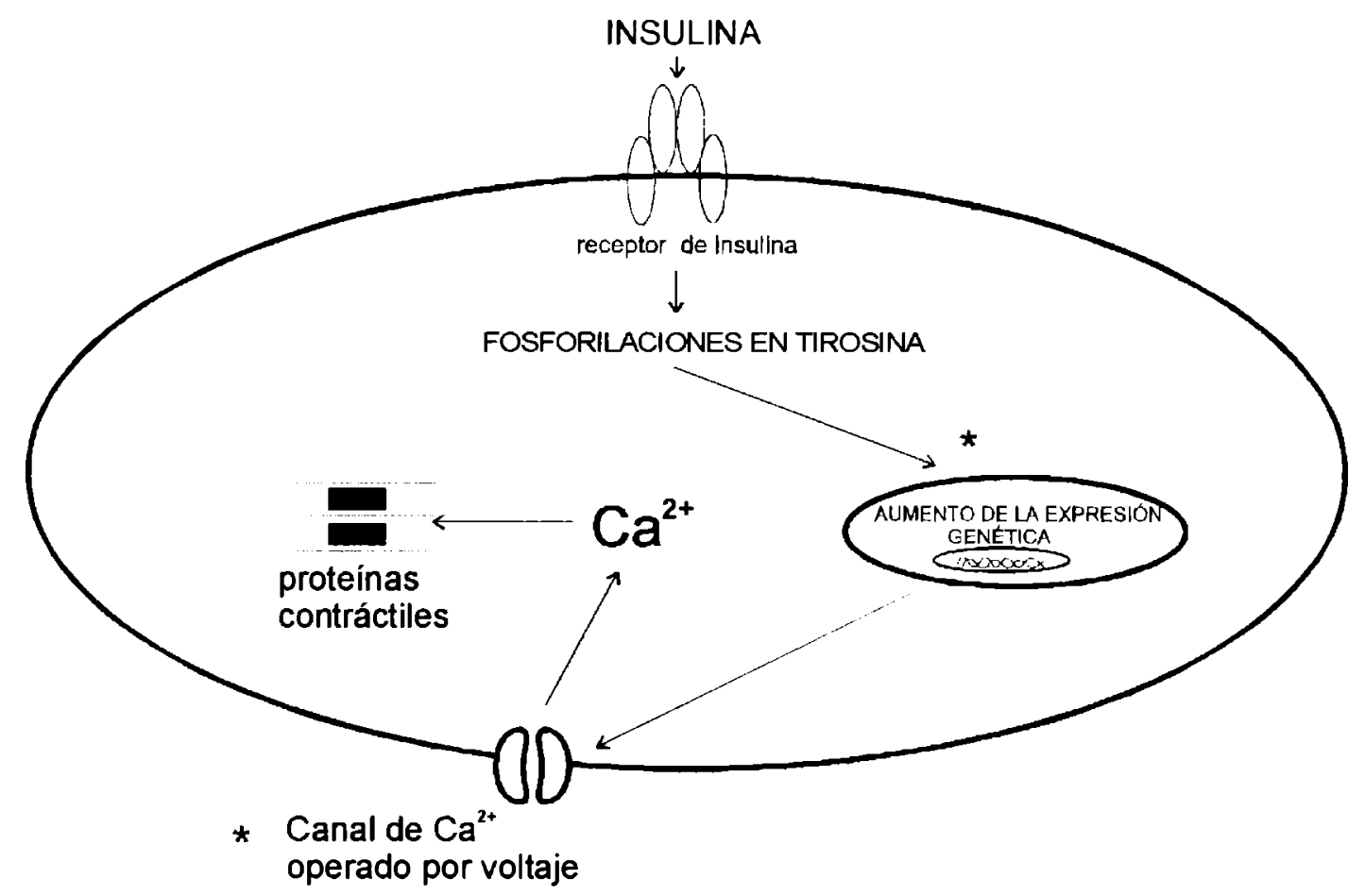

Fig 35: Esquema del posible mecanismo de acción de la insulina sobre los canales de $\mathrm{Ca}^{2+}$. 
El inhibidor de tirosín quinasas genisteina se utilizó para bloquear los efectos de la insulina sobre las células A7r5. La incubación con genisteína tuvo efectos per se sobre la densidad de corriente: el tratamiento por 24 hs con genisteina previno la atenuación de la densidad de corriente a través de los canales CaL producida por la disminución de la concentración de SFB desde $10 \%$ a 0,5\% en el medio de cultivo.

La preincubación con insulina en presencia de genisteína tuvo el mismo efecto que el tratamiento sólo con genisteína. Con nuestros resultados no podemos distinguir si ésto se debió a que la genisteína no fue capaz de bloquear la actividad de tirosín quinasa del receptor de insulina, o a que no se pudo observar el efecto de este bloqueo ya que la genisteína impidió que el valor de la corriente cayera por el pasaje a $0,5 \%$ de SFB.

Los efectos a largo plazo de la genisteina que observamos difieren de los vistos durante intervenciones agudas. Se ha informado que la inhibición aguda de las tirosin quinasas con genisteína produjo una rápida disminución en la corriente de $\mathrm{Ca}^{2+}$ de células de músculo liso vascular (136-138). Este efecto se debió a la disminución de la probabilidad de apertura de los canales $\mathrm{Ca}_{\llcorner}$y no a un cambio en la amplitud de la corriente de canal único (139). Los autores sugirieron que la fosforilación tónica de los canales por tirosín quinasas permitía que éstos fueran activados por la despolarización, y que la genisteina, al inhibir estas quinasas, disminuia la probabilidad de apertura del canal. Sin embargo, la genisteína tuvo efectos duales en miocitos auriculares de gato, donde una rápida inhibición inicial de los canales $C a_{L}$ fue seguida por una estimulación de la corriente (140). Estos investigadores propusieron que la genisteina podria estar actuando a través de dos rutas distintas que competían entre sí, una ligada a proteínas de membrana con actividad de tirosin quinasa y otra en la que estarian involucradas tirosín qui- 
nasas citosólicas. Esto podría explicar el por qué los efectos a largo plazo de la genisteína que nosotros observamos difieren de los agudos informados en la literatura.

En resumen, encontramos que la exposición aguda a la insulina no modificó la densidad de corriente a través de canales $\mathrm{Ca}_{L}$ en las células $\mathrm{A} 7 \mathrm{r} 5$. La preincubación por 2 o 24 hs con insulina no tuvo efectos sobre la $\mathrm{I}_{\mathrm{Ca}(L)}$ en un medio con alta concentración de SFB, mientras que la hormona previno la disminución de las corrientes observadas luego de 24 hs en un medio con poco SFB. La genisteina fue igualmente efectiva que la insulina en la estimulación de las corrientes, pero ya que es un inhibidor de tirosín quinasas, probablemente actúe por una via distinta a la de la insulina. 
Conclusiones 


\section{CONCLUSIONES}

Los estudios realizados en este trabajo tuvieron como antecedente directo la descripción en células aisladas de modificaciones debidas a la preincubación con insulina sobre diferentes mecanismos que regulan la contracción del músculo liso vascular.

Nuestro planteo fue investigar si a dosis fisiológicas o similares a las de un estado hiperinsulinémico la preincubación con insulina modificaba la actividad contráctil en el tejido vascular intacto, en el cual las células de músculo liso se hallan bajo la regulación paracrina del endotelio. No se utilizaron dosis de insulina que superaran los valores descriptos en la especie utilizada como valores de ayuno, postprandiales o de estados de hiperinsulinemia.

En tejido con membranas plasmáticas hiperpermeabilizadas por tratamiento químico se determinaron los efectos de la preincubación con insulina sobre los depósitos de $\mathrm{Ca}^{2+}$ intracelulares.

En células en cultivo derivadas de músculo liso se establecieron los efectos de la preincubación con insulina sobre las corrientes de $\mathrm{Ca}^{2+}$ de los canales de la membrana plasmática.

Se utilizó la rata como especie por el antecedente de que en ella la insulina administrada en forma crónica es capaz de producir hipertensión arterial. Los vasos fueron estimulados con agonistas fisiológicos, y se estudiaron en detalle las respuestas a $\mathrm{ET}_{1}$ por ser este factor derivado del endotelio un posible blanco para 
que la insulina produzca hipertensión arterial al aumentar su secreción y/o la expresión de sus receptores en las células de músculo liso vascular.

La primera conclusión general es que la preincubación con insulina a dosis fisiológicas e hiperinsulinémicas modifica mecanismos que pueden traducirse tanto en potenciación de la respuesta contráctil como en depresión de la misma, en tejidos vasculares de la misma especie, y aún en un mismo tipo de vaso.

La segunda conclusión general es que los efectos de la preincubación con insulina que se manifiestan en las contracciones inducidas por diversos agonistas son dependientes de fosforilaciones en tirosina, se evidencian con preincubaciones de 102 hs., y no se producen con preincubaciones de 15 minutos; esto último sugiere la activación de síntesis proteica por efectos de la hormona.

La tercera conclusión general es que aquellos efectos de la preincubación con insulina que son mediados por mayor sintesis y/o efectos de sustancias derivadas del endotelio tienen una interacción con la síntesis de óxido nítrico. Esto nos parece de importancia dado que pacientes con patología diabética y ratas espontáneamente hipertensas presentan hipofunción en la síntesis de NO, lo cual podría revelar o enmascarar efectos contráctiles de la insulina.

La cuarta conclusión general es que la insulina es un factor activador de la expresión de los canales de $\mathrm{Ca}^{2+}$ de membrana en células de músculo liso vascular. 
Las conclusiones particulares las podemos clasificar de acuerdo a la dosis utilizada:

\section{Dosis fisiológicas de insulina}

\section{Activación de la respuesta contráctil:}

- por disminuir la taquifilaxia a Ang II y a AVP en aorta de rata. Mecanismo posible: activación del reciclado de los receptores por la preincubación con insulina. El efecto no se produce en vasos donde el agonista no presenta taquifilaxia.

\section{Inhibición de la respuesta contráctil:}

- por aumentar la velocidad de relajación espontánea de las contracciones por Ang II y AVP en aorta de rata. Mecanismo posible: aumento de la velocidad de captación de $\mathrm{Ca}^{2+}$ por el retículo sarcoplásmico debido a la preincubación con insulina.

- por disminuir la fuerza desarrollada por contracciones de AVP y ET ${ }_{1}$ en aorta de rata cuando está inhibida la sintesis de NO. Mecanismo propuesto: aumento de la liberación y/o efectos de prostaciclinas debido a la preincubación con insulina que se manifiesta sólo en ausencia de NO 
Dosis hiperinsulinémicas de insulina

\section{Activación de la respuesta contráctil:}

- por aumentar la velocidad de desarrollo de la fuerza en las contracciones inducidas por $\mathrm{ET}_{1}$ en aorta de rata. Mecanismos propuestos: (a) aumento de la liberación de $\mathrm{Ca}^{2+}$ de depósitos intracelulares por la preincubación con insulina, sin afectar la capacidad de captación ni de liberación de $\mathrm{Ca}^{2+}$ desde depósitos sensibles a cafeína. Posible mediación a través del aumento de la señalización en la vía de $\mathrm{IP}_{3}$ o en sus efectos sobre los canales del retículo sarcoplásmico. (b) aumento de la actividad de PKC por la preincubación con insulina.

- por aumentar la fuerza máxima desarrollada en contracciones producidas por $E T_{1}$ en la arteria de la cola de rata. Mecanismo propuesto: aumento de la liberación y/o efectos de tromboxano $A_{2}$ por la preincubación con insulina. Necesidad de presencia de síntesis de NO para que se manifieste el efecto.

2. Inhibición de la respuesta contráctil:

- por disminuir la fuerza desarrollada por contracciones de AVP y ET $\mathrm{E}_{1}$ en aorta de rata estando inhibida la síntesis de NO. Mecanismo propuesto: aumento de la liberación y/o efectos de prostaciclinas por la preincubación con insulina que se manifiestan sólo sin efectos relajantes mediados por NO. 


\section{Efectos sobre las corrientes de calcio en células cultivadas:}

- las corrientes de $\mathrm{Ca}^{2+}$ de células de músculo liso en cultivo no son modificadas por preincubaciones de 2 o 24 hs con dosis hiperinsulinémicas de insulina. No es posible postular este mecanismo como participante en la activación de las repuestas contráctiles por insulina.

- las corrientes de $\mathrm{Ca}^{2+}$ de células de músculo liso en cultivo son estimuladas por preincubaciones de 24 hs con dosis hiperinsulinémicas de insulina en células mantenidas con baja concentración de factores de crecimiento. Posibilidad de que la expresión de canales de $\mathrm{Ca}^{2+}$ en las membranas de músculo liso vascular sea incrementada por la hiperinsulinemia sostenida.

Los numerosos estudios, incluido el presente, que tratan de establecer un nexo causal entre niveles de insulina e hipertensión arterial han comprobado acciones múltiples de la insulina que pueden tener consecuencias duales sobre el tono vascular. Futuros estudios deberán dilucidar en cuáles condiciones (especie, raza, herencia, patologia asociada, tipo de lecho vascular) se expresan más los efectos vasoconstrictores que los vasodilatadores de la insulina para explicar su participación en el desarrollo de hipertensión arterial. Por otra parte, como la resistencia insulínica está establecida en base a la falta de respuesta en sus efectos metabólicos, y no sobre sus efectos en el músculo liso vascular, resta por establecer: (1) si la resistencia insulínica se asocia a hipertensión arterial porque los efectos vasodilatadores de la hormona son predominantes y no se expresan y (2) si la resistencia insulínica promueve una hiperinsulinemia con efectos vasoconstrictores preponderantes. 


\section{BIBLIOGRAFÍA}




\section{BIBLIOGRAFIA}

1. Modan $M$, Halkin $H$, Almong $S$ et al. Hyperinsulinemia: a link between hypertension, obesity and glucose intolerance. J. Clin. Invest. 75:809-817, 1985.

2. Baba T, Neugebauer $\mathrm{S}$. The link between insulin resistance and hypertension. Drugs 47:383-404, 1994.

3. Meehan WP, Darwin $\mathrm{CH}$, Maalouf NB, Buchanan TA, Saad M. Insulin and hypertension: are they related? Steroids 58:621-634, 1993.

4. Epstein M, Sowers JR. Diabetes Mellitus and hypertension. Hypertension 19:403418, 1992.

5. Anderson EA, Mark AL. The vasodilator action of insulin. Implications for the insulin hypothesis of hypertension. Hypertension 21:136-140, 1993.

6. Baron A. Hemodynamic actions of insulin. Am. J. Physiol. 267:E187-202, 1994.

7. Julius S, Gudbrandsson T, Jamerson K, Shahab ST, Andersson O. The hemodynamic link between insulin resistance and hypertension. J. Hypertens. 9:983-986, 1991.

8. Rowe JW, Young JB, Minaker KL, Stevens AL, Pallota S, Landsberg L. Effect of insulin and glucose infusions on sympathetic nervous system activity in normal man. Diabetes 30:219-225, 1981.

9. Anderson EA, Balon TW, Hoffman RP, Sinkey CA, Mark AL. Insulin increases sympathetic activity but not blood pressure in borderline hypertensive humans. Hypertension 19:621-627, 1992.

10. Anderson EA, Balon TW, Hoffman RP, Sinkey CA, Mark LA. Hyperinsulinemia produces both sympathetic neural activation and vasodilation in normal humans. $J$. Clin. Invest. 87:2246-2252, 1991.

11. Brands MW, Mizelle HL, Gaillard CA, Hildebrandt DA, Hall JE. The hemodynamic response to chronic hyperinsulinemia in conscious dogs. Am. J. Hypertens. 4:164168, 1991.

12. Skøtt $P$, Hother-Nielsen $O$, Bruun $E N$ et al. Effect of insulin on kidney function and sodium excretion in healthy subjects. Diabetologia 32:694-699, 1989. 
13. De Fronzo RA, Goldberg $M$, Agus $M Z$. The effects of glucose and insulin on renal electrolyte transport. J. Clin. Invest. 58:83-90, 1976.

14. Kirchner KA. Insulin increases loop segment chloride reabsorption in the euglycemic rat. Am. J. Physiol. 255:F1206-1213, 1988.

15. Briffeuil P, Thu TH, Kolanowski J. Reappraisal of the role of insulin on the sodium handling by the kidney: effect of intrarenal insulin infusion in the dog. Eur. J. Clin. Invest. 22:523-528, 1992.

16. Brands MW, Hall JE, Van Vliet BN, Alonso Galicia M, Herrera GA, Zappe D. Obesity and hypertension: roles of hyperinsulinemia, sympathetic nervous system and intrarenal mechanisms. J. Nutr. 125:1725s-1731s, 1995.

17. Miller JA, Abouchacra S, Zinman B, Skorecki KL, Logan AG. Atrial natriuretic factor counteracts sodium retaining actions of insulin in normal men. Am. J. Physiol. 265:R584-590, 1993.

18. Pfeifle B, Ditschuneit. Effect of insulin on the growth of cultured arterial smooth muscle cells. Diabetologia 20:155-158, 1981.

19. Ridray S. Hyperinsulinemia and smooth muscle cells proliferation. Int. J. Obesity 19:S39-51, 1995.

20. Moore RD. Stimulation of Na:H exchange by insulin. Biophys. J. 33:203-210, 1981.

21. Blaustein M. Physiological effects of endogenous ouabain: control of intracellular $\mathrm{Ca}^{++}$stores and cell responsiveness. Am. J. Physiol. 264:C1367-1387, 1993.

22. Hermsmeyer RK. Vascular muscle membrane cation mechanisms and total peripheral resistance. Hypertension 10(1):20-22, 1987.

23. Canessa M, Adragna N, Solomon HS, Conolly TM, Tosteson DC. Increased sodium-lithium countertransport in red cells of patients with essential hypertension. N. Eng. J. Med. 302:772-776, 1980.

24. Trevisan M, Vaccaro O, Laurentzi M, De Chiara F, Di Muro M. Hypertension, noninsulin-dependent diabetes and intracellular sodium metabolism. Hypertension 11:264-268, 1988.

25. Hu R-M, Levin ER, Pedram A, Frank HJL. Insulin stimulates the production and secretion or endothelin from bovine endothelial cells. Diabetes 42:351-358, 1993. 
26. Piatti PM, Monti LD, Conti M, Baruffaldi L, Galli L, Phan CV, Guazzini B, Pontiroli $A E$, Pozza $G$. Hypertriglyceridemia and hyperinsulinemia are potent inducers of endothelin-1 release in humans. Diabetes. 45:316-321, 1996.

27. Frank HJL, Levin ER, Hu RM, Pedram A. Insulin stimulates endothelin binding and action on cultured vascular smooth muscle cells. Endocrinology 133:1092-1097, 1993.

28. Hopfner RL, Hasnadka RV, Wilson TW, McNeill JR, Gopalakrishnan V. Insulin increases endothelin-1-evoked intracellular free calcium responses by increased $E T_{A}$ receptor expression in rat aortic smooth muscle cells. Diabetes 47:937-944, 1998.

29. Dick GM, Sturek M. Effects of physiological insulin concentration on the endothelinsensitive $\mathrm{Ca}^{2+}$ store in porcine coronary artery smooth muscle. Diabetes 45:876$880,1996$.

30. Wu H, Jeng YY, Yue C, Chyu K, Hsueh WA, Chan TM. Endothelial-dependent vascular effects of insulin and insulin-like growht factor $I$ in the perfused rat mesenteric artery and aortic ring. Diabetes 43:1027-1032, 1994.

31. Steinberg HO, Bretchel G, Johnson A, Fineberg N, Baron AD. Insulin-mediated skeletal muscle vasodilation is nitric oxide dependent. A novel action of insulin to increase nitric oxide release. J. Clin. Invest. 94:1172-1179, 1994.

32. Chen Y-L, Messina EJ: Dilation of isolated skeletal muscle arterioles by insulin is endothelium dependent and nitric oxide mediated. Am. J. Physiol. 270:H2120-2124, 1996.

33. Van Veen S, Chang PC: Prostaglandins and nitric oxide mediate insulin-induced vasodilation in the human forearm. Cardiovasc. Res. 34:223-229, 1997.

34. Liang C-S, Doherty JU, Faillace R. et al Insulin infusion in concious dogs: efects on systemic and coronary hemodynamics, regional blood flows, and plasma catecholamines. J. Clin. Invest. 69:1321-1336, 1982.

35. Creager MA, Liang C-S, Coffman JD. Beta adrenergic-mediated vasodilator response to insulin in the human forearm. J. Pharmacol. Exp. Ther. 235:709-714, 1985. 
36. Gross R, Borkowski KR, Feldman RD. Human insulin-mediated enhancement of vascular $\beta$-adrenergic responsivenes. Hypertension 23:551-555, 1994.

37. Prakash TR, Mackenzie SH, Ram JL, Sowers JR. Insulin stimulates gene transcription and activity of $\mathrm{Na}^{+}-\mathrm{K}^{+}-\mathrm{ATPase}$ in vascular smooth muscle cells. Hypertension 20:443, 1992.

38. Blaustein MP. Sodium ions, calcium ions, blood pressure regulation, and hypertension: a reassessment of a hypotesis. Am. J. Physiol. 232:C165-173, 1977.

39. Ohara T, Sussman KE, Draznin B. Effect of diabetes on cytosolic free $\mathrm{Ca}^{++}$and $\mathrm{Na}^{+}-\mathrm{K}^{+}-\mathrm{ATP}$ ase in rat aorta. Diabetes 40:1560-1563, 1991.

40. Zemel MB, lannucci A, Moore JW. Role of insulin in regulating vascular smooth muscle $\mathrm{Ca}^{++}$-ATPase expression. J. Vasc. Med. Biol. 4:79-84, 1993.

41. Zemel MB, Johnson BA, Ambrozy SA. Insulin stimulated vascular relaxation: role of $\mathrm{Ca}^{++}$-ATPase. Am. J. Hypertens. 5:637-641, 1992.

42. Zemel MB, lannucci A, Johnson BA, Sowers JR. Reduced Ca ${ }^{++}$-ATPase expression in insulin resistant (Zucker obese) rats. Hypertension 18:442,1991.

43. Kim YC, Zemel MB. Insulin increases vascular smooth muscle recovery from intracellular calcium loads. Hypertension 22:74-77, 1993.

44. Kahn AM, Seidel CL, Allen JC, O'Neil RG, Shelat $H$, Song $T$. Insulin reduces contraction and intracellular calcium concentration in vascular smooth muscle. Hypertension 22:735-742, 1993.

45. Touyz RM, Tolloczko B, Schiffrin EL. Insulin attenuates agonist-evoked calcium transients in vascular smooth muscle cells. Hypertension 23:I-25-I-28, 1994.

46. Su E-N, Yu D-Y, Alder VA, Cringle SJ, Yu PK: Direct vasodilatory effect of insulin on isolated retinal arteries. Invest. Ophthalmol. Vis. Sci. 37:2634-2644, 1996.

47. Hasdai D, Rizza RA, Holmes DR Jr, Richardson DM, Cohen P, Lerman A: Insulin and insulin-like growht factor-I cause coronary vasorelaxation in vitro. Hypertension 32:228-234, 1998.

48. McKay M, Hester RL: Role of nitric oxide, adenosine, and ATP-sensitive potassium channels in insulin-induced vasodilation. Hypertension 28:202-208, 1996. 
49. Kahn AM, Song $T$. Insulin inhibits dog vascular smooth muscle contraction and lowers $\mathrm{Ca}^{2+}$ by inhibiting $\mathrm{Ca}^{2+}$ influx. J. Nutr. 125:1732S-1737S, 1995.

50. Mayhan WG. Effect of diabetes mellitus on response of the basilar artery to activation of ATP-sensitive potassium channels. Brain. Res. 636:35-39, 1994.

51. Marigliano A, Tedde R, Sechi LA, Pala A, Pisanu G, Pacifico A. Insulinemia andblood pressure: relationships in patients with primary and secondary hypertension, and with or without glucose metabolism impairment. Am. J. Hypertens. 3:521-526, 1990.

52. Donatelli M, Scarpinato A, Bucalo ML, Russo V, Iraci T, Vasallo G. Stepwise increase in plasma insulin and $C$-peptide concentrations in obese, obese hypertensive and in obese hypertensive diabetic subjects. Diabetes Res. 17:125-129, 1991.

53. Christlieb AR, Krolewski AS, Warran JH, Soeldener JS. Is insulin a link between hypertension and obesity? Hypertension 7(suppl 2):54-57, 1985.

54. Weisser B, Grune S, Spuhler T, Kistler T, Vetter W. Plasma insulin is correlated with blood pressure only in subjects with a family history of hypertension or diabetes mellitus: results from 11001 participants in the Heureka Study. J. Hypertens. 11:S308-309, 1993.

55. Feskens EJM, Kromhout D. Hyperinsulinemia, risk factors, and coronary heart disease. The Zutphen elderly study. Arterioscler. Thromb. 14:1641-1647, 1994.

56. Saad MF, Knowler WC, Pettit DJ, Nelson RG, Mott DM, Bennett PH. Insulin and hypertension: relationship to obesity and glucose intolerance in Pima Indians. Diabetes 39:1430-1435, 1990.

57. Sawicki PT, Baba T, Berger M, Starke A. Normal blood pressure in patients with insulinoma despite hyperinsulinemia and insulin resistance. J. Am. Soc. Nephrol. 3:S64-68, 1992.

58. Vettor R, Mazzonetto P, Macor C, Scandellari C, Federspil G. Effect of endogenous organic hyperinsulinaemia on blood pressure and serum triglycerides. Eur. J. Clin. Invest. 24:350-354, 1994.

59. Ferrannini E, Buzzigoli $G$, Bonadonna $R$ et al. Insulin resistance in essential hypertension. N. Engl. J. Med. 317:350-357, 1987. 
60. Dengel DR, Pratley RE, Hagberg JM, Goldberg AP. Impaired insulin sensitivity and maximal responsiveness in older hypertension men. Hypertension 23:320-324, 1994.

61. Facchini F, Chen IYD, Clinkingbeard C, Jeppsen J, Reaven GM. Insulin resistance, hyperinsulinemia, and dyslipidemia in nonobese individuals with a family history of hypertension. Am. J. Hypertens. 5:694-699, 1992.

62. Baba T, Kodama T, Tomiyama T, Sohn D-R, Ishizaki T. Serum insulin levels versus blood pressure: a cross-sectional, case controlled study in non-obese, middle aged Japanese subjects with normal glucose tolerance. Diabetic. Med. 11:42-49, 1994.

63. Doria $A$, Fioretto $P$, Avogaro $A$ et al. Insulin resistance is associated with high sodium-lithium countertransport in essential hypertension. Am. J. Physiol. 261:E684-691, 1991

64. Zimmermann S, Phillips RA, Dunaif $A$ et al. Polycystic ovary syndrome: lack of hypertension despite profound insulin resistance. J. Clin. Endocrinol. Metab. 75:508-513, 1992.

65. Saad MF, Lillioja S, Nyomba BL et al. Racial differences in the relation between blood pressure and insulin resistance. N. Engl. J. Med. 324:733-739, 1991.

66. Collins VR, Dowse GK, Finch CF, Zimmet PZ, Linnane AW. Prevalence and risk factors for micro- and macroalbuminuria in diabetics subjects and entire population of Nauru. Diabetes 38:1602-1610, 1990.

67. Yoshinaga $H$, Yamada $N$, Ichikawa $K$ et al. Hyperinsulinemia and coronary artery disease. Letter. N. Engl. J. Med. 321:616-617, 1989.

68. Hall JE, Coleman TG, Mizelle HL, Smith MJ. Chronic hyperinsulinemia and blood pressure regulation. Am. J. Physiol. 258:F722-731, 1990.

69. Hall JE, Brands MW, Zappe DH et al. Hemodynamic and renal responses to chronic hyperinsulinemia in obese, insulin-resistant dogs. Hypertension 25:994-1002, 1995.

70. Brands MW, Hildebrant DA, Mizelle HL, Hall JE. Sustained hyperinsulinemia increases arterial pressure in conscious rats. Am. J. Physiol. 260:R764-768, 1991.

71. Chen S, Yuan CM, Haddy FJ, Pammani MB. Effect of administration of insulin on streptozotocin-induced diabetic hypertension in rat. Hypertension 23:1046-1050, 1994. 
72. Kurtz TW, Morris RC, Pershadsingh HA. The Zucher fatty rat as a model of obesity and hypertension. Hypertension 13:896-901, 1989.

73. Katayama S, Abe M, Kashiwabara H, Kosegawa I, Ishii J. Evidence against a role of insulin in hypertension in spontaneously hypertensive rats. Hypertension 23(2): 1071-1074, 1994.

74. Bhanot S, McNeill J. Vanadyl sulfate lowers plasma insulin and blood pressure in spontaneously hypertensive rats. Hypertension 24:625-632, 1994.

75. Perhadsingh HA, Szollosi J, Benson S, Hyun W, Feuerstein BG, Kurtz TW. Effects of ciglitazone on blood pressure and intracellular calcium metabolism. Hypertension 21:1020-1023, 1993.

76. Verma S, Bhanot S, Mcneill JH. Metformin decreases plasma insulin levels and systolic blood pressure in spontaneously hypertensive rats. Am. J. Physiol. 267:H1250-1253, 1994.

77. Laakso M, Edelman SV, Brechtel G, Baron AD. Decreased effect of insulin to stimulate skeletal muscle blood flow in obese man: a novel mechanism for insulin resistance. J. Clin. Invest. 85:1844-1852, 1990.

78. Baron AD, Brechtel-Hook G, Johnson A, Henry D. Skeletal muscle blood flow. A possible link between insulin resistance and blood pressure. Hypertension 21:129$135,1993$.

79. Natali AG, Buzzigoli S, Taddei $S$ et al. Effects of insulin on Hemodynamics and metabolism in human forearm. Diabetes 39:490-500, 1990.

80. Egan B, Stepniakowski K. Compensatory hyperinsulinemia and the forearm vasodilator response during an oral glucose-tolerance test in obese hypertensives. J. Hypertens. 12:1061-1067, 1994.

81. Christ GJ, Valvic M, Gondre MC. Augmentation in the kinetic characteristics of phenylephrine and 5-hydroxytryptamine-induced contractions in the isolated rat aorta following eight weeks of stz-diabetes. Life. Sci. 55:807-814, 1994.

82. Félétou M, Moreau N, Duhault J. Vascular responsiveness in young, diabetic, and aging hyperinsulinemic rats. Life Sci. 54:1801-1813, 1994.

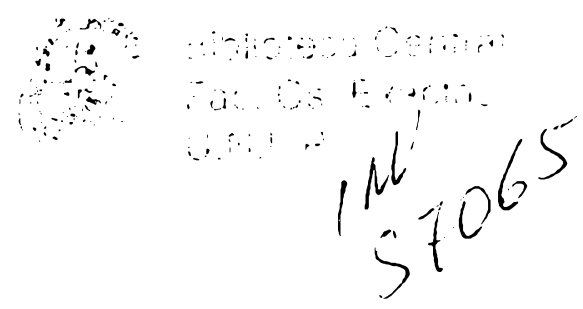


83. Hattori Y, Kawasaki H, Kanno M, Gando S, Fukao M. Attenuated contractile response of diabetic rat aorta to caffeine but not to noradrenaline in Ca-free medium. Eur. J. Pharmacol. 256:215-219, 1994.

84. McNally PG, Lawrence IG, Watt PAC, Hillier C, Burden AC, Thurston H. The effect of insulin on the vascular reactivity of isolated resistance arteries taken from healthy volunteers. Diabetologia 38:467-473, 1995.

85. Yagi S, Takata S, Kiyok $\mathrm{H}$ et al. Effects of insulin on vasoconstrictive responses to norepinephrine and angiotensin $I I$ in rabbit femoral artery and vein. Diabetes 37:1064-1067, 1988.

86. Jern S. Effects of insulin on vascular responses to mental stress and norepinephrine in human forearm. Hypertension 24:686-694, 1994.

87. Bodmer CW, Schaper NC, Janssen M, De Leeuw PW, Williams G. Selective enhancement of $\alpha 2$-adrenoceptor-mediated vasoconstriction in insulin-dependent diabetic patiens with microalbuminuria. Clin. Sci. 88:421-426, 1995.

88. Gaboury CL, Simonson DC, Seely EW, Hollenberg NK, Williams GH. Relation of pressor responsiveness to angiotensin II and insulin resistance in hypertension. J. Clin. Invest. 94:2295-2300, 1994.

89. Balon TW, Jasman A, Scott S, Meehan WP, Rude RK, Nadler JL. Dietary magnesium prevents fructose-induced insulin insensitivity in rats. Hypertension 23:1036-1039, 1994.

90. Bhanot S, Mc Neill JH, Bryer-Ash M. Vanadyl sulfate prevents fructose-induced hyperinsulinemia and hypertension in rats. Hypertension 23:308-312, 1994.

91. Hopfner RL, McNeill JR, Gopalakrishnan V. Vanadate treatment normalizes exaggerated vascular smooth muscle responses in the obese Zucker rat. Eur. J. Pharmacol. 357: 61-65, 1998.

92. Inagami T, Naruse M, Hoover R. Endothelium as an endocrine organ. Annu. rev. Physiol. 57:171-189, 1995

93. Boulanger CM, Caputo L, Lévy I.. Endothelial $A T_{1}$-mediated release of nitric oxide decreases angiotensin II contractions in rat carotid artery. Hypertension 26:752757,1995 
94. Chen L, McNeill JR, Wilson TW, Gopalakrishnan V. Heterogeneity in vascular smooth muscle responsiveness to angiotensin II: role of endothelin. Hypertension 26:83-88, 1995

95. Millette E, Lamontagne D. Endothelium-dependent and NO-mediated desensitization to vasopressin in rat aorta. Br. J. Pharmacol. 119:899-904, 1996.

96. Griendling KK, Lasségue B, Alexander RW. Angiotensin receptors and their therapeutic implications. Annu. Rev. Pharmacol. Toxicol. 36:281-306, 1996.

97. Thibonnier M. Signal transduction of V1-vascular vasopressin receptors. Regulatory Peptides 38:1-11, 1992.

98. Weil E, Sasson S, Gutman Y. Mechanisms of insulin-induced activation of $\mathrm{Na}^{+}-\mathrm{K}^{+}-$ ATPase in isolated rat soleus muscle. Am. J. Physiol. 261:C224-C239,1991.

99. Hundal HS, Marette A, Mitsumoto Y, Ramlal T, Blostein R, Klip A. Insulin induces traslocation of the a2 y b1 subunits of the $\mathrm{Na}^{+} / \mathrm{K}^{+}$-ATPase from intracellular compartments to the plasma membrane in mammalian skeletal muscle. J. Biol. Chem. 267:5040-5043, 1992.

100. Li Q, Feenstra $M$, Pfaffendorf $M$, Eijsman L, van Zwieten PA. Comparative vasoconstrictor effects of angiotensin II, III, and IV in human isolated saphenous vein. J. Cardiovasc. Pharmacol. 29:451-456, 1997.

101. Aiello EA, Grassi de Gende AO. Uptake and release of $\mathrm{Ca}^{++}$in chemically skinned aortic strips from spontaneously hypertensive (SHR) and normotensive (WKY) rats. Jpn. Heart J. 36:377-388, 1995.

102. Kwan ChY. Abnormalities of vascular muscle membranes in hypertension with special reference to calcium handling. En: Membrane abnormalities in hypertension. Ed. Kwan ChY.1989 Vol 1, Chap 6, p115.

103. Han S-Z, Ouchi $Y$, Karaki $H$, Orimo $H$.. Inhibitory effects of insulin on cytosolic $\mathrm{Ca}^{2+}$ level and contraction in the rat aorta: endothelium-dependent and -independent mechanisms. Circ. Res. 77:673-678, 1995.

104. Bassenge E. Endothelial function in different organs. Prog. Cardiovasc. Dis. 39:209-228, 1996. 
105. Waggoner WG, Genova SL, Rash VA. Kinetic analysis demonstrates that the equilibrium assumption does not apply to $\left[{ }^{125} \mid\right]$ endothelin-1 binding data. Life Sci. 51:1869-1876, 1992.

106. Hatano $Y$, Mizumoto K, Yoshiyama T, Yamamoto M, Iranami H. Endotheliumdependent and -independent vasodilation of isolated rat aorta induced by caffeine. Am. J. Physiol. 269:H1679-1684, 1995.

107. Miyauchi T. Pathophysiology of endothelin in the cardiovascular system. Annu. Rev. Physiol. 61:391-415,1999.

108. Verma S, Bhanot S, McNeill LH. Effect of chronic endothelin blockade in hyperinsulinemic hypertensive rats. Am. J. Physiol. 269:H2017-2021, 1995

109. Srinivas PR, Grunberger G. Inhibitors of the insulin receptor tyrosine kinase. Pharmac. Ther. 64: 23-35, 1994.

110. Mahnaz R, Pedram $A$, Rubin $T$, Levin ER. $P \mathrm{GE}_{2}$ and $P \mathrm{PI}_{2}$ inhibit $E T-1$ secretion from endothelial cells by stimulating particulate guanylate cyclase. Am. J. Physiol. 270: H1342-1349, 1996.

111. Motta AB, González ET, Rudolph I, de Gimeno MAF. Interaction between nitric oxide and prostaglandin $E$ pathways in rat smooth muscle myometrial cells. Prostaglandins Leukot. Essent. Fatty Acids 59: 357-361, 1998.

112. Pieper GM. Review of alterations in endothelial nitric oxide production in diabetes. Protective role of arginine on endothelial dysfunction. Hypertension 31: 1047-1060, 1998.

113. Stehouwer CDA, Lambert J, Donker AJM, van Hinsbergh WWM. Endothelial dysfunction and pathogenesis of diabetic angiopathy. Cardiovasc. Res. 34: 55-68, 1997.

114. Hogikyan RV, Galecki AT, Pitt B, Halter JB, Greene DA, Supiano MA. Specific impairment of endothelium-dependent vasodilation in subjects with type 2 diabetes independent of obesity. J. Clin. Endocrinol. Metab. 83: 1946-1952, 1998.

115. McVeigh GE, Brennan GM, Johnston GD, McDermott BJ, Mc Grath LT, Henry WR, Andrews JW, Hayes JR.. Impaired endothelium-dependent and independent vasodilation in patients with type 2 (non-insulin-dependent) diabetes mellitus. Diabetologia 35: 771-776, 1992. 
116. Morris SJ, Shore AC, Tooke JE. Responses of skin microcirculation to acetylcholine and sodium nitroprusside in patients with NIDDM. Diabetologia 38 : 1337-1344, 1995.

117. Williams SB, Cusco JA, Roddy MA, Johnstone MT, Creager MA. Impaired nitric oxide-mediated vasodilation in patients with non-insulin-dependent diabetes mellitus. J. Am. Coll. Cardiol 27: 567-574, 1996.

118. Taylor PD, McCarthy AL, Thomas CR, Poston L. Endothelium-dependent relaxation and noradrenaline sensitivity in mesenteric resistance arteries of streptozotocin-induced diabetic rats. Br. J. Pharmacol. 107: 393-399, 1992.

119. Tesfamarian B, Jakubowski JA, Cohen RA. Contraction of diabetic rabbit aorta caused by endothelium-derived PGH $2-\mathrm{TXA}_{2}$. Am. J. Physiol. 257: H327-333, 1989.

120. Mayhan WG, Simmons LK, Sharpe GM. Mechanism of impaired responses of cerebral arterioles during diabetes mellitus. Am. J. Physiol. 260: H319-326, 1991.

121. Douglas SA, Ohlstein EH. Signal transduction mechanisms mediating the vascular actions of endothelin. J. Vasc. Res. 34:152-164,1997.

122. Kasuya $Y$, Takuwa $Y$, Yanasigisana M, Masaki T, Goto K. A pertussis toxinsensitive mechanism of endothelium action in porcine artery smooth muscle. Br. J. Pharmacol. 107:456-462,1992.

123. Griendling KK, Tsuda T, Alexander RW. Endothelin stimulates diacylglycerol accumulation and activates protein kinase $C$ in cultured vascular smooth muscle cells. J. Biol. Chem. 264:8237-8240,1989.

124. Resink TJ, Scott-Burden T, Buhler RF. Activation of multiple signal transduction pathways by endothelin in cultured human vascular smooth muscle cells. Eur. J. Biochem. 189:415-421,1990.

125. Pollock DM, Keith TL, Highsmith RF. Endothelin receptors and calcium signaling. FASEB J. 9:1196-1204, 1995

126. Di Salvo J, Kaplan N, Senenchuck LA. Protein tyrosine phosphorylation and regulation of intracellular calcium in smooth muscle cells. En: Biochemistry of smooth muscle contraction, Ed: Bárány M, 1996, p283.

127. August $M$, Delaflotte $S$, Chabrier P-E, Braquet PC. Comparative effects of endothelin and phorbol 12-13 dibutyrate in rat aorta. Life. Sci. 45;2051-2059,1989 
128. Inoue $T$, Fukuo $K$, Morimoto $S$, Koh $E$, Ogiha $T$. Nitric oxide mediates interleukin1-induced prostaglandin E2 production by vascular smooth muscle cells. Biochem. Biophys. Res. Comun. 194:420-424, 1993.

129. Belles B, Malécot CO, Hescheler J, Trautwein W. Run-down of the Ca current during long whole-cell recording in guiena pig heart cells: role of phosphorylation and intracellular calcium. Pflüg. Arch. 411:353-360, 1988.

130. Standley PR, Zhang F, Ram JL, Zemel MB, Sowers JR. Insulin attenuates vasopressin-induced calcium transients and a voltage-dependent calcium response in rat vascular smooth muscle cells. J. Clin. Invest. 88:1230-1236, 1991.

131. Bkaily G, Economos D, Potvin L, Ardilouze J-L, Marriott C, Corcos J, Bonneau D, Fong CN. Blockade of insulin sensitive steady-state R-type Ca2+ channel by PN 200-110 in heart and vascular smooth muscle. Mol. Cell. Biochem. 117:93-106, 1992

132. Chik CL, Li B, Karpinski E, Ho AK. Insulin and insulin-like growth factor-I inhibit the L-type calcium channel current in rat pinealocytes. Endocrinology 138:2033-2042, 1997

133. Pfeifle $B$, Ditschuneit $H H$, Ditschuneit $H$. Insulin as a cellular growth regulator of rat arterial smooth muscle cells. Horm. Metab. Res. 12:381-385, 1980.

134. Cruzado M, Risler N, Castro C, Ortiz A, Rüttler ME. Proliferative effect of insulin on cultured smooth muscle cells from rat mesenteric resistance vessels. Am. J. Hypertens. 11:54-58, 1998.

135. Kamide K, Hori MT, Zhu J-H, Barret JD, Eggena P, Tuck ML. Insulin-mediated growth in aortic smooth muscle and the vascular renin-angiotensin system. Hypertension 32:482-487, 1998.

136. Yokoshiki H, Sumii K, Sperelakis N. Inhibition of L-type calcium current in rat ventricular cells by the tyrosine kinase inhibitor, genistein and its inactive analog, daidzein. J. Mol. Cell. Cardiol. 28:807-814, 1996.

137. Wijetunge $S$, Aalkjaer $C$, Schachter $M$, Hughes $A D$. Tyrosine kinase inhibitors block calcium channel currents in vascular smooth cells. Biochem. Biophys. Res. Commun. 189:1620-1623, 1992. 
138. Liu H, Li K, Sperelakis N. Tyrosine kinase inhibitor, genistein, inhibits macroscopic L-type calcium current in rat portal vein smooth muscle cells. Can. J. Physiol. Pharmacol. 75:1058-1062, 1997.

139. Liu H, Sperelakis $\mathrm{N}$. Tyrosine kinases modulate the activity of single L-type calcium channels in vascular smooth muscle cells from rat portal vein. Can. J. Physiol. Pharmacol. 75:1063-1068, 1997.

140. Wang YG, Lipsius SL. Genistein elicits biphasic effects on L-type $\mathrm{Ca}^{2+}$ current in feline atrial myocytes. Am. J. Physiol. 275:H204-212, 1998.

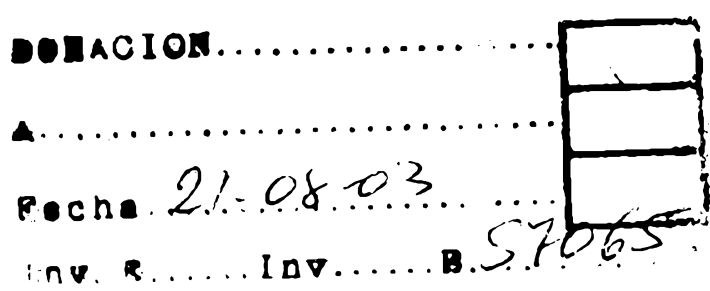

